PNL-7269

UC -000

\title{
Technology Evaluation for Space Station Atmospheric Leakage
}
D. K. Lemon
C. L. Shepard
M. A. Friesel
Z. I. Antoniak
I. W. Griffin
R. J. Kurtz
J. R. Skorpik

February 1990

Prepared for the

National Aeronautics and

Space Administration

under a Related Services Agreement

with the U.S. Department of Energy

under Contract DE-AC06-76RLO 1830

Pacific Northwest Laboratory

Operated for the U.S. Department of Energy

by Battelle Memorial Institute 


\title{
DISCLAJMER
}

This report was prepared as an account of work sponsored by an agency of the United States Government. Neither the United States Government nor any agency thereof, nor Battelle Memorial Institute, nor any of their employees, makes any warranty, expressed or implied, or assumes any legal liability or responsibilthy for the accuracy, completeness, or usefulness of any information, apparatus, product, or process disclosed, or represents that its use would not infringe privately owned rights. Reference herein to any specific commercial product, process, or service by trade name, trademark, manufacturer, or otherwise, does not necessarily constitute or imply its endorsement, recommendation, or favoring by the United States Government of any agency thereof, or Battelle Memorial Institute. The views and opinions of authors expressed herein do not necessarily state or reflect those of the United States Government or any agency thereof.

\author{
PACIFIC NORTHWEST LABORATORY \\ operated by \\ BATTELLE MEMORIAL INSTITUTE \\ for the \\ UNITED STATES DEPARTMENT OF ENERGY \\ under Contract DE-ACO6-76RLO 1830
}

Printed in the United States of America

Available to DOE and DOE contractors from the

Office of Scientific and Technical Information, P.O. Box 62, Oak Ridge, TN 37831; prices available from (615) 576-8401. FTS 626-8401.

Available to the public from the National Technical information Service, U.S. Department of Commerce, 5285 Port Royal Rd., Springfield, VA 22161.

NTIS Price Codes, Microfiche A01

Printed Copy

\begin{tabular}{cr}
\hline Price Code & Page Range \\
\hline A02 & $1-10$ \\
A03 & $11-50$ \\
A04 & $51-75$ \\
A05 & $76-100$ \\
A06 & $101-125$ \\
A07 & $126-150$ \\
A08 & $151-175$ \\
A09 & $176-200$ \\
A10 & $201-225$ \\
A11 & $226-250$ \\
A12 & $251-275$ \\
A13 & $276-300$ \\
A14 & $301-325$
\end{tabular}

\begin{tabular}{cc}
\hline Price Code & Page Range \\
\hline A15 & $326-350$ \\
A16 & $351-375$ \\
A17 & $376-400$ \\
A18 & $401-425$ \\
A19 & $426-450$ \\
A20 & $451-475$ \\
A21 & $476-500$ \\
A22 & $501-525$ \\
A23 & $526-550$ \\
A24 & $551-575$ \\
A25 & $576-600$ \\
A99 & $601-U p$
\end{tabular}



D. K. Lemon
C. L. Shepard
M. A. Friesel
Z. I. Antoniak
J. W. Griffin
R. J. Kurtz
J. R. Skorpik

February 1990

Prepared for the

National Aeronautics and Space Administration under a Related Services Agreement with the U.S. Department of Energy under Contract DE-AC06-76RLO 1830

Pacific Northwest Laboratory Richland, Washington 99352 


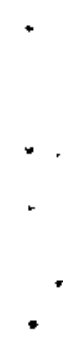




\section{ABSTRACT}

A concern in operation of a space station is leakage of atmosphere through seal points and through the walls as a result of damage from particle (space debris and micrometeoroid) impacts. This report describes a concept for a monitoring system to detect atmosphere leakage and locate the leak point. The concept is based on analysis and testing of two basic methods selected from an initial technology survey of potential approaches. 


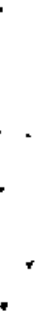




\section{EXECUTIVE SUMMARY}

BACKGROUND

An identified concern in the design and implementation of a space station is leakage of atmosphere past seal points in the structure and damage to the modules by the impact of micrometeoroids and particles of space debris on the outside of the modules with the resulting potential for leakage of the module atmosphere to space. An important element of coping with these concerns is to have the ability to detect seal leakage and to detect a particle impact, locate the point of impact, and determine if there is a resulting atmosphere leakage. Given this, it is feasible to repair damage before it becomes a major problem. The Pacific Northwest Laboratory (PNL) has performed preliminary feasibility determination for using pressure monitor methods to detect seal leaks and acoustic methods to detect and locate particle impacts on the wall of the module and any resulting leakage of module atmosphere to space. The work has been performed under support of NASA. This final report discusses the results from a technology survey, analytical evaluation and test work, and the conclusions and recommendations derived therefrom.

\section{RESOURCE STUDY}

Various potentially applicable technologies were assessed. Measurement of pressure differential was selected for detection of atmosphere leaks across seals and acoustic emission techniques were selected for detection of particle impacts on the module wall, cracking in the module wall, and atmosphere leaks through the module wall.

\section{PRESSURE MONITORING METHODS}

Pressure differential methods for detecting atmosphere leaks around seals were evaluated using analytical models and limited experimental validation with the conclusion that the necessary leak sensitivity was attainable and that proven, conventional electronic pressure sensors are well suited to the problem. A model describing the behavior of the pressures in the volumes between three 0 -rings and their dependence on the seal leak rates has been 
developed and tested. Experiments performed here confirmed the applicability and accuracy of the model. Use of the model along with experimental measurements of the time history of the intravolume pressures can provide the leak rates for all three seals under a wide range of conditions. Measurement of these pressures is a viable method for determination of leak rates.

\section{ACOUSTIC EMISSION TECHNOLOGY}

Signal propagation characteristics and detectability of transient and continuous signal sources were examined. From the results obtained, impact and leakage should be detected even at distances of 10 feet or more from a monitoring sensor. Crack growth acoustic emission (AE) may prove to be somewhat more difficult to detect at large distances due to low signal levels. Fatigue cracking produced thousand of $A E$ events per inch of crack growth, and sensor sensitivity for these tests may be improved.

Measured signal parameters indicated an anisotropic response in the plate, causing signal energy and amplitudes to vary depending on source and receiver locations. As a result, signal parameters do not change uniformly with distance, and source location or strength determination techniques which rely on smoothly varying amplitude or energy dependencies will probably be ineffective.

Leakage through a circular orifice ranging from 0.008 to 0.08 inches diameter and with a 15 psi pressure drop was detectable at a two-foot source/sensor separation. Linear dependance of signal RMS voltage on leak rate, observed for large leak rates, does not appear to hold for small leaks below about five or six pounds of air per day. The smallest hole size $(0.008$ inch diameter) attained and produced detectable emission with a leak rate of three times the maximum one-half pound per day specified. Smaller leaks should be detectable, depending on the eventual signal-to-noise ratio, and the final sensor configuration.

Effective source location of transient signals is attainable. Due to dispersion, large source/sensor distances cause a decrease in the apparent wavespeed, which will tend to mislocate sources in a reasonably consistent and predictable manner. Accurate location can be aided by a symmetric array by adjusting the location algorithm and by a truly broadband sensor. There 
is also developed methodology for locating the source of a continuous acoustic signal which would be generated by an established leak.

\section{THERMAL IMAGING}

Thermal imaging methods for detecting leaks by viewing the outside of the module units was evaluated. The results indicated that this could be a feasible approach; however, based on guidance received from NASA and Boeing Aerospace staff at the time of the review of results from Phase I of this program, thermal imaging is not included in the recommendations for further attention.

\section{INSTRUMENT SYSTEM CONCEPT}

An instrumentation concept has been developed which supports the conclusion that the pressure differential measurement and $A E$ monitoring methods are realistically implementable.

\section{RECOMMENDATIONS}

Recommendations for further effort include:

- Seal integrity monitoring system development

- Laboratory work to resolve anomalies in acoustic leak detection test results

- Verify acoustic leak location techniques

- Develop the design for a prototypic leak detection and location instrument system

- Fabricate and demonstrate a prototypic leak detection and location instrument system 


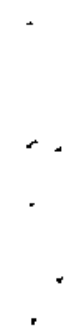




\section{ACKNOWLEDGMENTS}

The authors wish to recognize the individuals at the NASA Marshall Space Flight Center and Boeing Aerospace/Huntsville who have provided support and encouragement during the course of this project. Particular thanks go to Ton Hollingsworth who has been the NASA project monitor and to Earl Choate of Boeing who has provided liaison between PNL, NASA, and Boeing. We have also benefited from the input and guidance of other Boeing staff including Joe O'Neill, Brad McCall, Chris Dubuisson, and Greg 0lsen.

At the Pacific Northwest Laboratory, we wish to recognize Philip H. Hutton for his guidance and counsel in the area of acoustic emission technology, Kay E. Hass for her conscientious and willing efforts in preparing this manuscript, D. J. Criswell for his support in performing the crack growth tests, Kurt Stahl for assistance in evaluating pressure sensors, Dan Nelson for preparing the experimental setup used to verify the leak rate model, and Richard $A$. Craig for assistance in solving the coupled differential equations in the pressure-leak rate model. 



\section{CONTENTS}

ABSTRACT ...........................

EXECUTIVE SUMMARY ...................... v

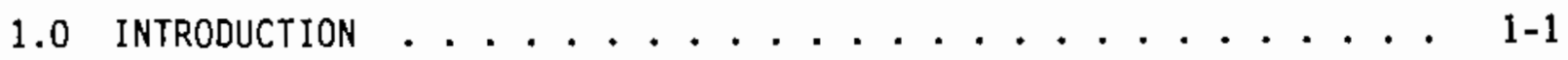

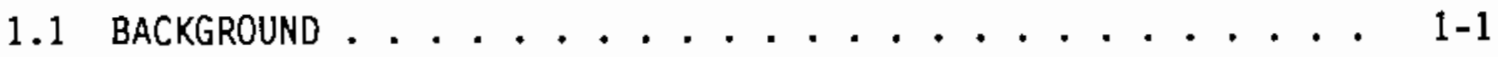

1.2 PURPOSE AND SCOPE OF THIS STUDY .................. 1 .

2.0 TECHNOLOGY SURVEY AND ASSESSMENT ............. . . . .

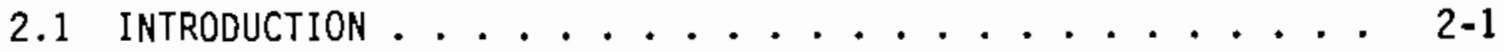

2.2 TECHNOLOGY ASSESSMENT FOR SEAL MONITORING ....... 2-2

2.3 TECHNOLOGY ASSESSMENT FOR LEAK/IMPACT MONITORING . . . . 2-15

2.4 ASSESSMENT OF LEAK DETECTION BY THERMAL IMAGING . . . 2-20

2.4.1 Introduction .................. 2-20

2.4 .2 Approach ............. 2- . . 21

2.4.3 Method ................. 2-21

2.4 .4 Results ................ 2- . 23

2.4.5 Proposed Future Activities . . . . . . . 2-25

3.0 SEAL LEAKS -. PRESSURE MEASUREMENT TECHNOLOGY . . . . . . . 3-1

3.1 OVERVIEH OF PROBLEM ........................ $3-1$

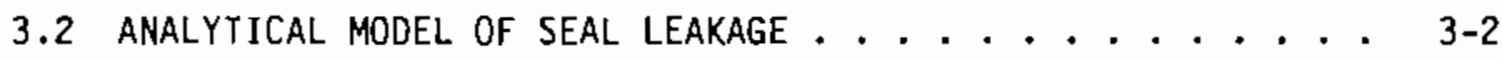

3.3 OPERATIONAL USE OF LEAK RATE AND PRESSURE MODEL . . . . 3-5

3.4 CALCULATED PRESSURE BEHAVIOR UNDER VARIOUS
LEAK RATE SCENARIOS . . . . . . . . . . . . . . . . . . . . . .

3.5 EXPERIMENTAL VALIOATION OF ANALYTICAL MODEL ...... 3-11

4.0 IMPACTS/LEAKAGE DETECTION -- ACOUSTIC EMISSION TECHNOLOGY . . . 4-1

4.1 OVERVIEW OF IMPACT/LEAKAGE ASSESSMENT TASK ........ . 4-1

4.2 Materials, equipMent, and Setup .............. 4-1 


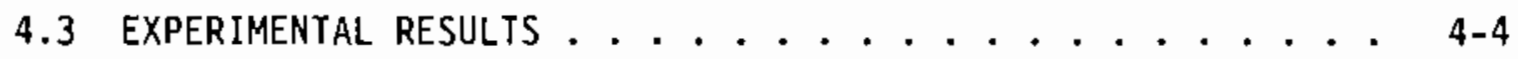

4.3.1 Experiment 1: Pencil Leak Break Calibration ... 4-4

4.3.2 Experiment 2: Helium Gas Jet Calibration . . . 4-6

4.3.3 Experiment 3: Detectability of Leakage and Effect of Source Position .......... 4-9

4.3.4 Experiment 4: Effect of Leak Rate on Acoustic Emission............... 4- 4- . .

4.3.5 Experiment 5: Fatigue Test ......... 4-15

4.3.6 Experiment 6: Location of Transient Sources . . 4 4-16

4.4 ANALYSIS AND DISCUSSION .............. . . . . . . . . . .

5.0 INSTRUMENTATION CONCEPT . ...................... 5-1

5.1 OVERVIEW .......................... 5-1

5.2 AE INSTRUMENTATION CONCEPT . . . . . . . . . 5-7

5.2.1 Impact Location with AE Methods ........ 5-9

5.2 .2 AE Leak Location ............. 5-11

5.2.3 AE System Specification ........... . . 5-13

5.2.4 Sensor Layout Design ............ 5- . . . . . . .

5.3 PRESSURE MEASUREMENT INSTRUMENT CONCEPT . . . . . . . 5-18

5.3 .1 overview ........................ 5-18

5.3.2 Seal Integrity Monitoring System (SIMS) . . . . 5-20

5.3.3 Pressure System Specification......... 5-23

6.0 CONCLUSIONS AND RECOMMENDATIONS ............. 6- . . . .

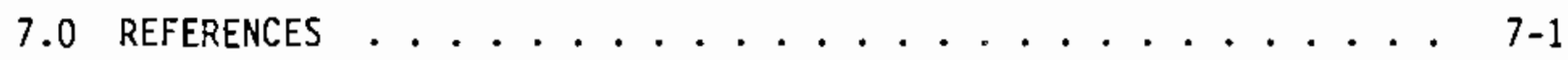

APPENDIX A: DESCRIPTION AND USE OF PRESSURE COMPUTATION COOE . . . A-1 


\section{FIGURES}

1.1 Artist's View of Space Station Freedom (photo courtesy

of Boeing Aerospace) .............. 1-2

1.2 Instrument Racks in a Laboratory Module Mock-up

(photo courtesy of Boeing Aerospace)............ 1-3

2.1 Configuration 1: Hatch Seals ............. 2-2

2.2 Configuration 2: Window Seals ........... 2-3

2.3 Configuration 3: Berthing Seals .......... 2-4

2.4 Detection of Leaks in Window Fixtures - Pressure Transducers. . 2-5

2.5 Detection of Leaks in Window Fixtures - Pressure Transducers. . 2-6

2.6 Detection of Leaks in Window Fixtures - Pressure Transducers. . . 2-7

2.7 Detection of Leaks in Window Fixtures - Optical Transducers . . 2-9

2.8 Detection of Leaks in Window Fixtures - Optical Transducers . . 2-10

2.9 Detection of Leaks in Window Fixtures - Optical Transducers . . 2-11

2.10 Detection of Leaks in Window Fixtures - Active Acoustic

Transducers ................ 2- . . . . . . . 2

2.11 Detection of Leaks in Window Fixtures - Active Acoustic

Transducers ................ 2-13

2.12 Detection of Leaks in Window Fixtures - Chemical Transducers. . 2-14

2.13 Detection of Leaks in Hatches and Berthing Rings -

Two Concepts ............... 2-16

2.14 Detection of Leaks in Hatches and Berthing Rings -

Berthing Seal Monitor.............. 2-17

2.15 Detection of Leaks in Hatches and Berthing Rings . . . . . 2-18

2.16 Detection of Leaks in Hatches and Berthing Rings . . . . . 2-19

2.17 Simplified Model Used in Analysis . . . . . . . . . . 2-23

3.1 Two Types of Triple 0-Ring Seal Configurations to be

Used on the Space Station............. 3-1

3.2 Conceptual Model for Air Leakage through a Triple 0-Ring

Seal Showing the Relevant Physical Parameters ........ 3-2 
3.3 Model Plot of the Intravolume Pressures as a Function of Time Where All Leak Rates are Equal and Typical of

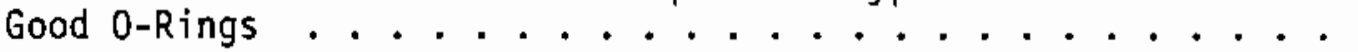

3.4 Mode1 PTot of the Intravolume Pressures for a Typical Hatch or Berthing Port (compare with Figure 3.3) . . . . . 3-8

3.5 Model Plot of the Intravolume Pressures where the Leak Rate for the Third Seal is Twice that for the Other Two Seals (compare with Figure 3.3; note the reduced pressure P2) ................ 3- . . . . .

3.6 Model Plot of the Intravolume Pressures which Simulate Failure of the First Seal . . . . . . . . . . . . 3-9

3.7 Mode1 Plot of the Intravolume Pressures where the Second Seal has a Leak Rate 10 Times that of the Other Two Seals (other conditions are identical to those of Figure 3.6) ...................... 3-10

3.8 Model Plot of the Intravolume Pressures where the Third Seal has a Leak Rate 10 Times that of the Other Two Seals (other conditions are identical to those of Figure 3.6) ................... 3-10

3.9 Experimental Arrangement to Test Applicability of the Leak Rate Model (atmospheric pressure is exterior to the 0 -rings while effectively zero pressure is internal to them) .................... 3-12

3.10 Experimental and Model Plots of the Intravolume Pressures with all Three Leak Rates Approximately Equal . . . . 3-13

3.11 Experimental and Model Plots of the Intravolume Pressures where the Outermost 0-Ring Leak Rate (see Figure 3.9) is about 8 Times that for the Other Two Seals . . . 3-14

3.12 Experimental and Model Plots of the Intravolume Pressures where the Middle 0-Ring Leak Rate is about 8 Times that for the other Two Seals .......... 3-14

3.13 Experimental and Model Plots of the Intravolume Pressures where the Innermost 0-Ring leak Rate is about 8 Times that for the Other Two Seals ........... 3-15

4.1 Detail of Ribbing on the Outer Side of the Space Station shell .................... 44-2

4.2 Layout for Pencil Lead Break and Gas Jet Experiments ..... . 4-5 
4.3 Signal Amplitudes Plotted Against Distance along

Different Test Lines (lead break calibration, Experiment 1) . . . 4-6

4.4 RMS Voltage Versus Distance along Two Lines with Similar Geometry (helium gas jet calibration, Experiment 2 )......

4.5 RMS Voltage Versus Distance along Two Lines with Similar Geometry (helium gas jet calibration, Experiment 2) . . . . 4-8

4.6 Layout for Leak Experiments . . . . . . . . . . . . . 4-10

4.7 RMS Voltage Versus Distance for Leakage from a Round Hole (hole diameter is 0.014 inch, the leak rate is 5.7 pounds per day, and the pressure drop constant at 15 psi) . . . . 4-11

4.8 Power in $50 \mathrm{kHz}$ Bands Plotted against Distance for Leakage from a Round Hole (hole diameter is 0.0145 inch, the leak rate is 5.7 pounds per day, and the pressure drop

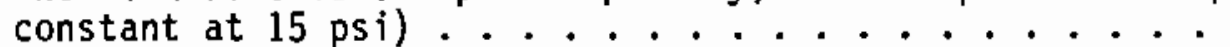

4.9 Leak Rate Versus Hole Diameter (pressure drop is a constant 15 psi; Experiment 4) ............ 4-13

4.10 RMS Signal Voltage Plotted Against Leak Rate (pressure drop 15 psi; Experiment 4).

4.11 Nomalized Signal Energy versus Leak Rate (pressure drop 15 psi; Experiment 4) .............. 4-14

4.12 Amplitude Distribution for AE from Fatigue Crack Growth; Experiment 5

5.1 Conceptual Electronic Interface for PNL Sensors . . . . . . 5-2

5.2 Configuration of AE and Pressure Monitor Systems ....... 5-3

5.3 Use of Hand-Held Acoustic Detector to Pinpoint Leak Location . . . . . . . . . . . . . 5-5

5.4 Conceptual Acoustic Emission Shell Impact and Leak Detector Interface ............. 5-7

5.5 Acoustic Emission Sensor Packages ... . . . . . . 5-8

5.6 Conceptual Acoustic Emission Impact Location System . . . . . 5-10

5.7 Conceptual Acoustic Emission Leak Location System . . . . . . 5-12

5.8a Sensor Layout Plan -- Space Station Module Roll-Out View . . . 5-15

$5.8 \mathrm{~b}$ Sensor Layout Plan .- Module/Node End Section View ...... 5-16 
5.8C AE Sensor Layout Plan -- Node Element - Roll-Out View . . . . 5-17

5.9 Conceptual PNL/NASA Seal Leak Detection Interface...... 5-19

5.10 Conceptual Design for Seal Leak Monitor . . . . . . . . . 5-21

5.11 Pressure Transducer Data Acquisition System . . . . . . . 5-22

5.12 Data Analysis Protocol for Seal Leak Monitor . . . . . . . 5-24

5.13 Miniature Ruggedized Is Pressure Transducer . . . . . . . 5-25

5.14 High Sensitivity IS Pressure Transducers . . . . . . . 5-26 


\section{$\underline{\text { TABLES }}$}

2.1 Analysis of Heat Transfer in Leak . . . . . . . . . . . 2-24

5.1 AE System Concept Design Specifications . . . . . . . . . . 5-4

5.2 Pressure Sensor Systen Concept Design Specification . . . . . . 5-6

5.3 PNL Acoustic Emission Analyzer Specifications . . . . . . . . 5-14

5.4 PNL Pressure Sensor Package Specifications . . . . . . . . . 5-23 



\subsection{INTRODUCTION}

\subsection{BACKGROUND}

The United States Space Station Freedom is scheduled to be launched in 1995 and will be a significant step toward the effective utilization of nearearth space. The presently proposed configuration upon which we base our analysis and conclusions shows the space station as a set of inter-connected aluminum cylinders with a large instrument boom, as shown in Figure 1.1. The main modules house the working and living quarters for the crew and contain most of the instrumentation for day-to-day operation of the station. The instruments are mounted in racks connected to a framework which runs the length of the module (Figure 1.2). The instrument racks can be pulled out to provide access to the wiring and the inner surface of the pressure shell. The shell is made from 12 sections welded together to form a cylinder about 14 feet ID and 38 feet long, excluding the end caps. Each section is 12 feet 10 inches by 10 feet 9 inches, made from a one inch thick 2219-T87 aluminum sheet, milled to produce a waffle-grid ribbed pattern with square elements roughly 14 inches on the edge. The ribs are $1 / 8$ inch wide, with one inch shell-plus-rib thickness. The final shell thickness between ribs is also $1 / 8$ inch, except near the edges where the thickness is $3 / 16$ inch. The shell sections are formed to fabricate the module with the ribs on the outside surface. Just outside the pressure shell will be a blanket of multi-layer insulation, and outermost will be a debris shield whose purpose is to prevent direct impact on the pressure shell by meteoroids and space debris.

Space debris, consisting mostly of bits of aluminum and paint accumulating in orbit since the dawn of the space age, are of more concern to space station designers than natural objects. The accumulation of such space debris is such that one impact per orbit is expected, compared to an expected impact by micrometeorites of about one per decade. Although most incident objects should be deflected by the shield, any damage to the pressure shell must be quickly identified and located. Other types of degradation which threaten the integrity of the pressure shell must also be identified and located so repairs can be made. Three types of damage (particle impact, crack growth, and seal deterioration -- all of which can result in atmosphere leakage) are of 


\section{Space Station General Arrangement}

Showing Work Package Distribution

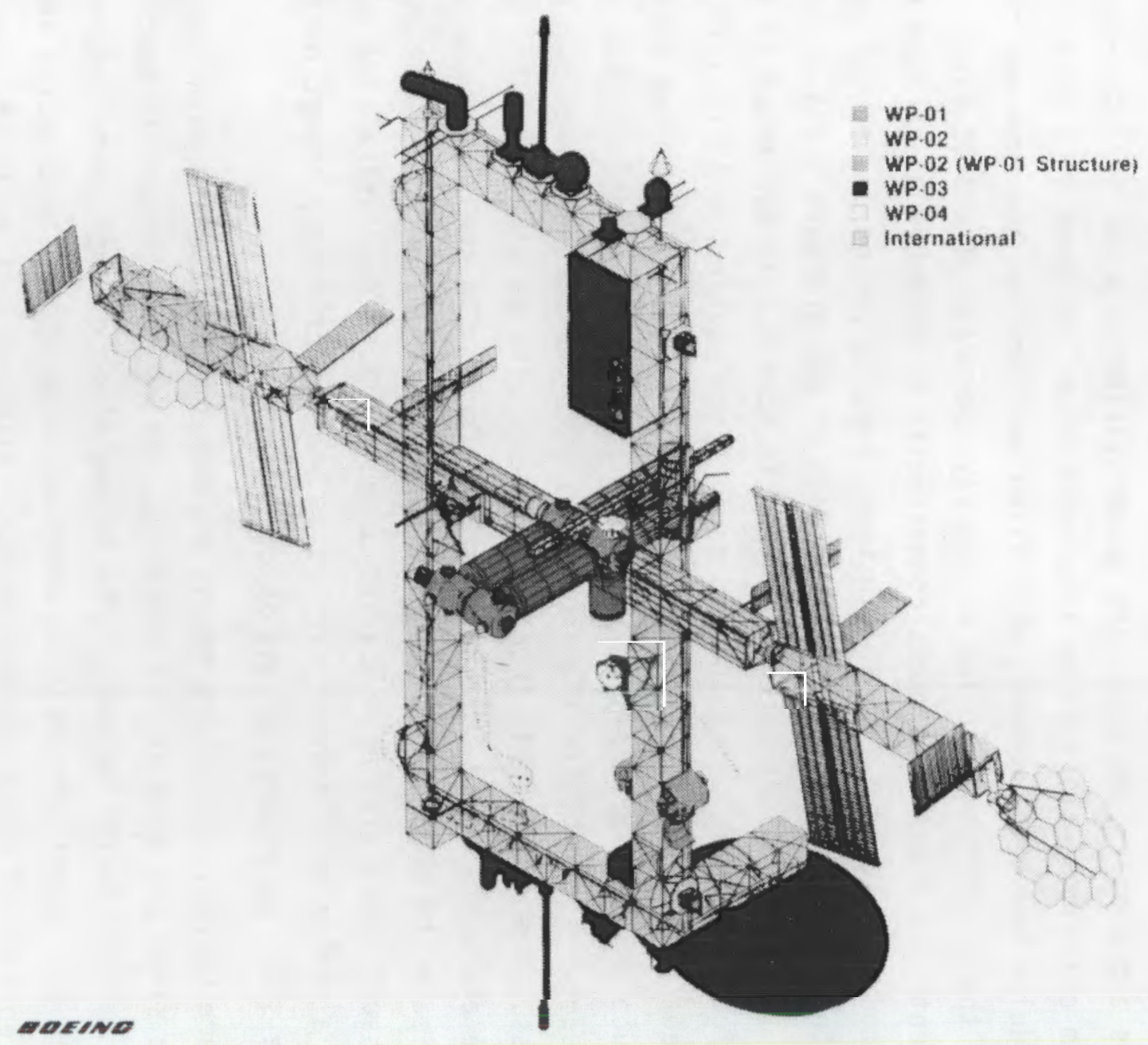

FIGURE 1-1. Artist's View of Space Station Freedom (photo courtesy of Boeing Aerospace) 


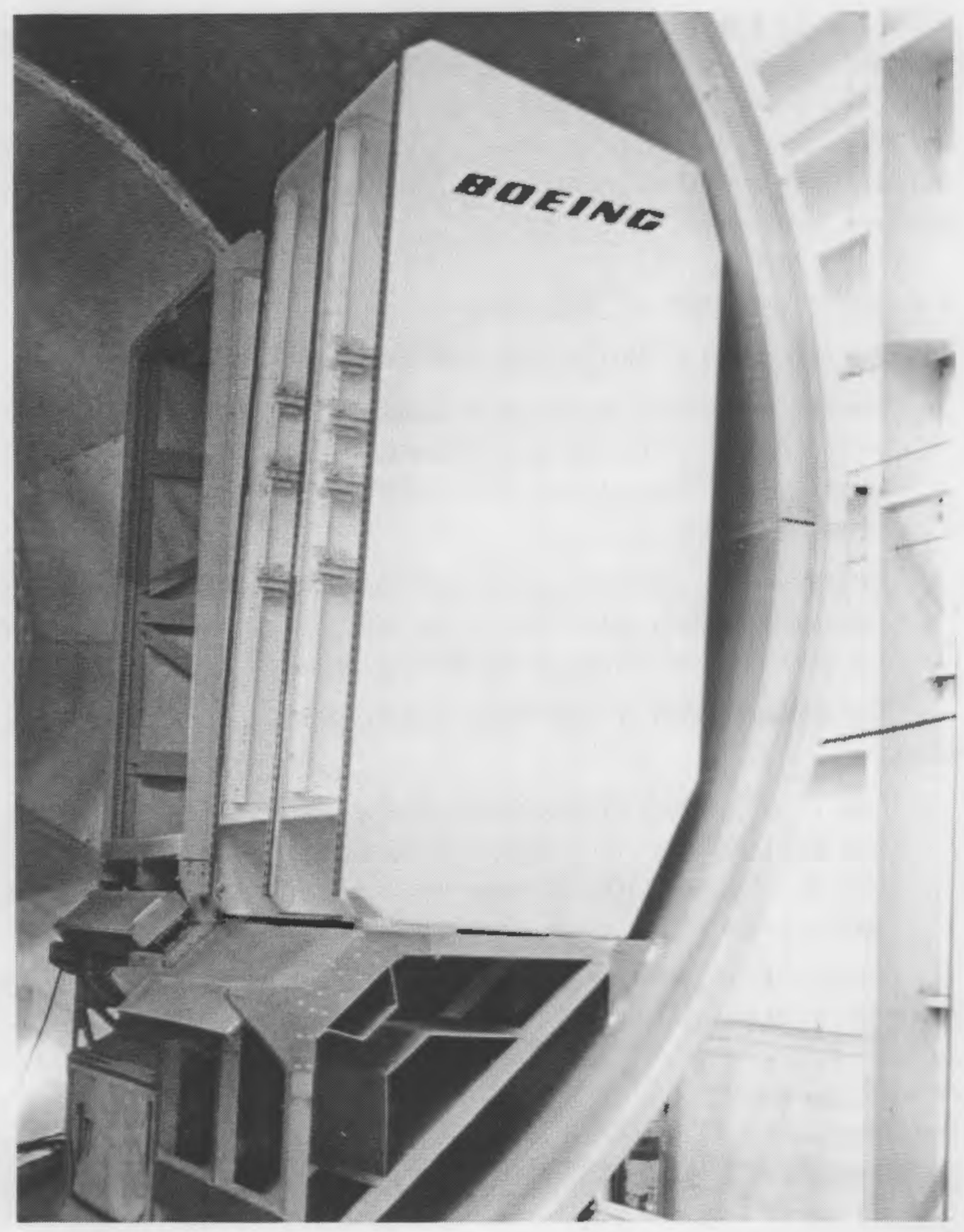

FIGURE 1-2. Instrument Racks in a Laboratory Module Mock-up (photo courtesy of Boeing Aerospace) 
principal concern. Of these three, leakage is by far the most important, since loss of atmosphere threatens the mission and the lives of the astronauts. of less concern are impacts which do not penetrate the shell, and crack growth which is expected to have a low probability of occurrence. Acoustic emission was brought into the program because of its unique capability for continuous monitoring to detect and locate structural damage and leaks with minimal manpower involvement.

\subsection{PURPOSE AND SCOPE OF THIS STUDY}

The objectives of this project were twofold:

1. Identify and assess technologies capable of detecting and locating leaks in the Space Station due to seal leaks, cracks, and micrometeoroid penetrations. Detection of seal leaks also includes detection of redundant seal failures.

2. Define an instrument concept to meet the leakage detection requirements. This would include definition of the size, weight, power requirements, and complexity to relate to feasibility of implementation.

The approach taken to meet these objectives was divided into four primary tasks:

Task 1: Technology Evaluation and Analysis

Task 2: Experimental Validation of Concepts

Task 3: Instrumentation Concept Development and Capability Definition

Task 4: Reporting, Reviews, and Project Management

The results of Task 1 are described briefly in Section 2. This work was reviewed in detail with NASA and Boeing staff during a Task 1 Design Review held at PNL in September 1989. The experimental investigation and validation of seal leak technologies is covered in Section 3. Likewise, Section 4 covers the study of acoustic emission as the preferred method for detecting impacts and general shell leaks. The instrument concept developed from this project is described in Section 5. The final Section 6 of the report discusses overall conclusions and recommendations for further development of the needed technology. 


\subsection{TECHNOLOGY SURVEY ANO ASSESSMENT}

\subsection{INTRODUCTION}

The first phase of the project was to survey a broad range of measurement methods and sensor technologies to determine the best technologies for use in a leak monitoring system. The problem was divided into three general areas: 1) leaks from seals, 2) leaks from impacts or cracking, and 3) thermal techniques for outside viewing. The results of the survey and analys is performed in these areas are given in the next three subsections.

\subsection{TECHNOLOGY ASSESSMENT FOR SEAL MONITORING}

This task began with a survey of applicable measurement techniques for detection and monitoring of leaks in the Space Station portals. Three types of seals were anticipated: hatch seals, window seals, and berthing seals. All seal sets were assumed to be 1) double fault tolerant, 2) of an 0-ring or bead geometry, and 3) manufactured from elastomeric materials. The respective conceptual seal geometries are depicted schematically in Figures 2.1, 2.2, and 2.3. Four transduction methods were considered for seal leak detection; pressure transduction, optical transduction, active acoustic transduction, and chemical transduction (via diffusion and leakage of chemical tracers). Candidate transduction schemes are depicted in Figures 2.4 through 2.12. A brief narrative of each concept follows.

In Figure 2.4 conventional solid-state pressure transducers are used to monitor intra-window cavity pressures in real time. In a healthy seal, the pressures in these volumes are expected to partition themselves equally (i.e., $10 \mathrm{psi}$ in the innermost volume and $5 \mathrm{psi}$ in the outermost volume). Departures from this situation are indicative of a leak.

In Figure 2.5 the same concept is implemented using mechanical transducers.

In Figure 2.6 the same concept is implemented using a self-contained pressure transducer capable of telemetering its data (via radio frequency or optical beam) to a hand-held interrogation unit operated by an astronaut on the Space Station. 


\section{CONFIGURATION 1: HATCH SEALS}

MODULE END FACE

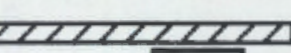

20170

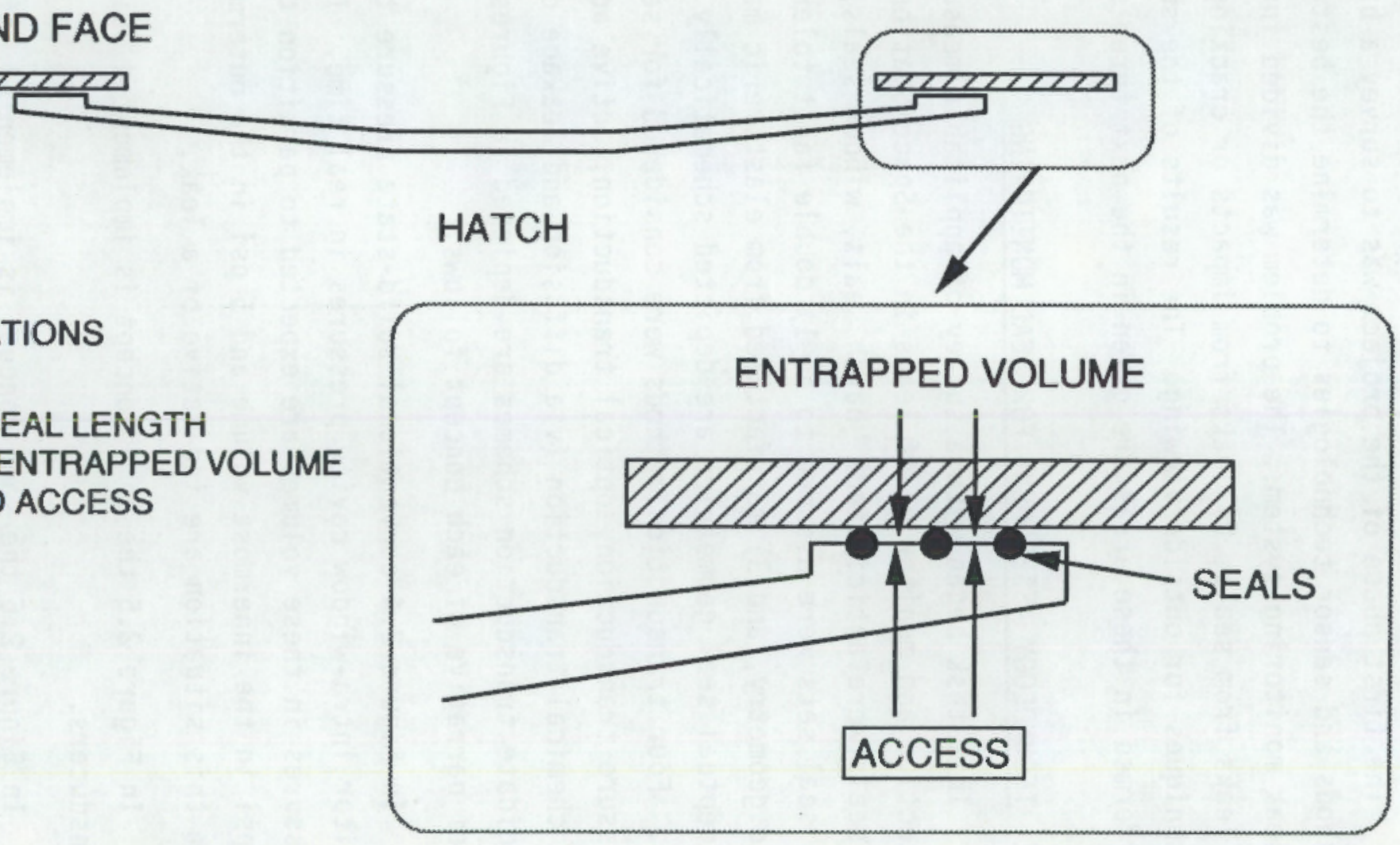

\section{CONSIDERATIONS}

- LONG SEAL LENGTH

- SMALL ENTRAPPED VOlume

- LIMITED ACCESS

FIGURE 2.1. Configuration 1: Hatch Seals 


\section{CONFIGURATION 2: WINDOW SEALS}

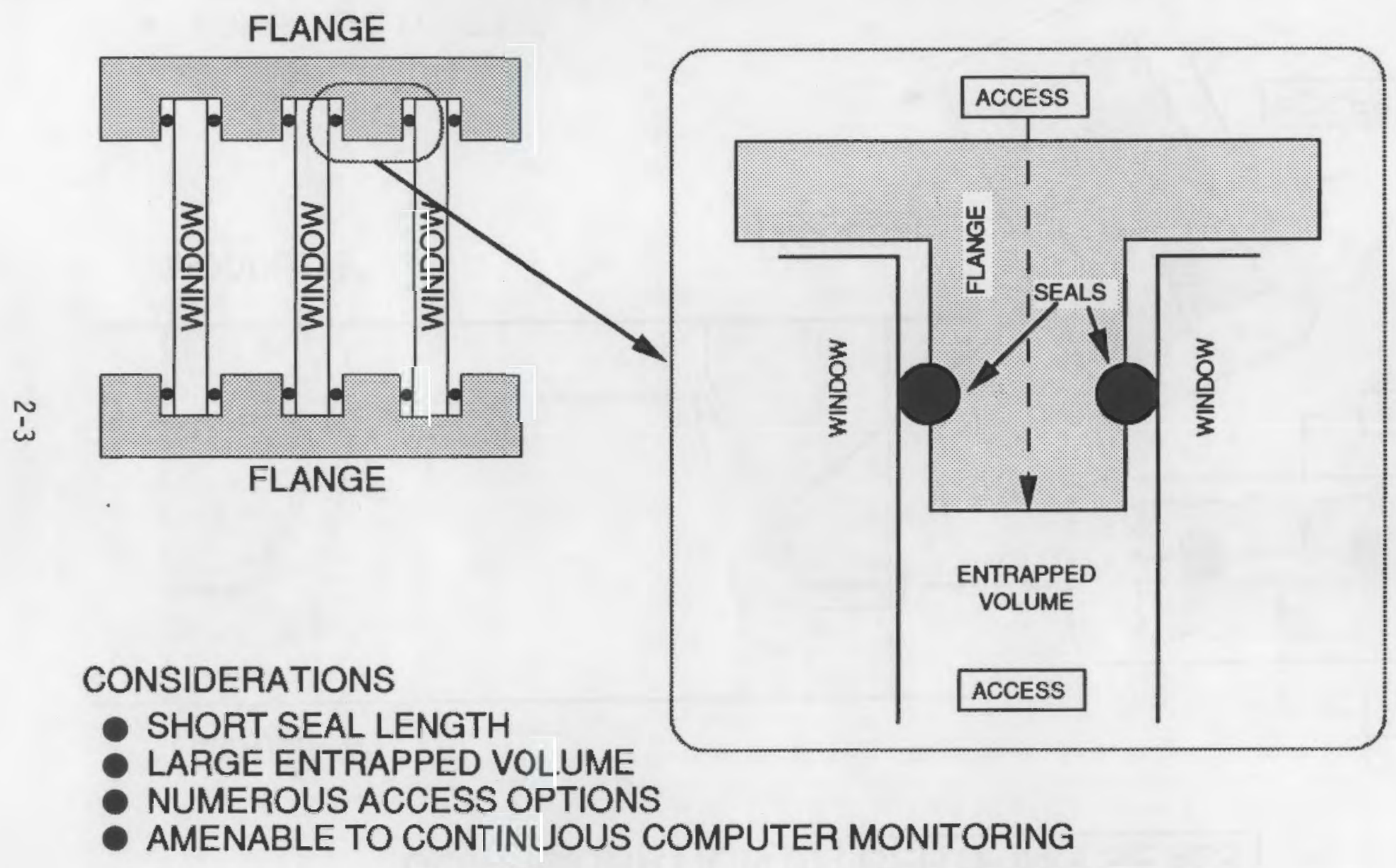

FIGURE 2.2. Configuration 2: Window Seals 


\section{CONFIGURATION 3: BERTHING SEALS}

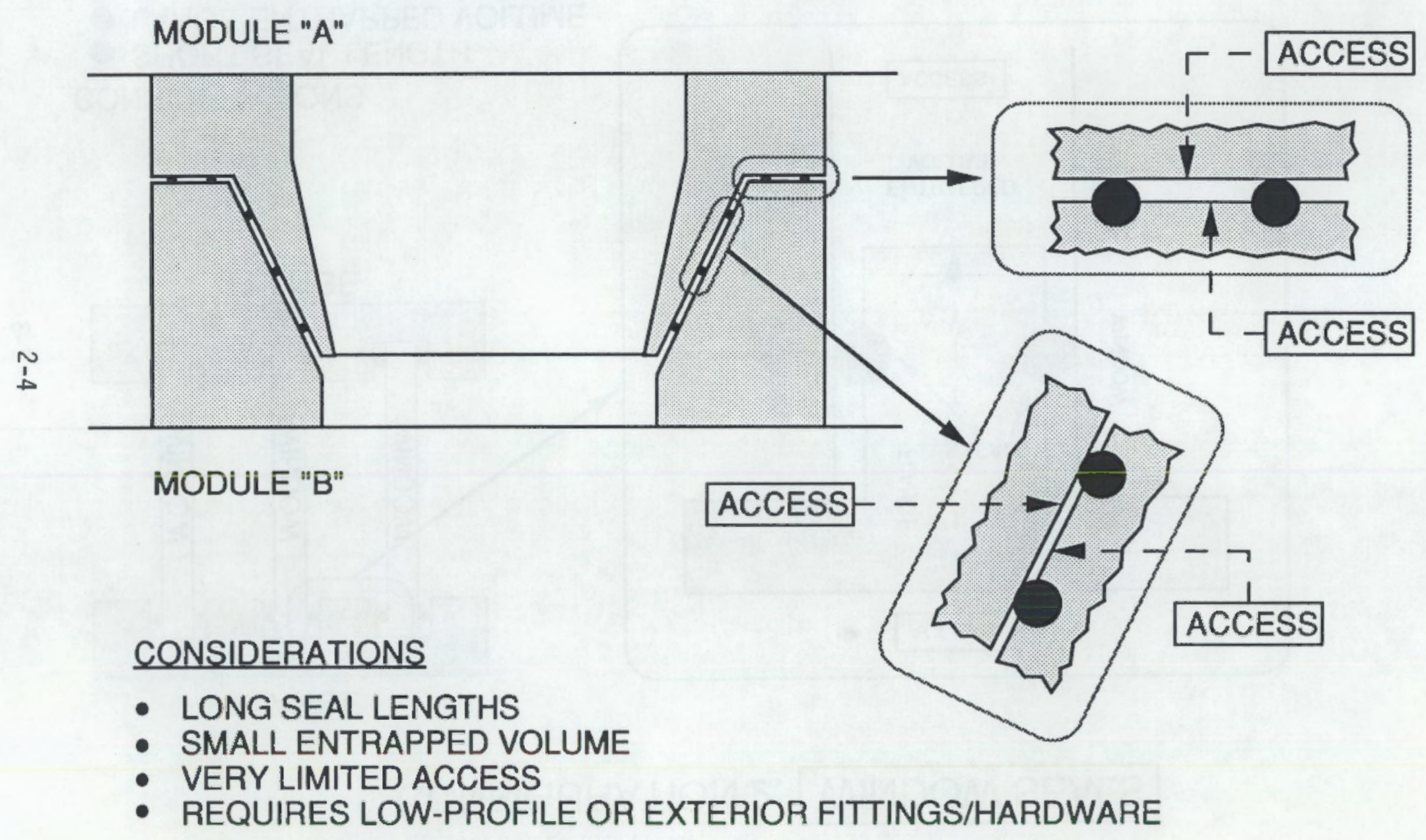

FIGURE 2.3. Configuration 3: Berthing Seals 


\section{DETECTION OF LEAKS IN WINDOW FIXTURES}

\section{PRESSURE TRANSDUCERS}

- MONITOR DIFFERENTIAL PRESSURE BETWEEN WINDOWS

- CHANGE IN $\triangle P$ IS INDICATIVE OF WINDOWISEAL FAILURE

CONCEPT IS AMENABLE TO CONTINUOUS MONITORING VIA COMPUTER

G

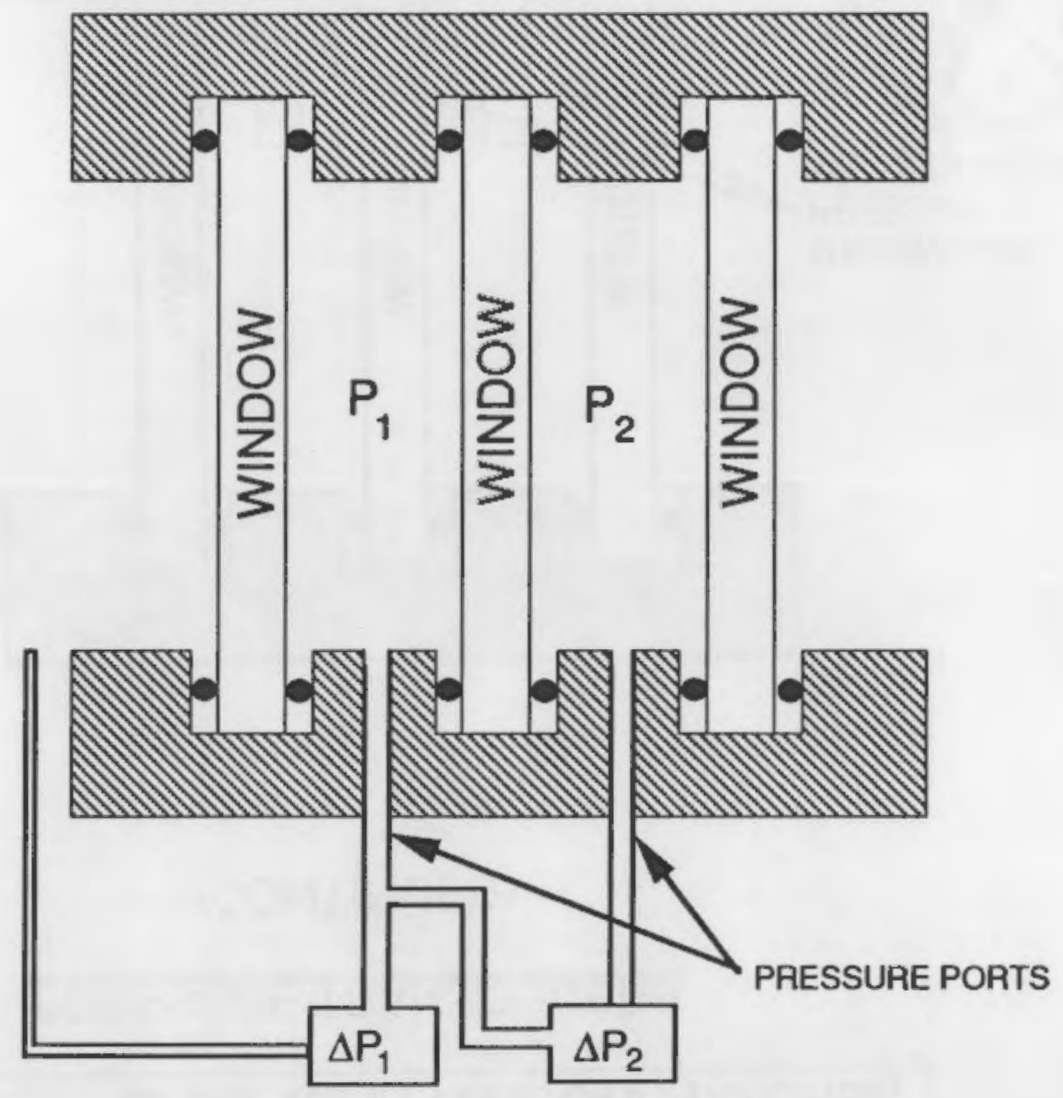

DIFFERENTIAL PRESSURE TRANSDUCERS

FIGURE 2.4. Detection of Leaks in Window Fixtures - Pressure Transducers 


\section{DETECTION OF LEAKS IN WINDOW FIXTURES}

\section{PRESSURE TRANSDUCERS}

(CONTINUED)

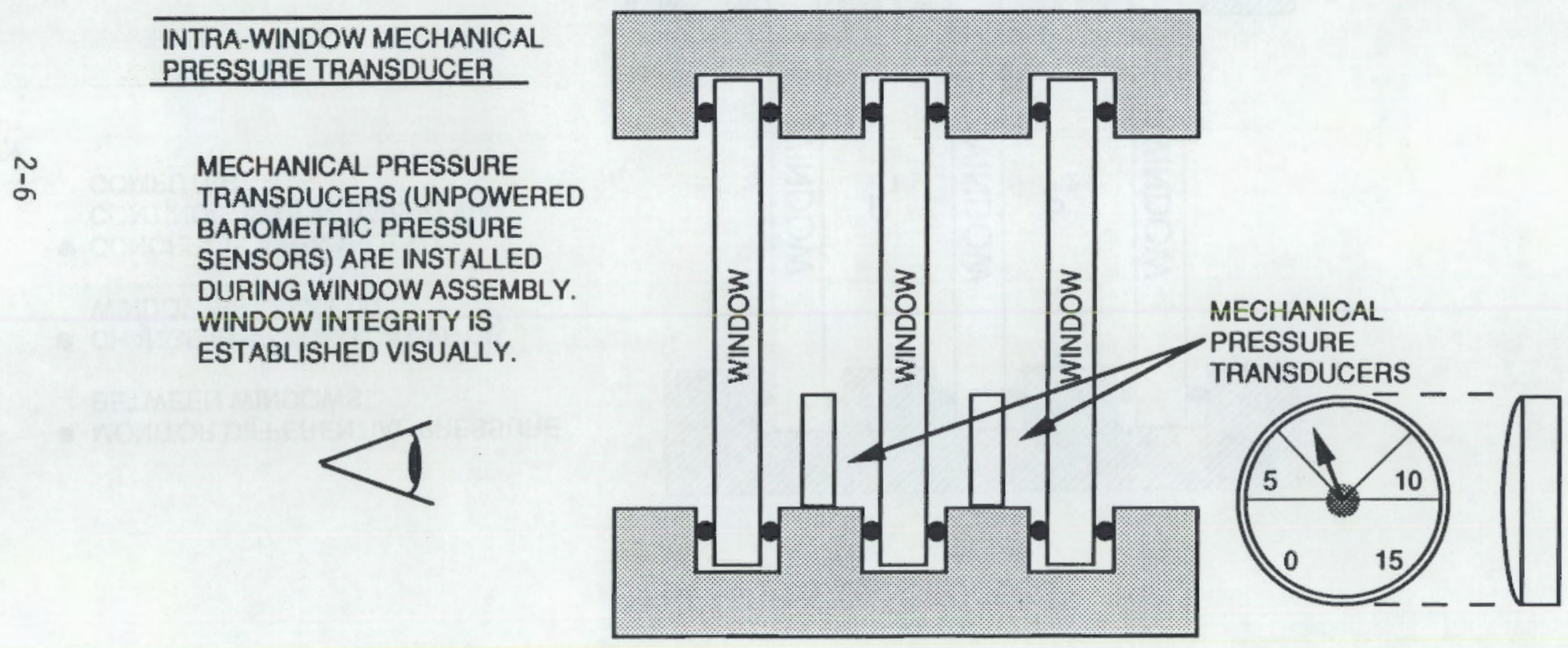

FIGURE 2.5. Detection of Leaks in Window Fixtures - Pressure Transducers 


\section{DETECTION OF LEAKS IN WINDOW FIXTURES}

\section{PRESSURE TRANSDUCERS}

\section{(CONTINUED)}

INTRA-WINDOW ELECTRONIC PRESSURE TRANSDUCER

INTRA-WINDOW ELECTRONIC PRESSURE SENSORS ARE POWERED AND INTERROGATED BY HAND-HELD PROBE. ONCE

THE SENSOR IS POWERED,

IT MEASURES THE AMBIENT

PRESSURE AND TRANSMITS

(EITHER OPTICALLY OR VIA

RF) THE DATA TO A RECEIVER

IN THE INTERROGATOR PROBE.
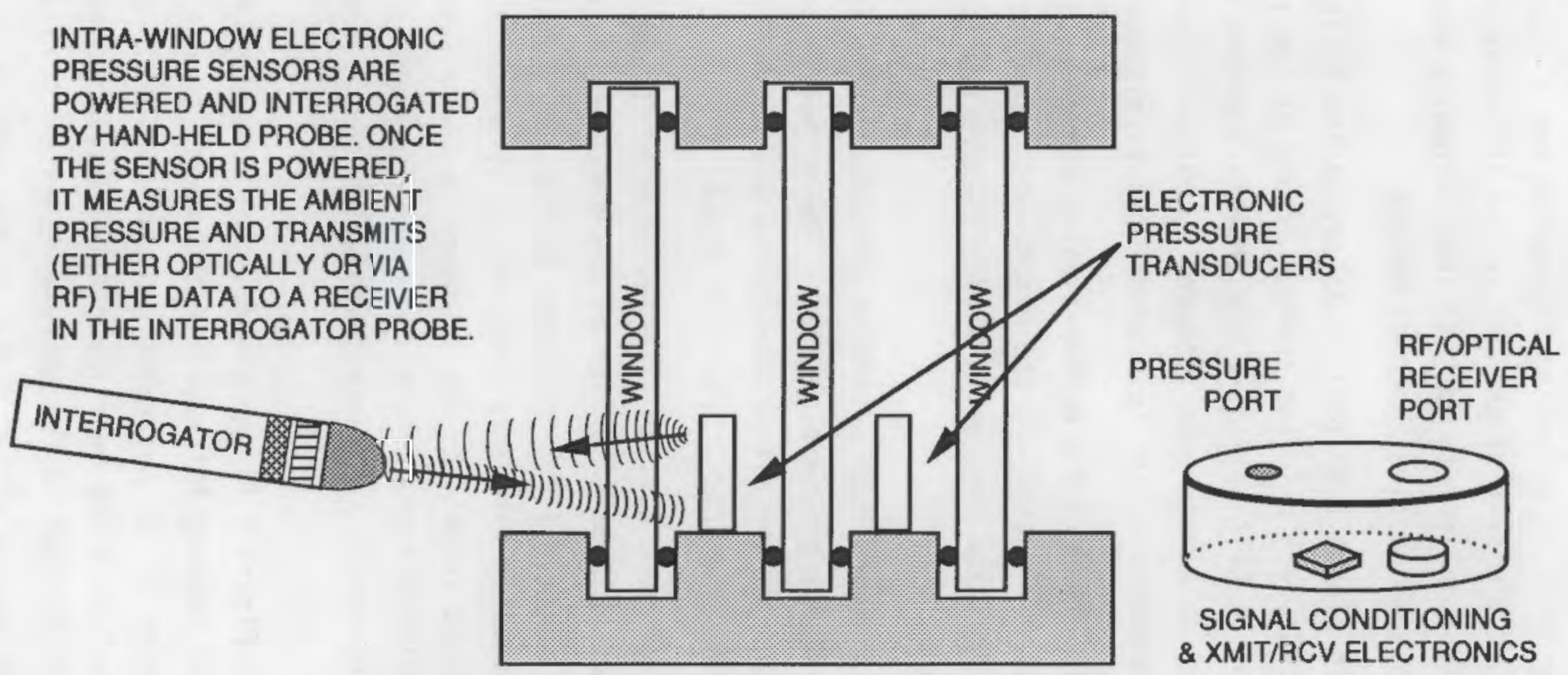

FIGURE 2.6. Detection of Leaks in Window Fixtures - Pressure Transducers 
In Figure 2.7 two optical transduction schemes are depicted. These schemes rely on detecting changes in the flexure (and shape) of the window panes as a result of changes in the intra-window cavity pressures. The first technique implements optical interferometry while the second implements a conventional optical gauging method.

In Figure 2.8 (top) a variant on the optical interferometry method is depicted where only the surface figure of the innermost window pane is sensed. The bottom half of Figure 2.8 depicts a method based on the detection of strain in a given window pane (induced by the anticipated pressure differential) via a measurement of the induced optical birefringence.

In Figure 2.9 a window-flexure sensor is depicted which embodies multiple optical reflections at the window-air interfaces. Once again this method would indicate changes in window flexure due to changes in intra-window cavity pressures.

In Figure 2.10 an active acoustic method is suggested for monitoring intra-cavity pressure changes. The method relies on propagation of an acoustic wave through the air in the cavity and monitoring changes in acoustic attenuation and/or propagation speed.

In Figure 2.11 an alternative acoustic method is presented in which the outermost window is driven by a piezoelectric (acoustic) transducer. Intracavity pressures are monitored by two additional acoustic transducers, $R_{1}$ and $R_{2}$. Acoustic resonance frequencies in the intra-window volumes should be determined largely by the pressure in these volumes. Consequently, if the excitation transducer (on the innermost window) is swept in frequency, changes in intra-cavity resonance frequencies can be monitored for indication of a leak.

In Figure 2.12 two concepts are presented for leak detection based on chemical sensing methods. In the first concept, colorimetric chemical indicators on the outermost windows are monitored to detect the presence of a chemical which has been impregnated in the outernost portal 0-ring. Presence of this chemical in the intra-window cavity volumes is indicative of air flow from the inside of the portal to the outside of the portal. 


\section{DETECTION OF LEAKS IN WINDOW FIXTURES}

\section{OPTICAL TRANSDUCERS}

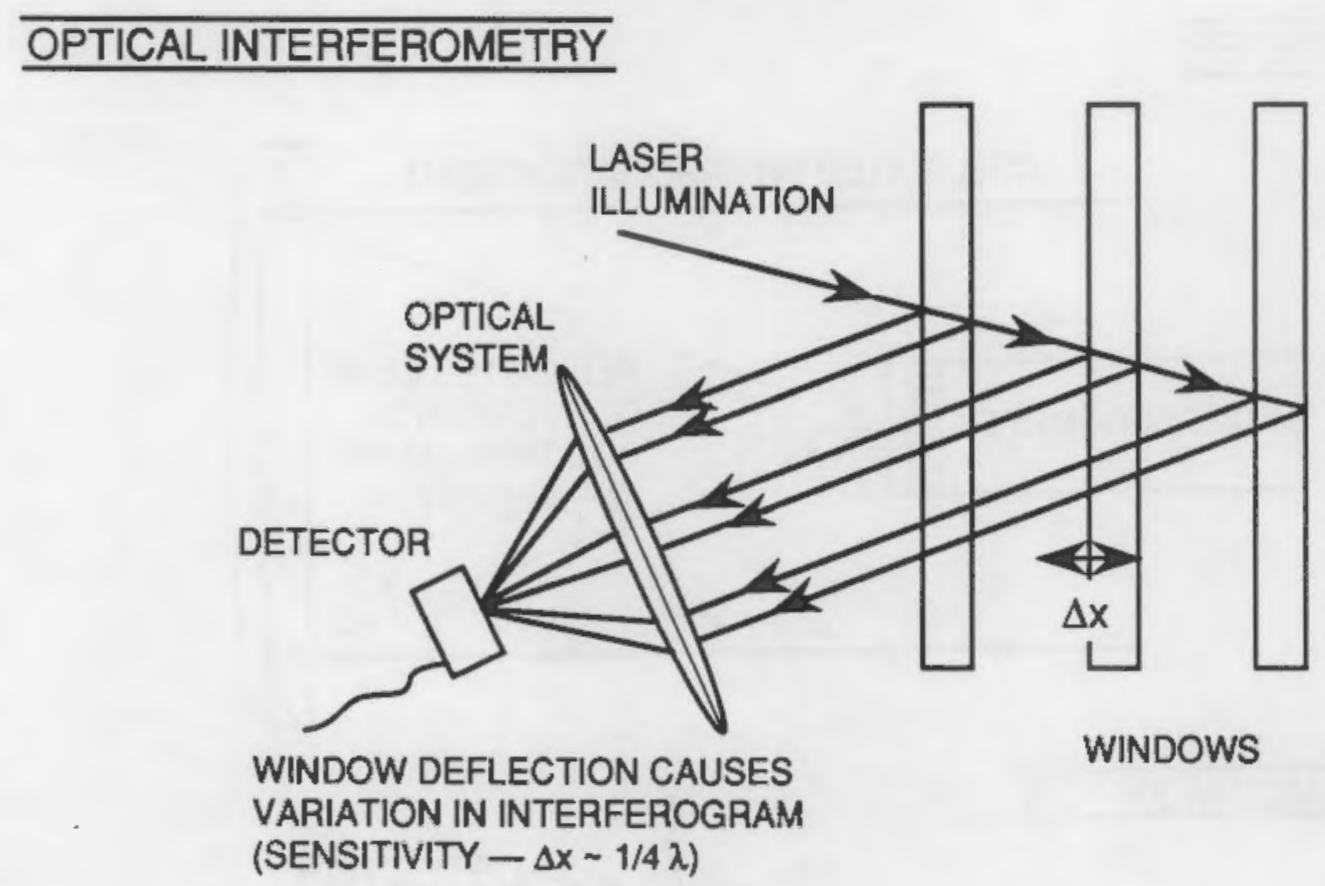

OPTICAL GAUGE

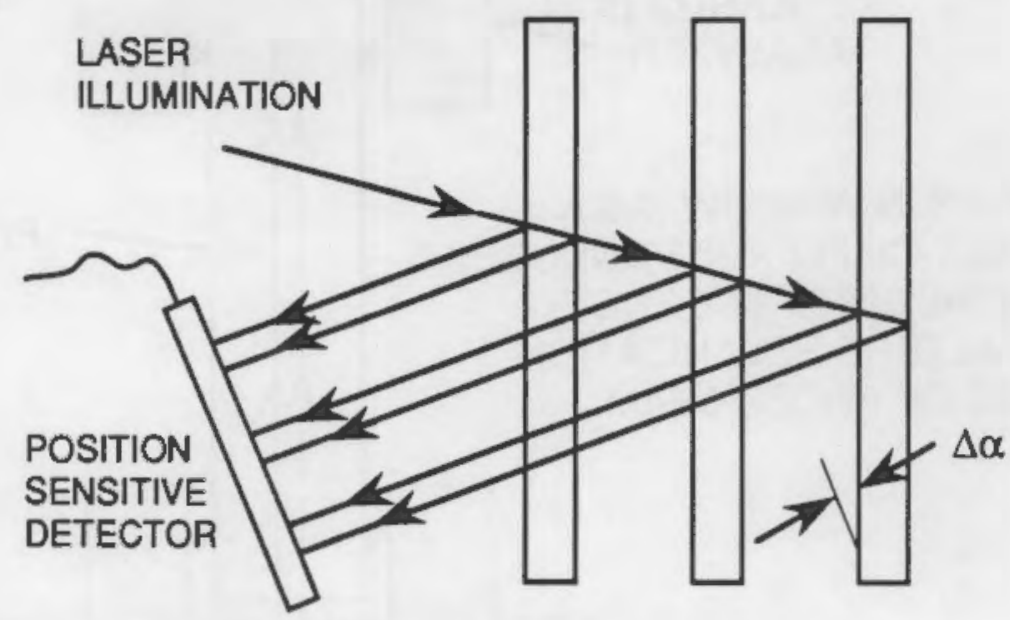

WINDOW DEFLECTION CAUSES

VARIATION IN BEAM INTERCEPT

WINDOWS

\section{POSITIONS}

(SENSITIVITY $-\Delta \alpha-$ SEVERAL MRAD)

FIGURE 2.7. Detection of Leaks in Window Fixtures - Optical Transducers 


\section{DETECTION OF LEAKS IN WINDOW FIXTURES}

\section{OPTICAL TRANSDUCERS}

(CONTINUED)

\section{$\overline{\text { SPHEROMETER }}$}

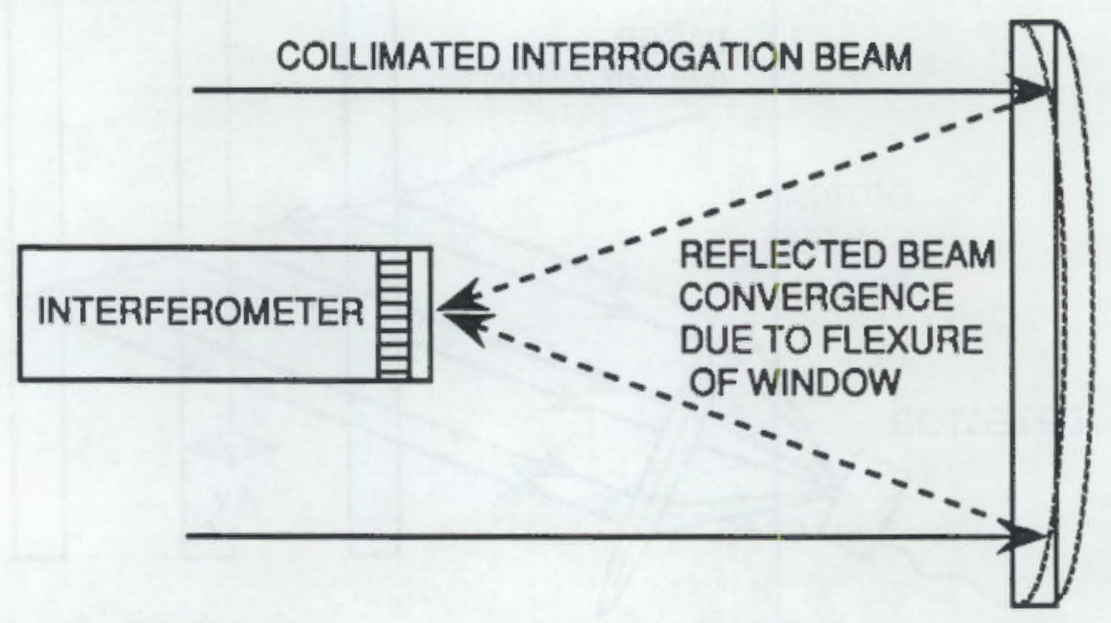

\section{BIREFRINGENCE MONITOR}

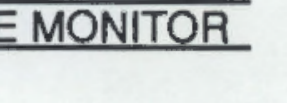

STRESS IN WINDOW (AS A

RESULT OF FLEXURE) INDUCES

OPTICAL BIREFRINGENCE AND ALTERS POLARIZATION STATE OF PROBE BEAM.

\section{POLARIZED LIGHT SOURCE}

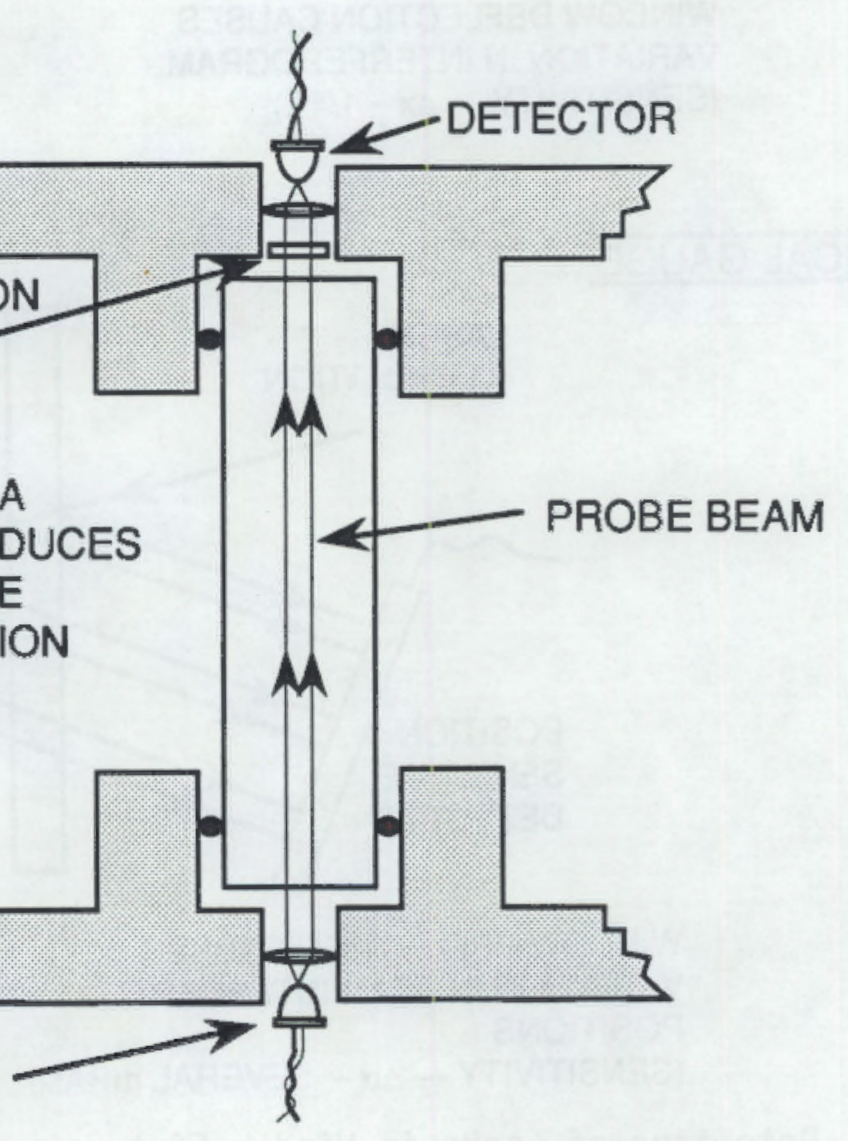

FIGURE 2.8. Detection of Leaks in Window Fixtures - Optical Transducers 
DETECTION OF LEAKS IN WINDOW FIXTURES

OPTICAL TRANSDUCERS

(CONTINUED)

OPTICAL SCISSOR PROBES - 2 CONCEPTS

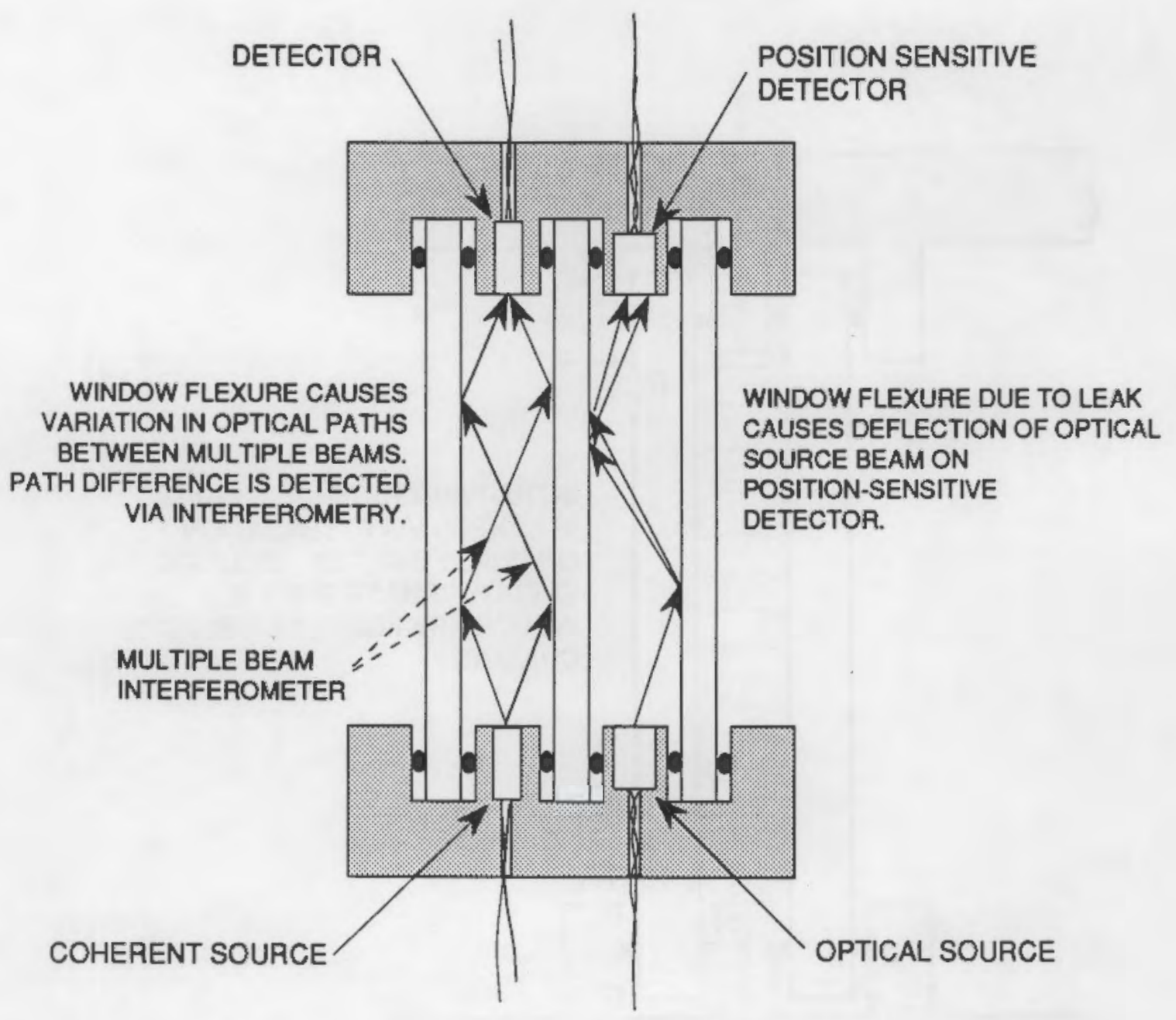

FIGURE 2.9. Detection of Leaks in Window Fixtures - Optical Transducers 


\section{DETECTION OF LEAKS IN WINDOW FIXTURES}

ACTIVE ACOUSTIC TRANSDUCERS

ACOUSTIC PHASE SHIFT AND/OR ATTENUATION

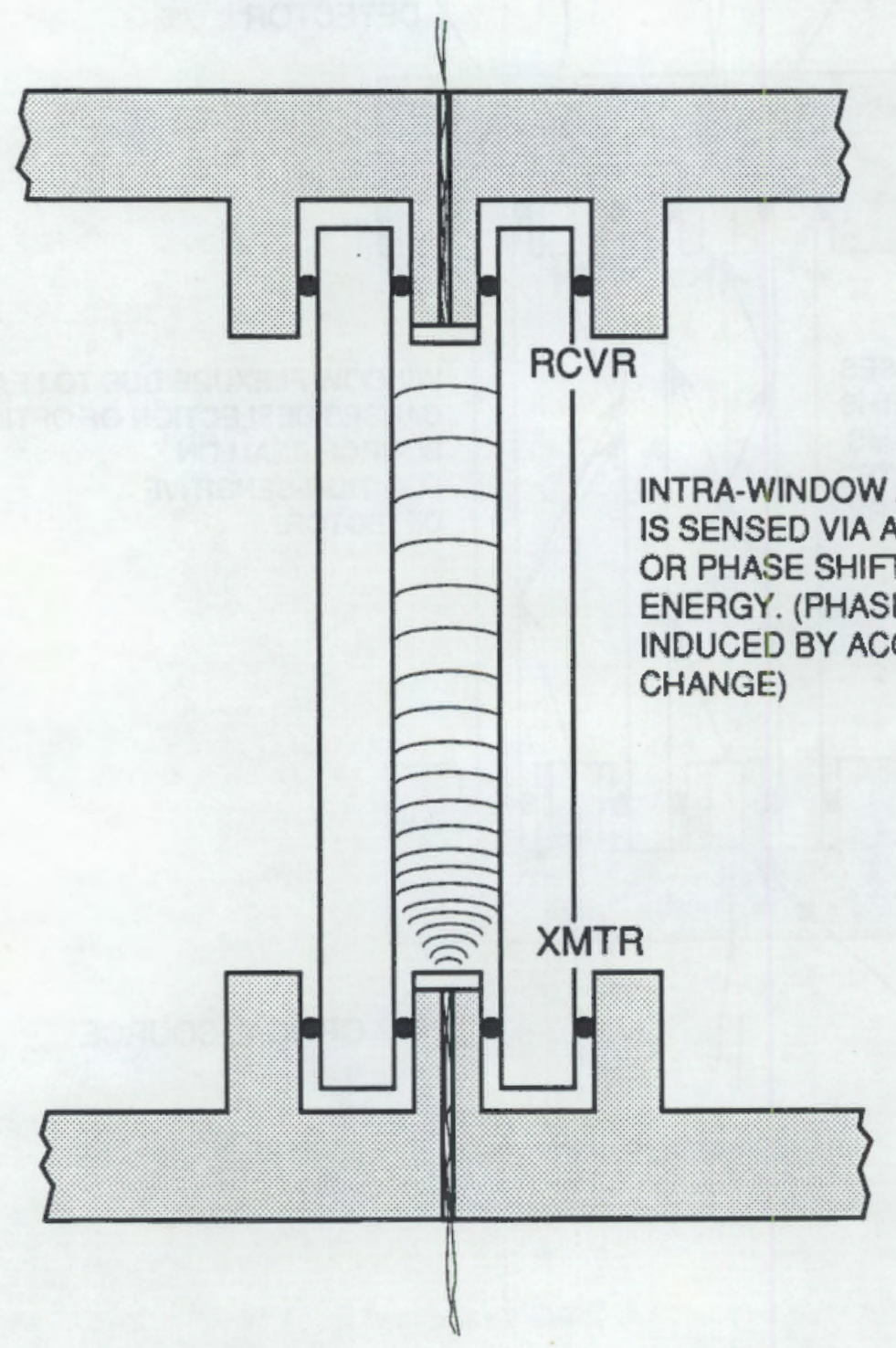

FIGURE 2.10. Detection of Leaks in Window Fixtures - Active Acoustic Transducers 


\section{DETECTION OF LEAKS IN WINDOW FIXTURES}

ACTIVE ACOUSTIC TRANSDUCERS

(CONTINUED)

\section{ACOUSTIC RESONANCE METHOD}

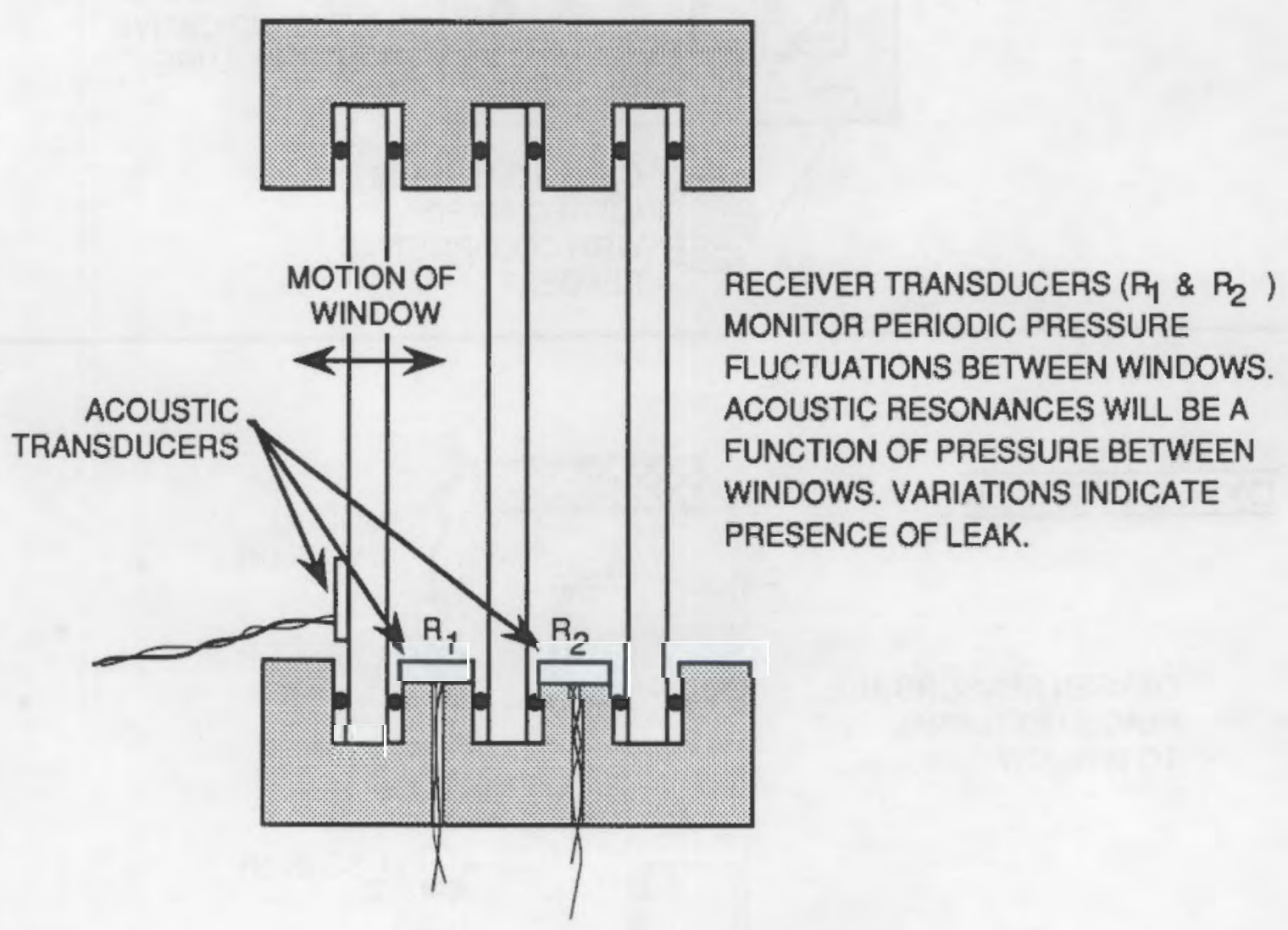

FIGURE 2.11. Detection of Leaks in Window Fixtures - Active Acoustic Transducers 


\section{DETECTION OF LEAKS IN WINDOW FIXTURES}

\section{CHEMICAL TRANSDUCERS}

\section{CHEMICAL INDICATOR}

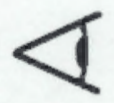

VISUAL INSPECTION OF INDICATOR PATCHES. PATCH COLOR INDICATES INTEGRITY OF SEAL.

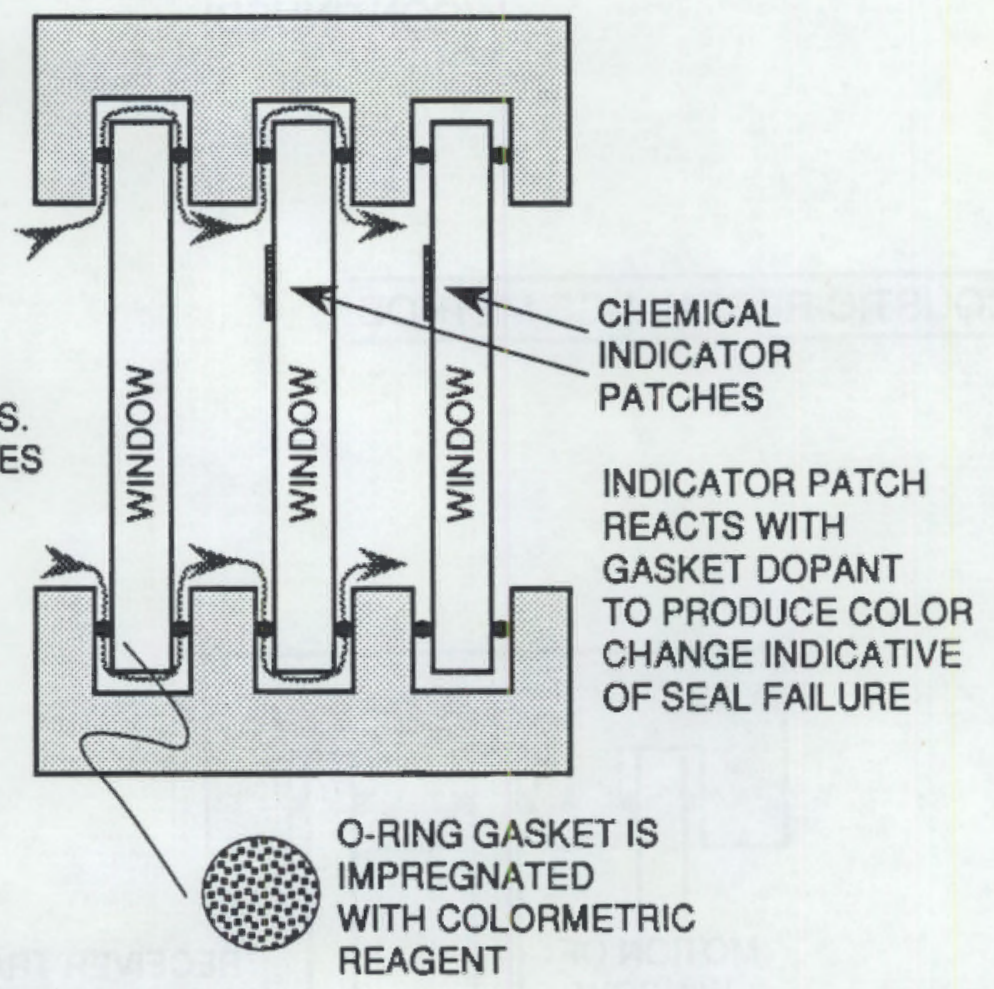

OXYGEN SENSOR

OXYGEN SENSORS ARE PLACED EXTERNAL TO WINDOW

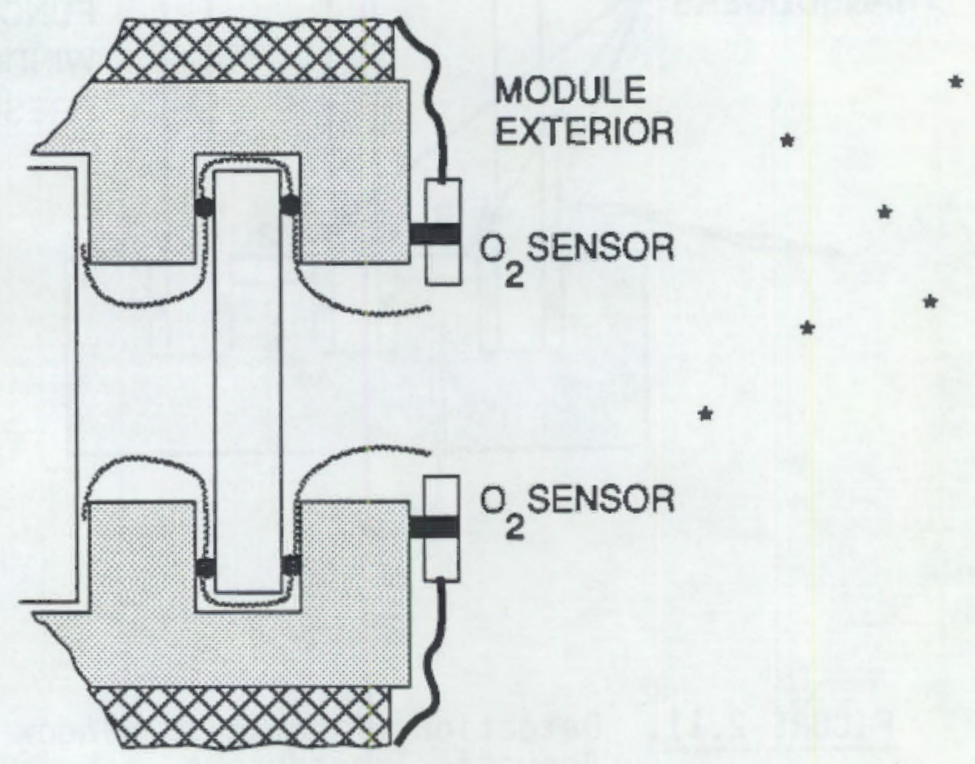

FIGURE 2.12. Detection of Leaks in Window Fixtures - Chemical Transducers 
Proposed leak sensor configurations for hatches and berthing rings are depicted in Figures 2.13 and 2.14 respectively. Note that the sensing scheme for these seals relies entirely on the use of solid-state pressure transducers for monitoring the intra-seal volumes. Depending on the required degree of automation, the seal integrity sensor systems for either hatches or berthingrings can be battery powered or umbilically powered. A more detailed conceptual design for this sensor type appears in Figure 2.15. Predicted pressure-versus-time profiles for "good" and "bad" seals appear in Figure 2.16 .

The conclusion of this study was that conventional electronic pressure sensors are both well proven and well suited to this problem. There is no need to develop new sensors for this task.

Guidance received from project engineers at Boeing/Aerospace is that the pressure sensors should be tied to a central data acquisition system. Therefore, the focus of the experimental studies was on performance of solidstate (piezo-resistive) pressure sensors.

\subsection{TECHNOLOGY ASSESSMENT FOR LEAK/IMPACT MONITORING}

The purpose and objective of Phase I of the program was to identify and assess available technology with potential for detecting and locating impacts, cracking, and leakage in the space station shell.

The conclusion of this task is that many techniques with potential for detecting any or all of the above listed damage types were examined, but were found to be unsuitable. Some of these techniques would require intensive use of space station personnel. These include dye penetrant, eddy current, potential drop, radiography, ultrasonic scanning, and ultrasonic attenuation. Although some of these procedures may be automated to reduce personnel involvement, the tradeoff would be increased equipment weight and size, probably beyond reasonable tolerance.

Radiography is objectionable for other reasons: access to both sides of the shell is required, there is some radiation hazard, and the application may be personnel intensive. Monitoring techniques capable of continuous or periodic scanning of large areas are compromised by limited space between the 
DETECTION OF LEAKS IN HATCHES AND BERTHING RINGS

\section{TWO CONCEPTS}

UMBILICAL TO POWER SUPPLY AND COMPUTER-BASED

BATTERY-POWERED SURFACE-MOUNT MONITORING SYSTEM SEAL MONITOR WITH LIQUID CRYSTAL DISPLAY

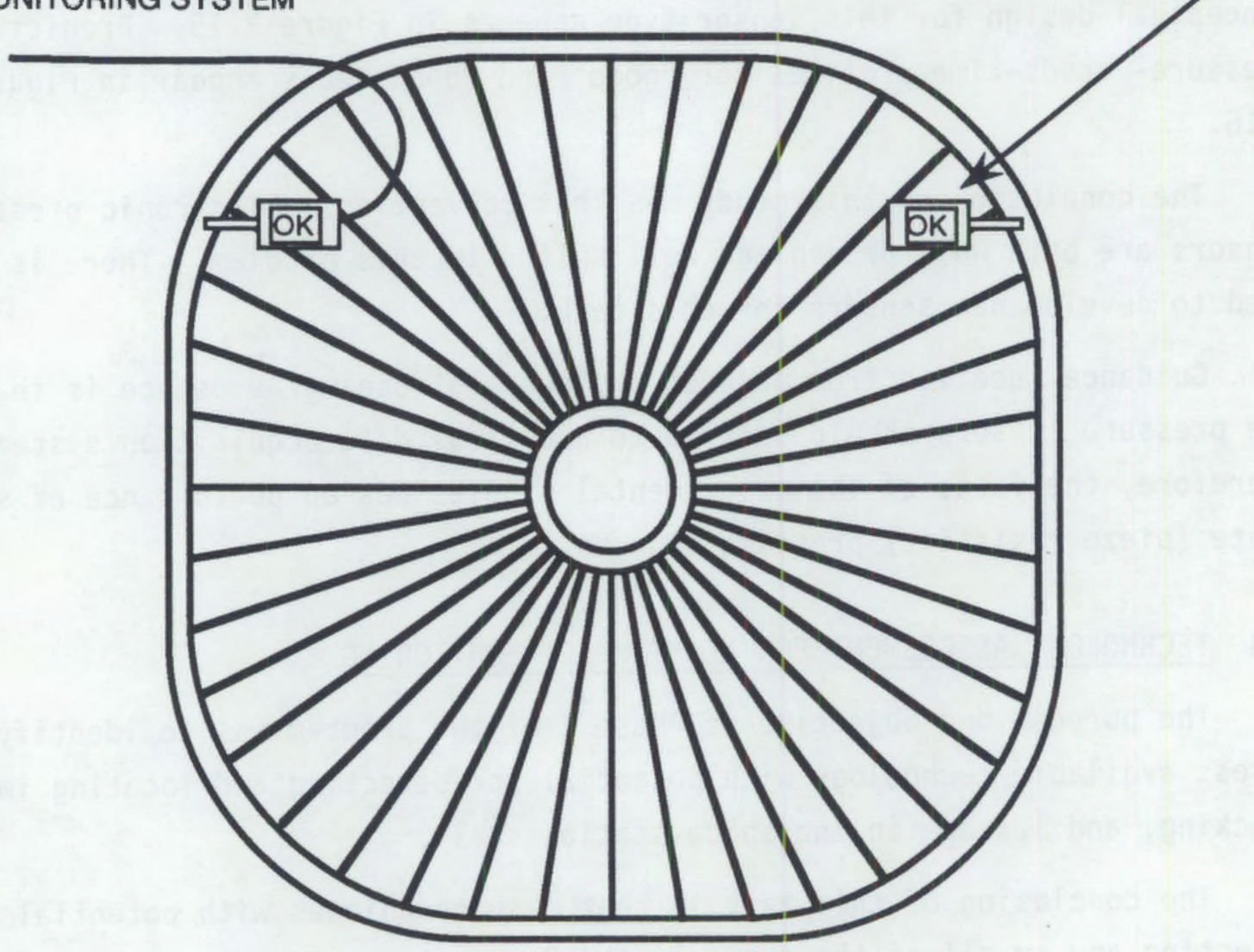

$\mathrm{HATCH}$

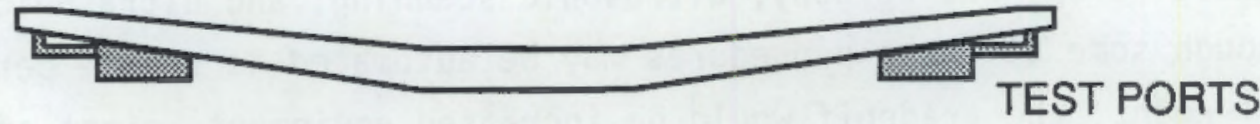

ONLY ONE MONITOR IS NECESSARY PER HATCH, HOWEVER, REDUNDANT MONITORS MAY BE DESIRABLE

FIGURE 2.13. Detection of Leaks in Hatches and Berthina Rings Two Concepts 


\section{DETECTION OF LEAKS IN HATCHES AND BERTHING RINGS}

\section{BERTHING SEAL MONITOR}

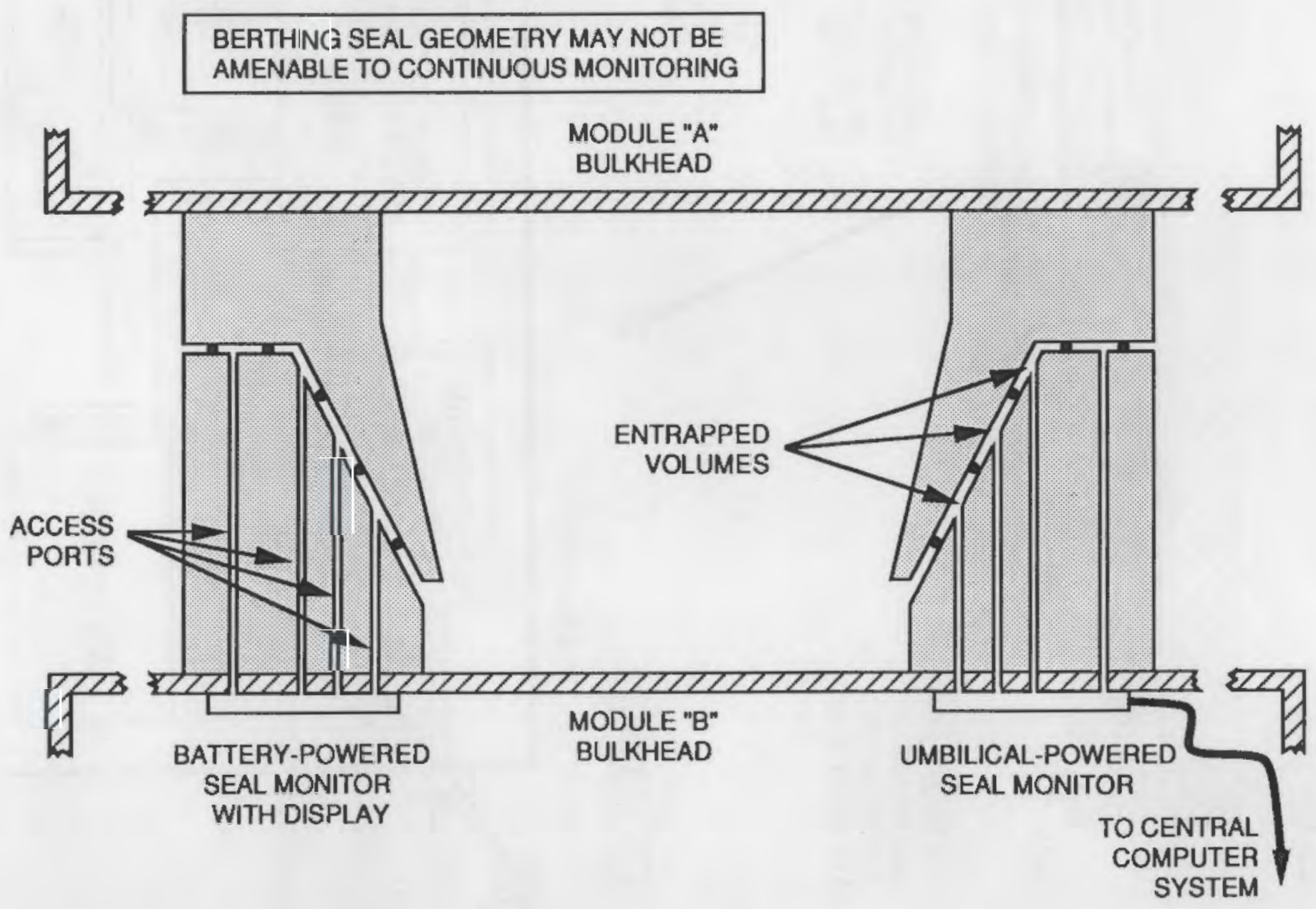

FIGURE 2.14. Detection of Leaks in Hatches and Berthing Rings - Berthing Seal Monitor 


\section{DETECTION OF LEAKS IN HATCHES \& BERTHING RINGS}

$\overline{\text { SEAL GEOMETRY }}$

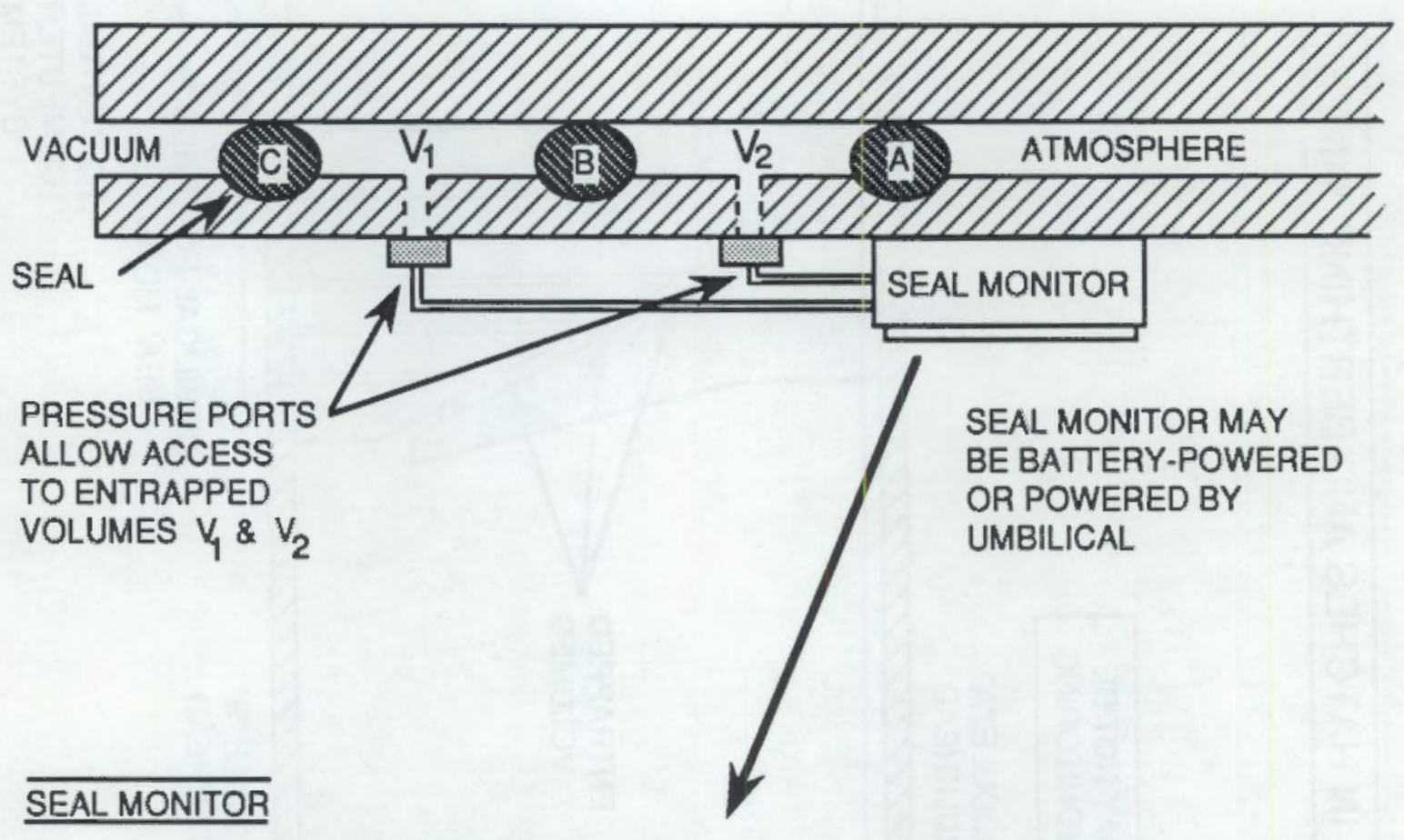

TO ATMOSPHERE

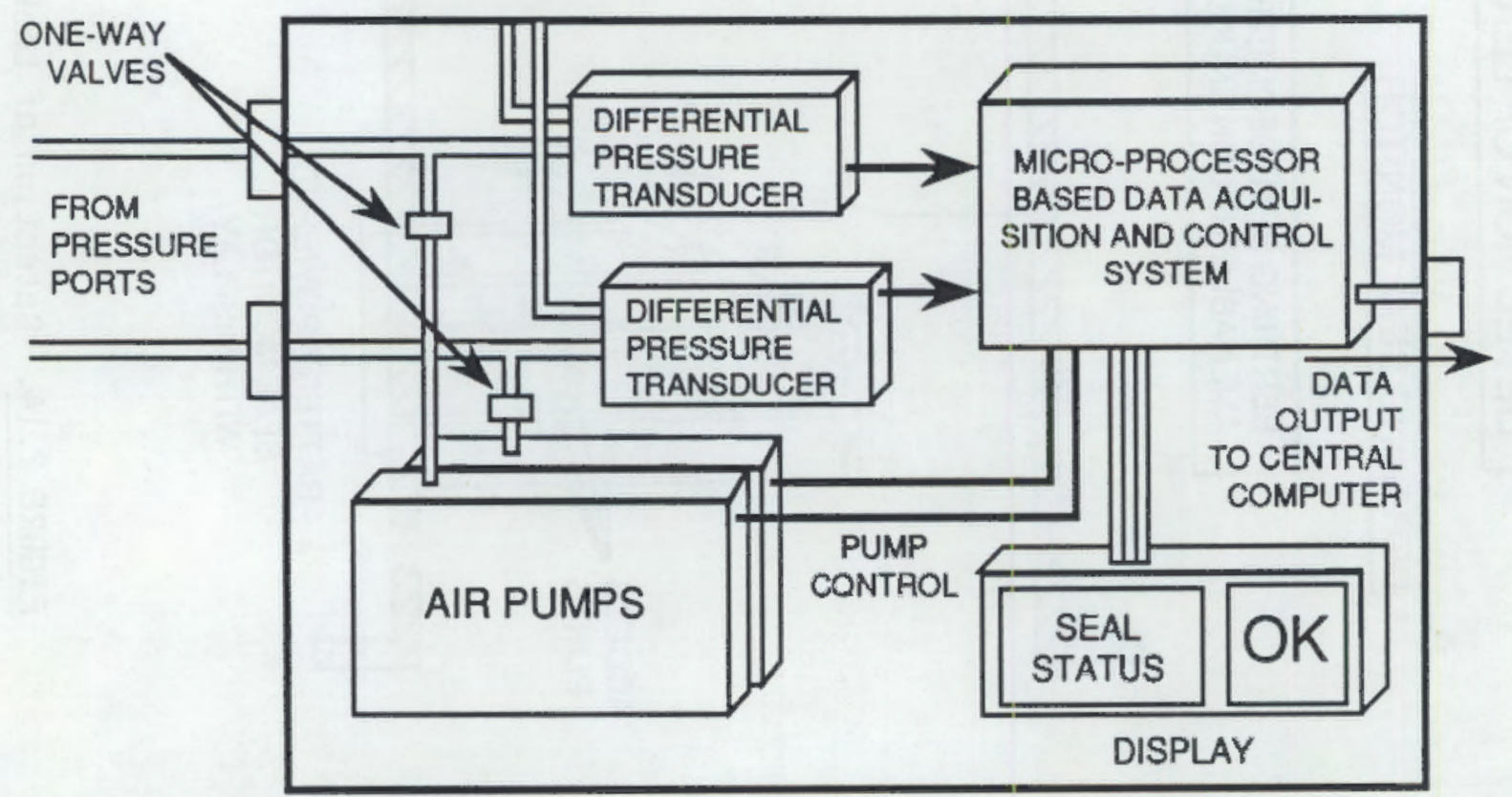

FIGURE 2.15. Detection of Leaks in Hatches and Berthing Rings 


\section{DETECTION OF LEAKS IN HATCHES AND BERTHING RINGS}

\section{GOOD SEAL}

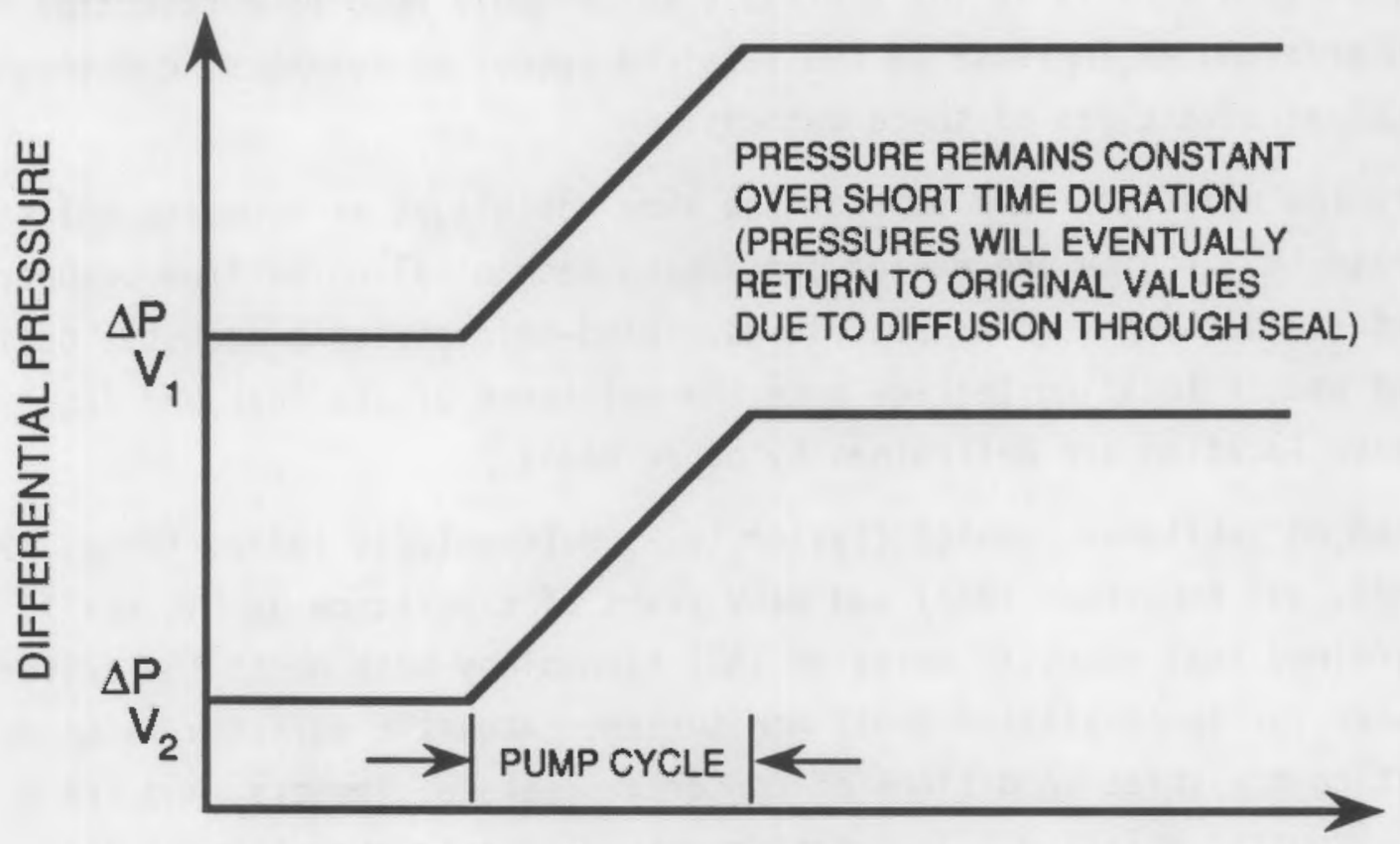

TIME

\section{BAD SEAL}

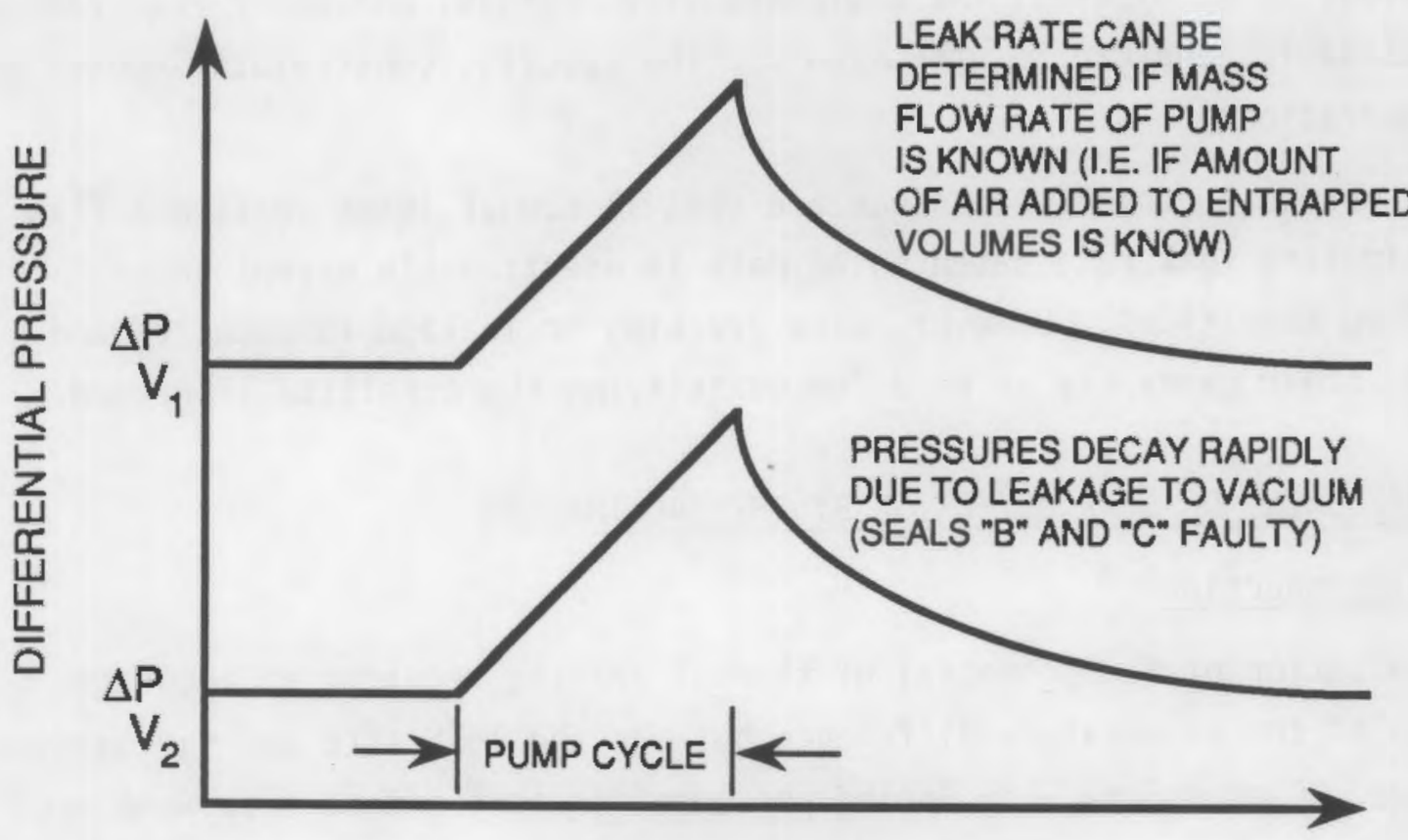

TIME

FIGURE 2.16. Detection of Leaks in Hatches and Berthing Rings 
equipment racks and the shell in the space station interior, and by the blanket and debris shield for external monitoring. Infrared and visual photography and cinematography techniques fall into this category. To place an array of such sensors in the available space would require a reduction in scanning area and an increase in the required number of scanners, counteracting the principal advantages of these methods.

Airborne acoustics have some of the same advantages as acoustic emission, but operate in a regime and medium containing mechanical noise from on-board equipment and daily personnel activities. Hand-held airborne acoustic devices may be of use in locating leakage once the existence of the leak and its approximate location are determined by other means.

Based on published results (Taylor 1982; Hutton 1984, 1985a, 1985b, 1988; Scott 1985, and Kupperman 1988) and many years of experience by PNL staff, it was determined that acoustic emission (AE) technology best meets the criteria established for space station shell monitoring. Acoustic emission is capable of detecting the three conditions of concern: leakage, impacts, and crack growth. Acoustic emission allows continuous volumetric surveillance from fixed sensors allowing monitoring, data acquisition, and analys is to be performed automatically. Space station personnel need only be involved for status checks or if a warning condition arises. Source location capability is inherent in $A E$ systems. AE equipment size, weight, and power requirements are reasonable, and can be optimized for the specific constraints imposed by space operations.

Drawbacks to the $A E$ technique are that it cannot image or size a flaw and estimating leak rate based on AE data is questionable except under controlled conditions. However, once cracking or leakage is detected and located, other means may be used for quantifying the condition if needed.

\subsection{ASSESSMENT OF LEAK DETECTION BY THERMAL IMAGING}

\subsubsection{Introduction}

Evaluation of the potential of thermal imaging requires an accurate estimate of the temperature difference between the leak site and surrounding structure. Discussions with Boeing personnel indicated that they were not 
aware of any precise analyses of small leaks caused by micrometeoroids. Apparently, neither the range of puncture hole sizes and geometries nor air loss rates have been computed. Because such analyses are beyond the scope of this task, assumptions were made regarding the puncture hole geometry and size. The thermal analysis itself uses equations from jet impingement heat transfer, which is a common cooling technique in various earth-based applications. It was felt that this approach most closely simulated a true puncture, without resorting to a very complex heat and mass transfer analysis.

\subsubsection{Approach}

An ideal approach would begin with detailed, finalized space station design specifications, which would serve as parameters for micrometeoroid penetration models. Subsequently, air loss rates could be calculated based on a probabilistic assessment of the most likely hole size for a given lifetime. A detailed heat transfer analysis taking into account multiple heat loss paths could then be performed. As mentioned, although this approach was not feasible, it is, in a way, irrelevant to the main goal of this task, which is to determine if infrared (IR) camera detection of station air leaks from minuscule punctures is a viable detection method.

Given these constraints and the available resources, a practical engineering approach was adopted. This consisted of the following:

1. Literature reviews on the subjects of micrometeoroid damage, leakage models and experiments, and applicable heat transfer correlations.

2. Consideration of applicable simplifying assumptions that would make the problem tractable without invalidating the results.

3. Parametric study of air mass loss rates and heat transfer to the bumper (micrometeoroid shield) for a range of likely hole sizes.

4. Evaluation of results based on engineering judgement.

\subsubsection{Method}

The phenomena associated with hypervelocity impacts are complex (CourPalais 1987; Herrmann and Wilbeck 1987), and no correlation has yet been developed to predict hole size as a function of penetrating particle size for 
small particles and thin targets (Merrigan 1988). Also, it is likely that the micrometeoroids encountered by space station will be much smaller than $1 \mathrm{~mm}$ in diameter. Furthermore, although the debris cloud from a punctured bumper is near-spherical, rupture of the pressure wall is unlikely to be circular, and most impacts will be at angles between 30 and 50 degrees to the surface normal axis (Cour-Palais 1987). Debris models are undergoing refinement as well (Aerospace America 1988 and 1989). Given all these factors, a simplified approach in the current leak study was unavoidable, and included these assumptions:

1. The potential range of hole sizes due to micrometeoroid penetrations can realistically be anticipated to be between 1 and $1000 \mathrm{um}$.

2. Penetrations will be circular, with the hole in the bumper $\ll$ the hole in the pressure wall, such that it can be ignored in the heat transfer analysis.

3. Any perturbing effects of the MLI between the bumper and the bulkhead will be trivial.

4. Heat transfer correlations for impinging jet flow developed on earth (Martin 1983) apply here, and the expansion of the air into vacuum can be ignored. Because the heat transfer from oblique jets is little different from normal impingement (Sparrow and Lovell 1980), the fact noted above regarding non-normal micrometeoroid penetrations can reasonable be neglected. Note that the applicable correlation is only truly valid over the range of $2 \leq H / D \leq 12$ (see Figure 2.17), which is considerably smaller than the space station geometry examined.

5. Heat conduction along the walls (transverse) is negligible.

6. Air loss through the penetration is accurately predicted by the choked flow equation (Tilton and Chow 1986 and 1988) as it appears in standard texts (Shapiro 1953).

7. All the heat lost from the air, parametrically considered as a 1 and a $10^{\circ} \mathrm{F}$ cooldown of the jet, serves to heat the (solid) bumper wall. The calculation requires an assumption regarding the size of the area for heat transfer, taken here to be $5^{*}$ penetration hole diameter (see figure 2.17). 


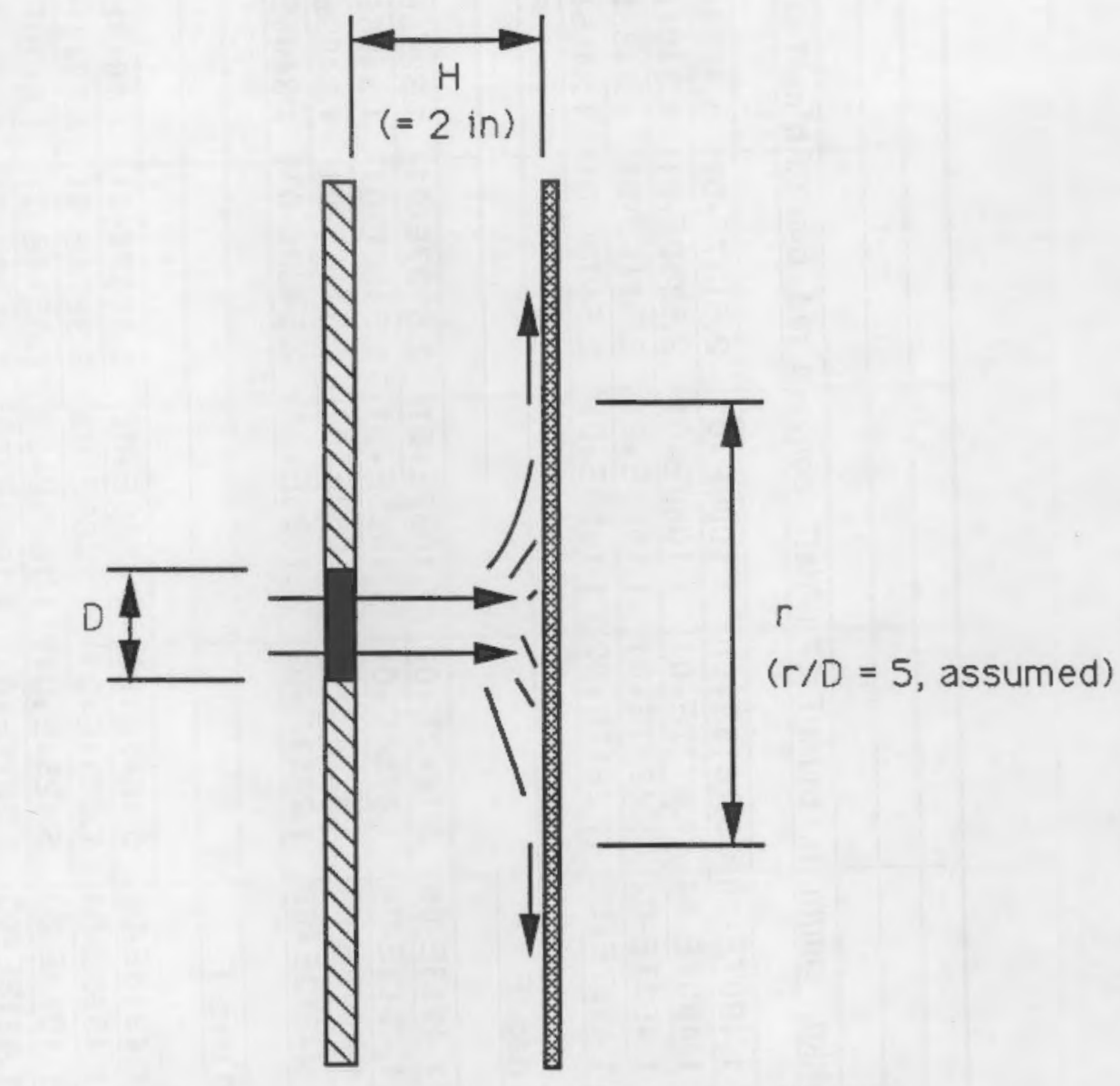

PRESS. BOUNDARY

METEOROID BUMPER

\section{FIGURE 2.17. Simplified Model Used in Analysis}

These assumptions lead to the simplified configuration depicted in Figure 2.17, which represents the geometrical model used. The actual computation involved inputting the compressible flow equation, plus the jet impingement heat transfer equation, into a spreadsheet program. Both the equations and the data/results are included in the accompanying tables and figures.

\subsubsection{Results}

The tabulated results (Table 2.1) indicate that, based on a number of simplifying assumptions, significant heatup of the bumper shield can occur. This can be seen in column 4 of the results, "delta T, F", which shows excellent heat transfer to the bumper and thus a very small temperature 
TABLE 2-1. Analysis of Heat Transfer in Leak

\begin{tabular}{|c|c|c|c|c|c|c|c|c|}
\hline \multicolumn{9}{|c|}{ Space Station Leak Analysis } \\
\hline \multicolumn{9}{|c|}{ Performed by $Z$. Antoniak $9 / 15 / 89$} \\
\hline Hole Dia., um & $\mathrm{Re}$ & $\mathrm{Nu}$ & delta T, F & Mdot, $\mathrm{lbm} / \mathrm{hr}$ & h, btu/hrFt2F & \multicolumn{3}{|c|}{$h * d e l T$ convedh rad, $b / h F t 2 h h^{*}$ delT radiat } \\
\hline 10 & $2.1162 E+02$ & $3.9882 \mathrm{E}-02$ & $6.6292 \mathrm{E}-01$ & $1.4907 \mathrm{E}-04$ & $1.6727 E+01$ & $1.1089 \mathrm{E}+01$ & $2.5350 \mathrm{E}-01$ & $1.3406 E+02$ \\
\hline 100 & $2.1162 E+03$ & $1.2939 E+00$ & 2.0433E-01 & $1.4907 \mathrm{E}-02$ & $5.4269 E+01$ & $1.1089 E+01$ & $2.5416 \mathrm{E}-01$ & $1.3453 E+02$ \\
\hline \multicolumn{2}{|c|}{ alculated based on an assumed local Temp. drop of air $=1$ deg. $F$} & & & & & & & \\
\hline 1 & $2.1162 E+01$ & $1.2313 E-03$ & $2.1473 E+00$ & $1.4913 E-06$ & $5.1642 E+00$ & $1.1089 E+01$ & $2.5137 \mathrm{E}-01$ & $1.3256 \mathrm{E}+02$ \\
\hline 10 & $2.1162 \mathrm{E}+02$ & 3.9899E-02 & $6.6264 \mathrm{E}-01$ & $1.4913 \mathrm{E}-04$ & 1.6734E+01 & $1.1089 E+01$ & $2.5350 \mathrm{E}-01$ & $1.3406 \mathrm{E}+02$ \\
\hline 100 & $2.1162 E+03$ & $1.2943 E+00$ & $2.0427 E-01$ & $1.4913 \mathrm{E}-02$ & $5.4284 E+01$ & $1.1089 E+01$ & $2.5416 \mathrm{E}-01$ & $1.3453 E+02$ \\
\hline 1000 & $2.1162 E+04$ & $3.0545 E+01$ & $8.6556 \mathrm{E}-02$ & $1.4913 \mathrm{E}+00$ & $1.2811 \mathrm{E}+02$ & $1.1089 \mathrm{E}+01$ & $2.5433 \mathrm{E}-01$ & $1.3465 E+02$ \\
\hline 10 & $2.1162 E+02$ & $3.9899 \mathrm{E}-02$ & $6.6264 E+00$ & $1.4913 \mathrm{E}-04$ & $1.6734 \mathrm{E}+01$ & $1.1089 E+02$ & $2.3875 \mathrm{E}-01$ & $1.2376 \mathrm{E}+02$ \\
\hline 100 & $2.1162 E+03$ & $1.2943 E+00$ & $2.0427 \mathrm{E}+00$ & $1.4913 \mathrm{E}-02$ & $5.4284 \mathrm{E}+01$ & $1.1089 E+02$ & $2.4514 \mathrm{E}-01$ & $1.2820 E+02$ \\
\hline 1000 & $2.1162 \mathrm{E}+04$ & $3.0545 E+01$ & $8.6556 \mathrm{E}-01$ & $1.4913 E+00$ & $1.2811 \mathrm{E}+02$ & $1.1089 E+02$ & $2.4680 \mathrm{E}-01$ & $1.2935 E+02$ \\
\hline
\end{tabular}


differential between it and the impinging air flow. Over time, the bumper temperature will be about equal to the values shown in the last column "Tsurface, $R^{\prime \prime}$ (based on a $70^{\circ} \mathrm{F}$ air temperature). Radiation from the bumper to space $(e=1)$ can be compared against the jet impingement heat transfer, as shown in columns 7 and 9 . These heat transfer mechanisms are approximately equal for the $10^{\circ} \mathrm{F}$ air cooldown case, indicating that a heat balance has been achieved and the surface temperature shown is about correct. With a lower emittance (say 0.1, not atypical for IR emittance from a clean metal surface) heat rates are approximately matched for the $1^{\circ} \mathrm{F}$ case.

The somewhat cursory analysis performed here suggests that with an IR camera of sufficient sensitivity and resolution the shield surface could be effectively scanned for small air leaks (defined as $\leq 0.5 \mathrm{lbm} /$ day). Detection would not require extreme camera sensitivity (currently limited to about $0.25^{\circ} \mathrm{F}$ ). But a number of cameras, or a single camera continuously traversing the bumper surface, are needed to adequately cover the full space station module surface.

\subsubsection{Proposed Future Activities}

Although guidance from the Phase I review with NASA and Boeing staff that this work was to be concluded with this preliminary assessment, a suggested direction of follow-on investigation is presented for consideration if new conditions should alter the guidance.

The conclusions reached here are preliminary, and require validation. Validation tests should be of two kinds: analytical and experimental. The analytical one would encompass a more detailed thermal model, with a finemesh noding scheme and coupling to space. Experimental validation would serve to point out deficiencies in the analysis, and reduce the number of key assumptions. Fairly straightforward tests of a space station wall mock-up taken in a vacuum chamber with a small puncture simulated would provide confidence that the IR approach is a viable one. 



\subsection{SEAL LEAKS -- PRESSURE MEASUREMENT TECHNOLOGY}

\subsection{OVERVIEW OF PROBLEM}

Obviously, one requirement for the NASA Space Station is that it must be very well sealed. The Space Station will have thousands of inches of 0-ring seals, and it becomes imperative that all such seals perform well. Leakage through the 0 -rings will be less than $1 \%$ of the total leak budget if all the 0 -rings have standard performance. To this end, 0 -ring seals will be double fault protected, so that three 0 -rings must fail in order for a significant leak to develop in any sealed location. A diagram of two seal configurations is shown in Figure 3.1. From the point of view of the analysis which will be presented later in this report, the examples shown in Figure 3.1 cover the

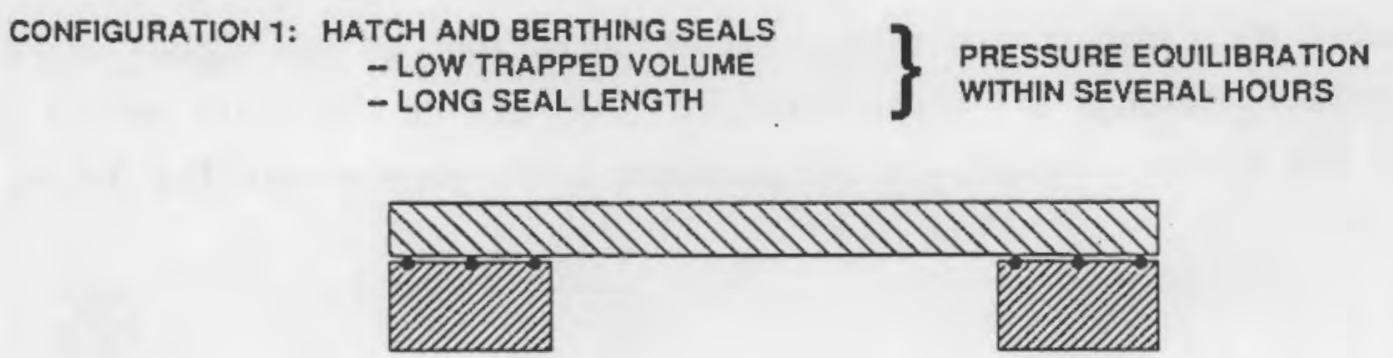

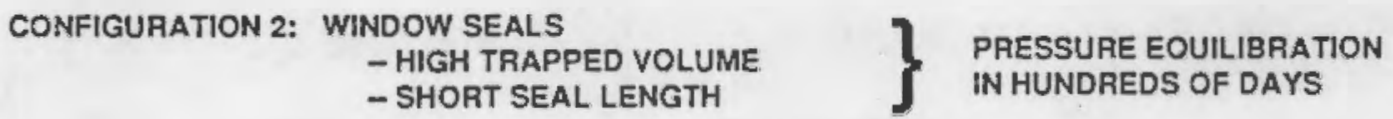

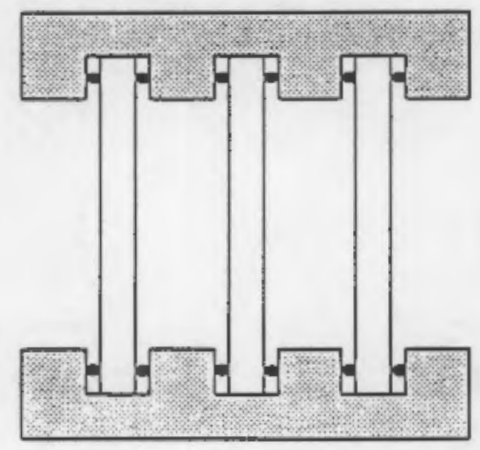

FIGURE 3.1. Two Types of Triple 0-Ring Seal Configuration to be Used on the Space Station 
sea1 types of interest. A program to monitor the performance of 0 -ring seals is being established so that leaks which develop can be quickly identified and repaired. Seal performance will be measured by measuring the air pressure in the two volumes contained by the three 0-rings. The pressure distributions during a transient phase and at equilibrium provide the necessary data for determination of seal performance. The remainder of this section will be concerned with showing how this is true. First a leak model will be developed and analytical calculations performed to determine the dependence of pressure on leak rates. The results of experimental tests to confirm the model will then be presented.

\subsection{ANALYTICAL MODEL OF SEAL LEAKAGE}

The conceptual model for the triple seal problem is shown in Figure 3.2. Constant atmospheric pressure is maintained on the left side of the figure to represent the cabin environment. Air which escapes to the vacuum leaks sequentially through all three 0-rings. The rate at which air passes through any of the 0-rings depends on the pressure difference across the 0-ring. The

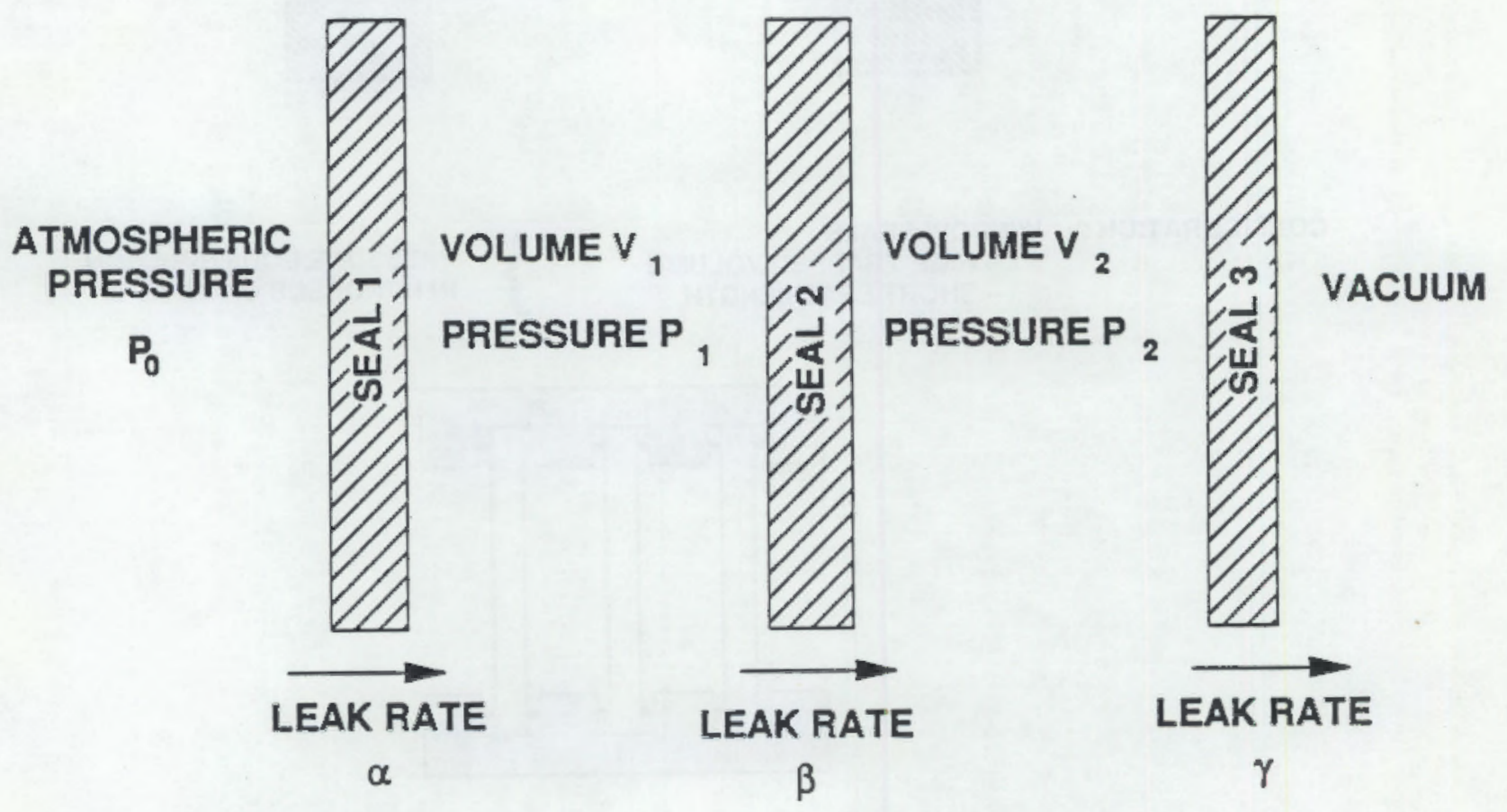

FIGURE 3.2. Conceptual Model for Air Leakage through a Triple 0-Ring Seal Showing the Relevant Physical Parameters 
units for the leak rate are volume/time per unit seal length and thus have dimensions of area/time. This rate is the fundamental quantity associated with the seal itself. Let the rates for the seals be $\alpha^{\prime}, \beta^{\prime}$, and $\gamma$ respectively. Multiplication by the respective seal lengths gives the total leak rates (vol/time) through the seals. Multiplication by the mass density difference across a seal will then give the mass flow rate through the seal. In order to determine the mass change in either volume $V_{1}$ or $V_{2}$ of Figure 3.2 , it is necessary to consider all of the sources and sinks. For example, for volume $v_{1}$ the differential equation for the time rate of mass change is given by

$$
\frac{d M_{1}}{d t}=-\left(N_{1}-N_{2}\right) \beta^{\prime} \ell_{2}+\left(N_{0}-N_{1}\right) a^{\prime} l_{1}
$$

where $d M_{1} / d t$ is the change in the amount of mass in volume $V_{1}$ and $N_{0}, N_{1}$, and $N_{2}$ are the mass densities in the cabin and in volumes $V_{1}$ and $V_{2}$ respectively. The seal lengths are $\ell_{1}, \ell_{2}$, and $\ell_{3}$. In the usual case where $N_{0}>N_{1}$ and $N_{1}$ $>\mathrm{N}_{2}$, the first term represents a loss of mass from $V_{1}$ to $V_{2}$ while the second term is a mass gain from the cabin into $V_{1}$. Dividing both sides of Equation (3.1) by $V_{1}$ yields the equation for the change in mass density, $N_{1}$, for volume $v_{1}$,

$$
\frac{d N_{1}}{d t}=\left(N_{1}-N_{2}\right) \frac{\beta^{\prime} \ell_{2}}{V_{1}}+\left(N_{0}-N_{1}\right) \frac{a^{\prime} \ell_{1}}{V_{1}}
$$

Since the pressures are directly proportional to the mass densities through the ideal gas law, an entirely equivalent equation is obtained by substituting the pressures $\mathrm{PD}_{0}, \mathrm{P}_{1}$, and $\mathrm{P}_{2}$ for the respective mass densities. Also, in the cases of interest here, $V 1 \simeq V_{2}$, and the analys is below assumes that they are equal for mathematical simplicity. In the case that they are grossly different then more general relationships need to be worked out. Equation (3.2) becomes 


$$
\frac{d P_{1}}{d t}=-\left(P_{1}-P_{2}\right) \beta+\left(P_{0}-P_{1}\right) \alpha
$$

where $\alpha=\alpha^{\prime} \ell_{1} / V$ and $\beta=\beta^{\prime} \ell_{2} / V$, and $V_{1}=V_{2}=V$. A similar equation can be written for the volume $v_{2}$,

$$
\frac{d P_{2}}{d t}=-P_{2} \gamma+\left(P_{1}-P_{2}\right) \beta
$$

where $\gamma=\gamma^{\prime} \ell_{3} / V$. Equations (3.3) and (3.4) are the coupled differential equations which describe how the pressures in the volumes $V_{1}$ and $V_{2}$ change with time. The primary assumption of the model is that mass flow through a seal depends linearly on the pressure differences across the seal. It is clear that the time behavior of the intravolume pressures depends upon the seal leak rates and thus monitoring these two pressures should allow determination of the leak rates.

The differential equations are coupled in that the equation for $P_{1}$ depends on $P_{2}$ and the equation for $P_{2}$ depends on $P_{1}$. A powerful method for dealing with coupled equations of this type is the Laplace Transform which essentially turns a coupled set of differential equations into a coupled set of algebraic equations which generally are easier to solve. After solution of the algebraic equations the resulting equations are inverse transformed to obtain the solutions to the original differential equations. There are several mathematical textbooks which describe the Laplace Transform (Butkov 1968, Scott 1955). No details of the calculations will be shown here, but rather the solutions will simply be presented. These solutions have been thoroughly examined for mathematical consistency and they provide correct answers in all cases where they can be checked, such as at the initial time and at long times where equilibrium is obtained. The time dependent solutions for the pressures within volumes $v_{1}$ and $v_{2}$ are: 


$$
\begin{aligned}
& P_{1}(t)=\frac{P_{0}(\alpha \beta+\alpha \gamma)}{\theta}+e^{-(\sqrt{\Gamma+\theta} t)}\left\{\left[P_{1}(0) \frac{P_{0}(\alpha \beta+\alpha \gamma)}{\theta}\right] \cosh \sqrt{\Gamma} t\right. \\
& \left.+\left[\frac{P_{1}(0)(\beta+\gamma)+P_{2}(0) \beta+\alpha P_{0}}{\sqrt{\Gamma}}-\frac{\sqrt{\Gamma+\theta}}{\sqrt{\Gamma}}\left(P_{1}(0)+\frac{P_{0}(\alpha \beta+\alpha \gamma)}{\theta}\right)\right] \sinh \sqrt{\Gamma} t\right\} \\
& P_{2}(t)=\frac{\left.P_{0}^{\alpha \beta}+e^{-(\sqrt{\Gamma+\theta}} t\right)}{\theta}\left\{\left[P_{2}(0)-\frac{\left.\alpha \beta P_{0}\right)}{\theta}\right] \cosh \sqrt{\Gamma} t\right. \\
& \left.+\left[\frac{P_{2}(0)(\beta+a)+P_{1}(0) \beta}{\sqrt{\Gamma}}-\frac{\sqrt{\Gamma+\theta}}{\sqrt{\Gamma}}\left(P_{2}(0)+\frac{P_{0} \alpha \beta}{\theta}\right)\right] \sinh \sqrt{\Gamma} t\right\}
\end{aligned}
$$

where $\Gamma=B^{2}-\alpha \gamma+\left(\frac{a+\gamma}{2}\right)^{2}$

$$
\theta=\alpha \beta+\alpha \gamma+\beta \gamma
$$

It is seen that the pressures depend in a complicated way on combinations of the leak rates. However, in both equations there is a constant term and there are time dependent terms. The time dependent terms will approach zero at long times and the final equilibrium pressures are given by the constant terms. Generally, the time required to approach equilibrium becomes shorter as the leak rates increase. It is very important to understand that the leak rates cannot be determined solely from the equilibrium pressures, which only allow a determination of relative leak rates. Three seals which are leaking profusely at equal rates cannot be distinguished from three good seals by casual observation of the final equilibrium pressures. The true magnitude of the leak rates is determined only from the time dependent terms.

\subsection{OPERATIONAL USE OF LEAK RATE AND PRESSURE MODEL}

From an operational point of view some suggestions can be made for the use of these equations. Suppose that the pressure history of the two volumes has been measured for long enough times so that final equilibrium pressures have been obtained. From these data, how are the leak rates determined? The final equilibrium pressures available from the data can be used to uniquely establish the ratios of the leak rates. By then varying a single parameter 
(say the leak rate $a^{\prime}$ ) while preserving the determined leak rate ratios the theoretical curves can be made to match the experimental ones. The absolute leak rates are then determined from these best fit curves. The total air mass loss rate through the seal at equilibrium can then be evaluated by taking any one of the leak rates and multiplying by the seal length and the pressure difference across the particular seal.

The difficulty with the above approach is that the leak rates cannot be determined until equilibrium has been reached, which may require many days. Additionally it requires interpretation and judgenent, either on the part of an operator or a computer system. A more desirable approach would be the computation of leak rates automatically and "on the fly." In principle, only three data points are required in order to determine the three unknown leak rates. There is little question that an inversion or curve fitting routine which utilizes the measured pressures and determines the leak rates from these measurements can be developed in a reasonably straightforward manner. The accuracy of the derived leak rates would improve as more data are acquired. It is envisioned that an algorithm can be developed which calculates best fit leak rates along with estimated accuracy by using all of the pressure data available at the time of calculation. The estimated leak rates would be recalculated and updated and made available with each new measurement. Implementation of such an algorithm appears to be an effective means for utilizing the pressure data.

A computer program has been written to solve Equations (3.5) and (3.6). A description of the program and its use is given in Appendix A. Basically the program asks for input parameters such as leak rates, seal lengths, entrapped volumes, and initial pressures and then calculates the intravolume pressures as a function of time. Both plots and tables of the pressures are available as output.

\subsection{CALCULATED PRESSURE BEHAVIOR UNDER VARIOUS LEAK RATE SCENARIOS}

Some sample calculations obtained from exercising the program are now in order. In Figure 3.3 the pressures are plotted as a function of time in a case where all three leak rates are equal and of a value expected for good 0 -rings. The volumes between the 0 -rings are relatively large to simulate a typical 


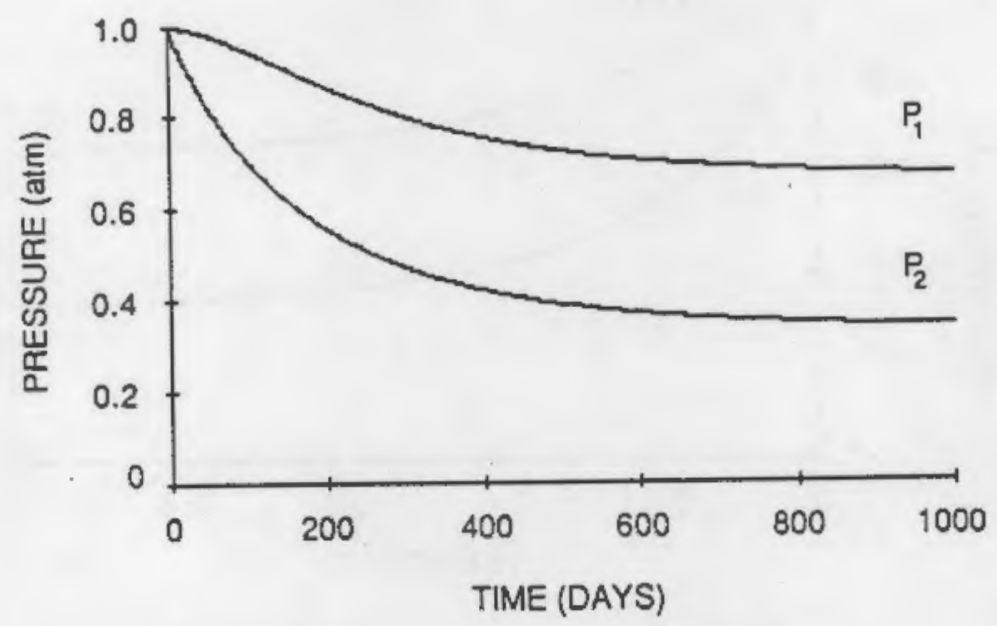

PARAMETERS:

$$
\begin{aligned}
& \alpha=\beta=\gamma=1 \times 10^{-6} \mathrm{~cm}^{2} / \mathrm{sec} \\
& V=2000 \mathrm{~cm}^{3} \\
& L=100 \mathrm{~cm}
\end{aligned}
$$

FIGURE 3.3. Model Plot of the Intravolume Pressures as a Function of Time where All Leak Rates are Equal and Typical of Good O-Rings

window application. Note that the final equilibrium pressures are at $2 / 3$ and $1 / 3$ of atmospheric, as expected for seals with equal leak rates. Also, it takes a considerable length of time for equilibrium to be reached. For good seals, the length of the seal and the volume enclosed are important factors for determining the equilibration time. A similar calculation is shown in Figure 3.4 where the volume has been reduced and the seal length increased to simulate conditions for a hatch or a berthing port. The leak rates $\left(\alpha^{\prime}, \beta^{\prime}\right.$, and $\boldsymbol{T}^{\prime}$ ) are identical. Equilibrium is reached much sooner and the final pressures are the same as in the case of Figure 3.3. In fact, the curves are identical except for the time scale. Since the volume, seal length, and leak rate appear in combination (e.g., $\alpha=\alpha^{\prime} \ell_{1} / V$ ), it is important to know the enclosed volumes and seal lengths in order to determine the leak rates. Even with good 0 -rings some variation in leak rates can be expected and so the final equilibrium pressures may not be at exactly $2 / 3$ and $1 / 3$ of the cabin pressure. In Figure 3.5 the pressures are plotted with parameter values identical to those for Figure 3.3 except the leak rate for the third seal (see 


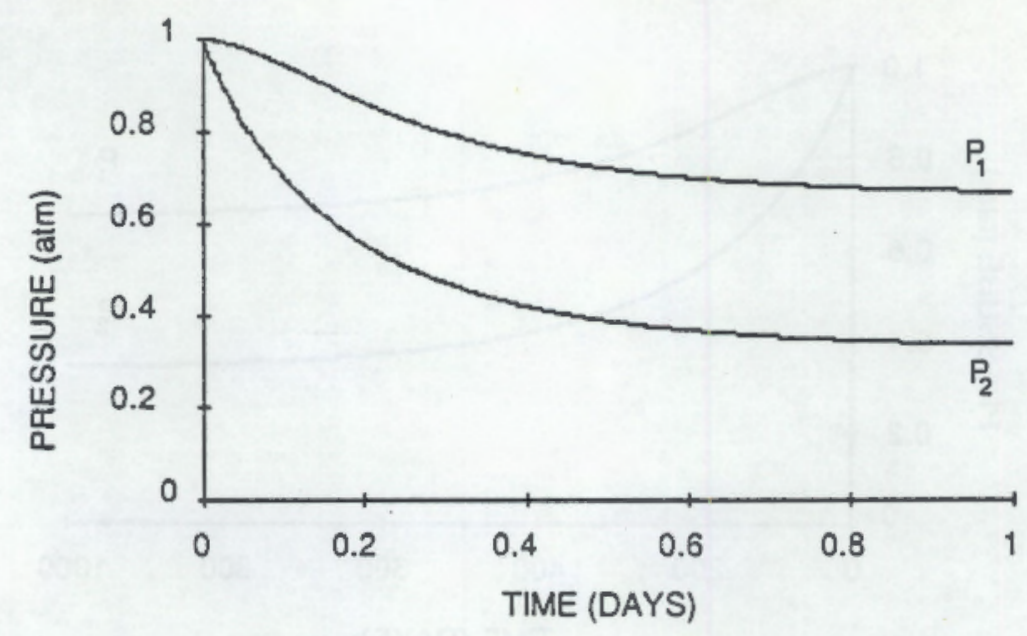

PARAMETERS:

$$
\begin{aligned}
& \alpha=\beta=\gamma=1 \times 10^{-6} \mathrm{~cm}^{2} / \mathrm{sec} \\
& V=10 \mathrm{~cm}^{3} \\
& L=500 \mathrm{~cm}
\end{aligned}
$$

FIGURE 3.4. Model Plot of the Intravolume Pressures for a Typical Hatch of Berthing Port (compare with Figure 3.3)

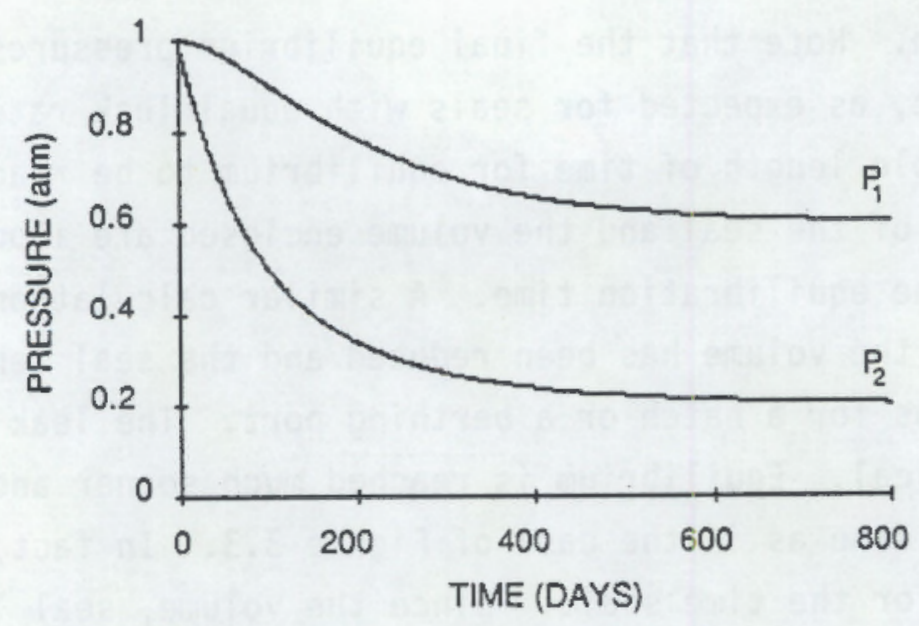

PARAMETERS:

$$
\begin{aligned}
& \alpha=\beta=1 \times 10^{-6} \mathrm{~cm}^{2} / \mathrm{sec} \\
& \gamma=2 \times 10^{-6} \mathrm{~cm}^{2} / \mathrm{sec} \\
& V=2000 \mathrm{~cm}^{3} \\
& L=100 \mathrm{~cm}
\end{aligned}
$$

FIGURE 3.5. Model Plot of the Intravolume Pressures where the Leak Rate for the Third Seal is Twice that for the Other Two Seals (compare with Figure 3.3 ; note the reduced pressure P2) 
Figure 3.2) is twice that for the other two seals. The effect is most noticeable for the final value of pressure $P_{2}$.

Another important example simulates the catastrophic failure of a seal long after the Space Station is in orbit and equilibrium pressures have been reached in the two volumes. For these calculations it is assumed that the initial pressures are at $2 / 3$ and $1 / 3$ of atmospheric and then one of leak rates is increased by a factor of 10 over the other two. Other parameters are equal to those used for Figure 3.3 (the good window seals). Figures 3.6, 3.7, and 3.8 show the consequence and signature of a failed first seal, middle seal, and third seal respectively. It is clear that the behavior of the pressures readily reveals the faulty seal. Slowly varying leak rates cannot be addressed with these calculations.

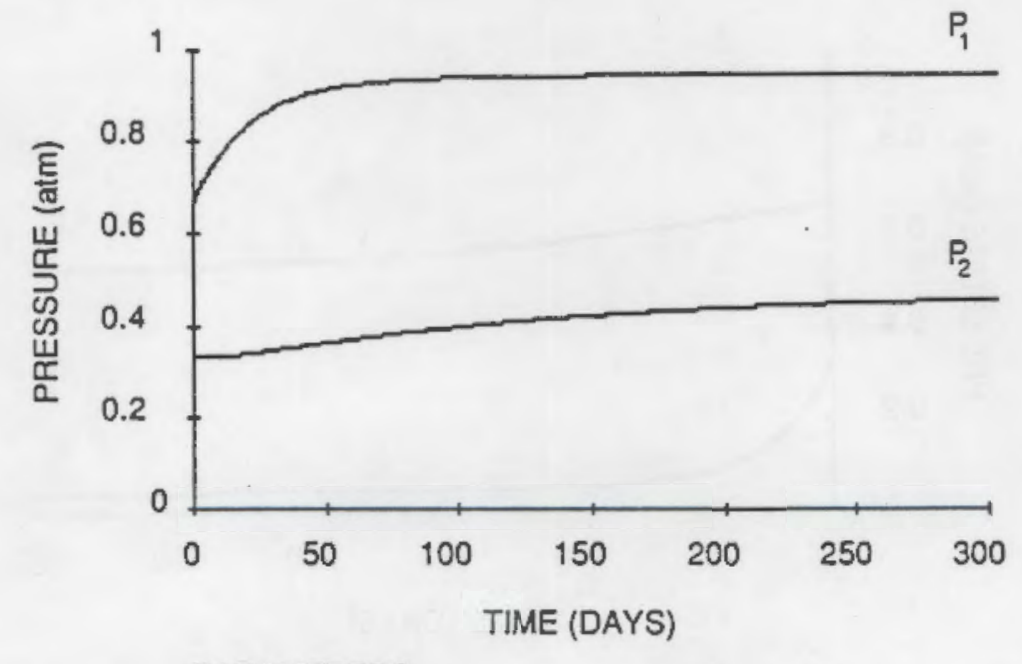

PARAMETERS:

$$
\begin{aligned}
& \alpha=1 \times 10^{-5} \mathrm{~cm}^{2} / \mathrm{sec} \\
& \beta=\gamma=1 \times 10^{-6} \mathrm{~cm}^{2} / \mathrm{sec} \\
& V=2000 \mathrm{~cm}^{3} \\
& L=100 \mathrm{~cm}
\end{aligned}
$$

FIGURE 3.6. Model Plot of the Intravolume Pressures which Simulate Failure of the First Seal 


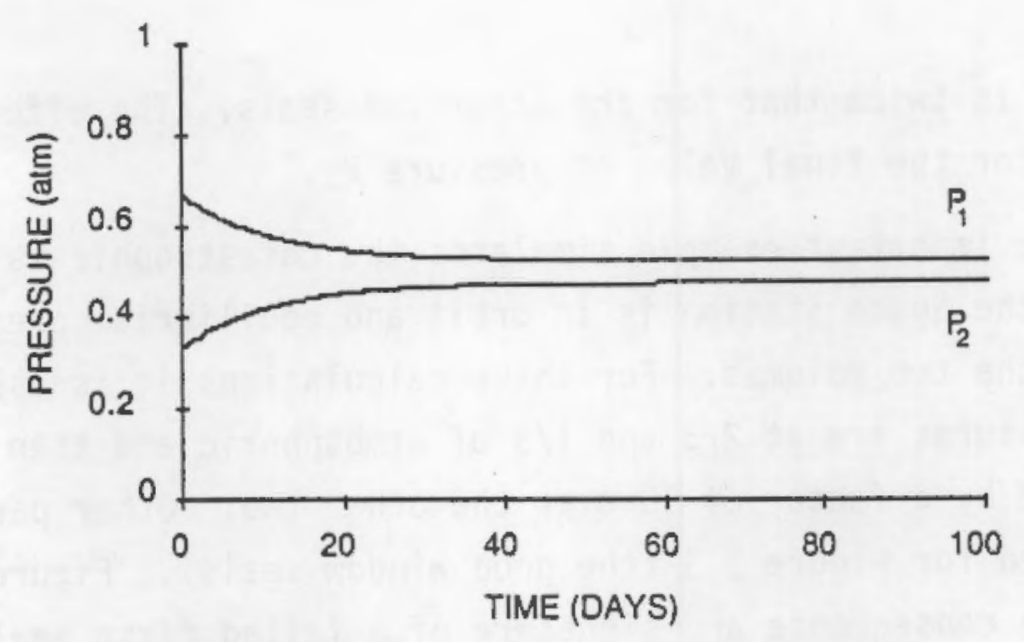

PARAMETERS:

$$
\begin{aligned}
& \alpha=\gamma=1 \times 10^{-6} \mathrm{~cm}^{2} / \mathrm{sec} \\
& \beta=1 \times 10^{-5} \mathrm{~cm}^{2} / \mathrm{sec} \\
& V=2000 \mathrm{~cm}^{3} \\
& L=100 \mathrm{~cm}
\end{aligned}
$$

FIGURE 3.7. Model Plot of the Intravolume Pressures where the Second Seal has a Leak Rate 10 Times that of the Other Two Seals (other conditions are identical to those of Figure 3.6)

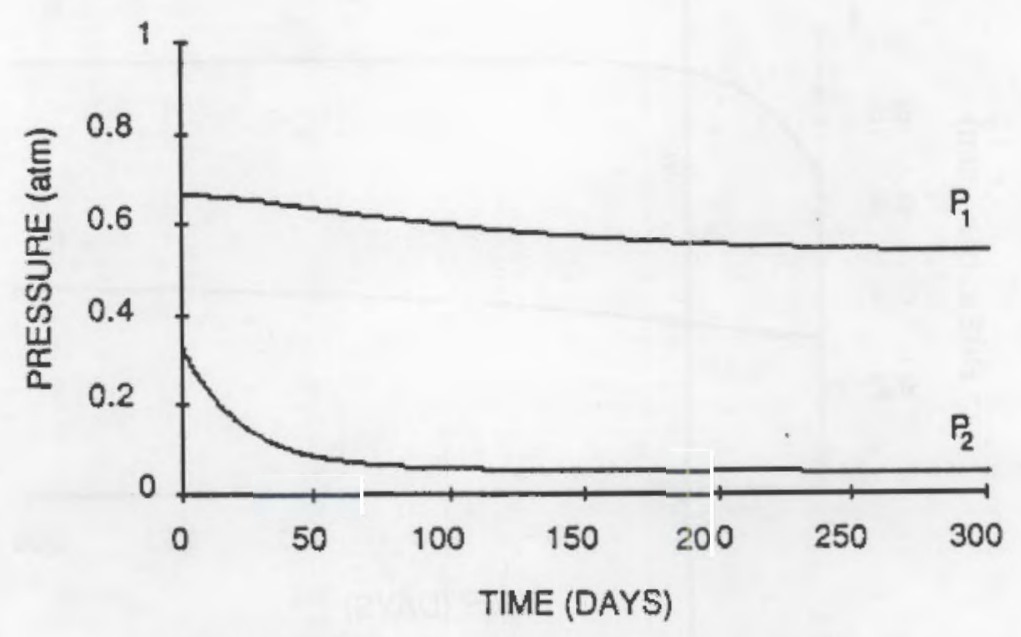

PARAMETERS:

$$
\begin{aligned}
& \alpha=\beta=1 \times 10^{-6} \mathrm{~cm}^{2} / \mathrm{sec} \\
& \gamma=1 \times 10^{-5} \mathrm{~cm}^{2} / \mathrm{sec} \\
& V=2000 \mathrm{~cm}^{3} \\
& L=100 \mathrm{~cm}
\end{aligned}
$$

FIGURE 3.8. Model Plot of the Intravolume Pressures where the Third Seal has a Leak Rate 10 Times that of the Other Two Seals (other conditions are identical to those of Figure 3.6) 


\subsection{EXPERIMENTAL VALIDATION OF ANALYTICAL MODEL}

Experimental verification of the leak model was performed using the apparatus diagrammed in Figure 3.9. Three 0 -ring grooves were machined into a circular aluminum plate with nominal diameters of $5.5,6.0$, and 6.5 inches for $3 / 16$ inch thickness 0 -rings. This plate bolted to a mating flange. A mechanical vacuum pump evacuated the volume interior to the inner 0-ring to a pressure of about $50 \mathrm{mTorr}$. Two small holes were drilled in each of the two volumes separating the three 0 -rings. One port was a vent and the other was connected to a pressure transducer in order to measure the pressures in the volumes. The experiment turned out to be quite difficult. Initial tests showed that the 0 -rings sealed very well and indicated that it would take days or weeks of testing before the pressures between the 0-rings fell to an equilibrium value.

An additional complication was that there was little confidence that the vent and transducer ports were sealed better than the 0 -rings, a clear necessity if the experiment was to test the 0-rings. Early investigation showed that indeed the transducers did leak and while these leaks were stopped it remained uncertain if their leak rate was less than those of the 0 -rings. In order to reduce the time required to run an experiment to a tolerable level and assure that the 0 -ring leak rates greatly exceeded those of the vent and pressure ports, leaks were created around the 0 -rings by placing $1.5 \mathrm{mil}$ diameter wire under the 0 -rings. Apart from the fact that the leak rates were entirely unknown and were not truly 0 -ring leaks, the problem with this approach was that although the same wire ran under all three 0 -rings it was not necessarily true that the same leak rate was established for each 0-ring. Repeated tests showed that the final equilibrium pressures in the two volumes as well as the equilibration times could be varied over a fairly wide range by adjusting where the wire was placed, how the 0 -rings were oriented, and how the 0 -rings were prepared. Generally however, in unbiased testing it appeared that the outermost 0 -ring leaked at about three times the rate of the inner two 0-rings (this was determined from model calculations). Therefore two additional $1.5 \mathrm{mil}$ wires were placed under the inner two 0 -rings to create the important condition of nearly equal leak rates for all three 0-rings. The experimental curves for the two intravolume pressures along with the best 


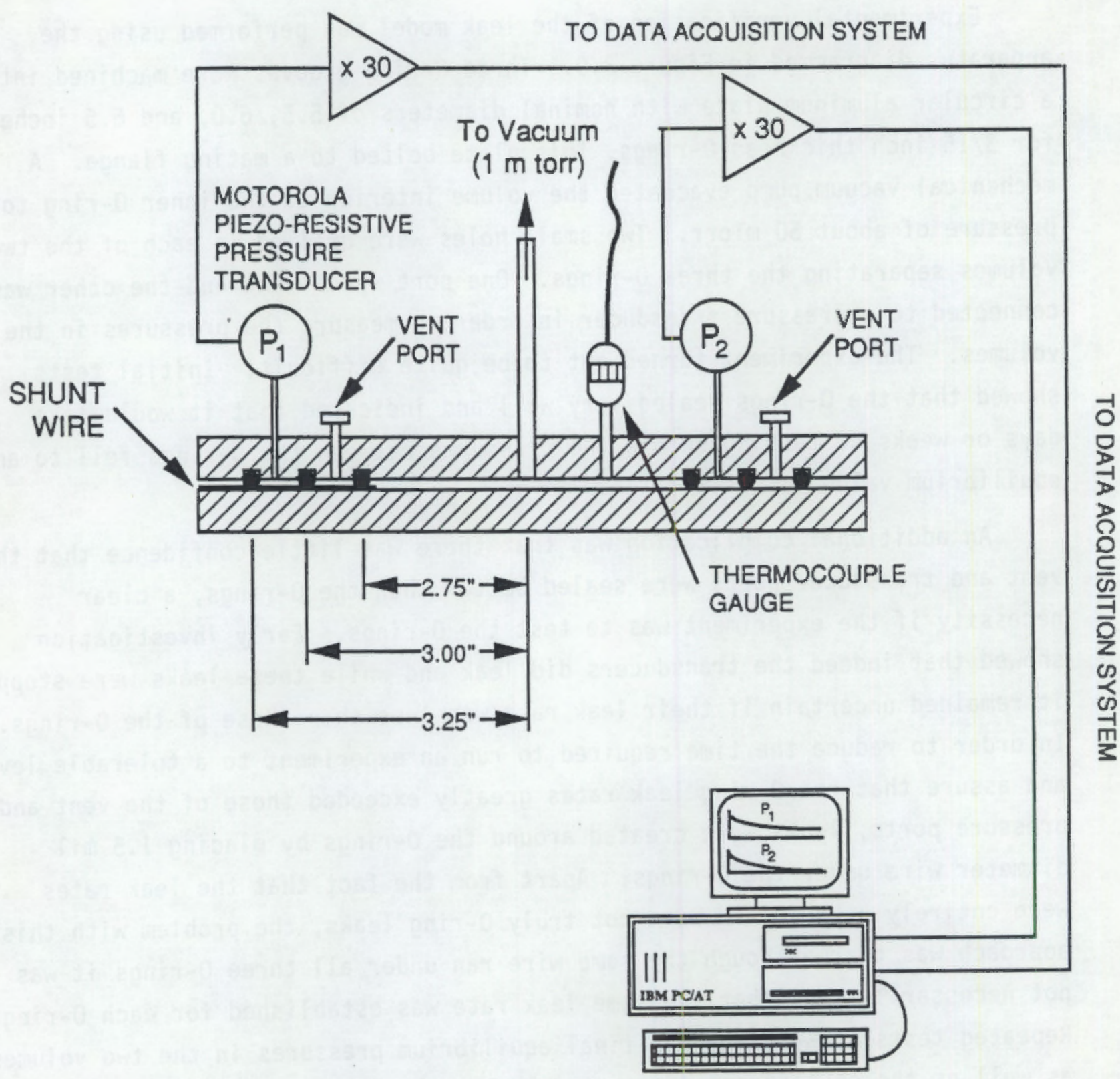

FIGURE 3.9. Experimental Arrangement to Test Applicability of the Leak Rate Model (atmospheric pressure is exterior to the 0 -rings while effectively zero pressure is internal to them) 
fit model calculations assuming equal leak rates are shown in Figure 3.10. This plot shows very good agreement between the model and the data throughout the whole curve and serves as preliminary verification of the model.

Data were also taken to simulate the condition of a single faulty seal. An additional 4 mil diameter wire was placed under the outermost 0 -ring and then the middle 0-ring and finally the innermost 0 -ring in Figure 3.9. Experimental data for each case were compared to the model calculations which assumed the same leak rates for the unaffected 0-rings as in Figure 3.10 and an increased (by a factor of 8 ) leak rate for the 0 -ring with the extra $4 \mathrm{mil}$ wire beneath $i t$. These data are shown in Figures $3.11,3.12$, and 3.13 respectively. Again fairly good agreement is observed between the experimental curves and the model predictions. The leak rate is estimated to scale roughly as the square of the wire diameter and so it is expected that the affected leak rate should be increased by about a factor of eight. No attempt was made to optimize the agreement between model calculations and experimental data in Figures $3.11,3.12$, and 3.13 by further adjustment of the leak rates.

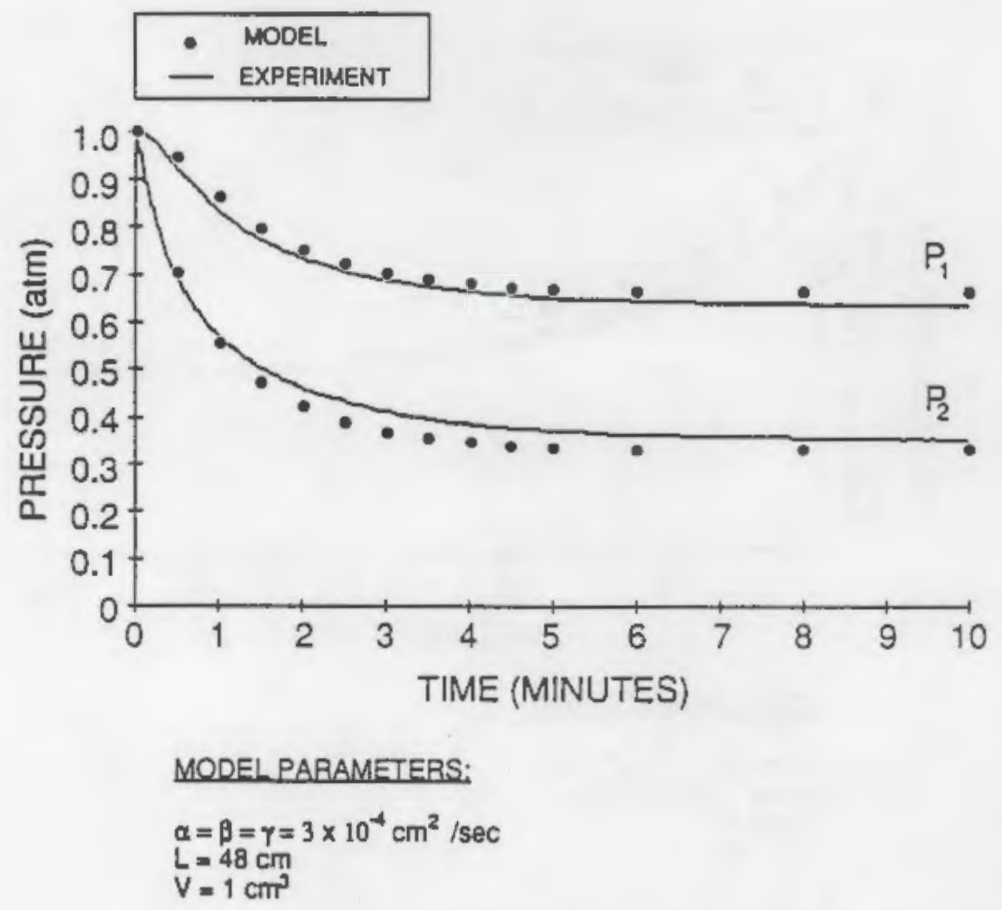

FIGURE 3.10. Experimental and Model Plots of the Intravolume Pressures with all Three Leak Rates Approximately Equal 


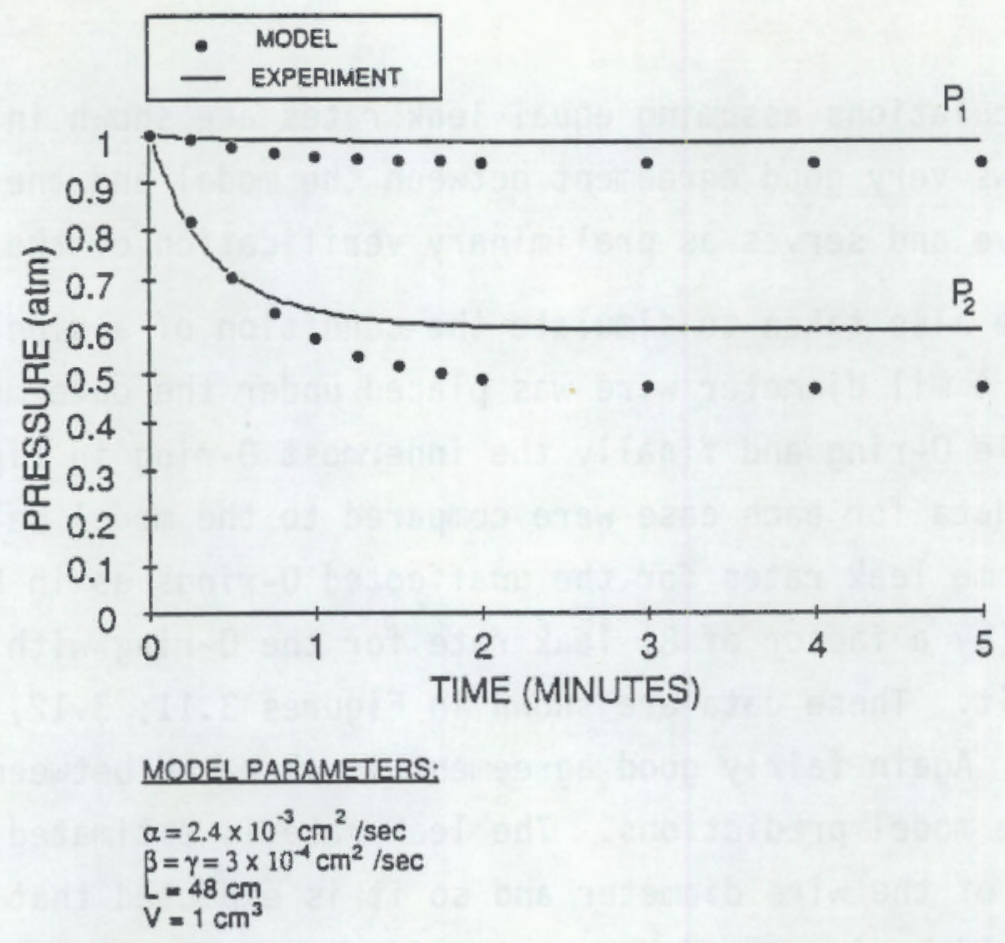

FIGURE 3.11. Experimental and Model Plots of the Intravolume Pressures where the Outermost 0-Ring Leak Rate (see

Figure 3.9) is about 8 Times that for the Other Two Seals

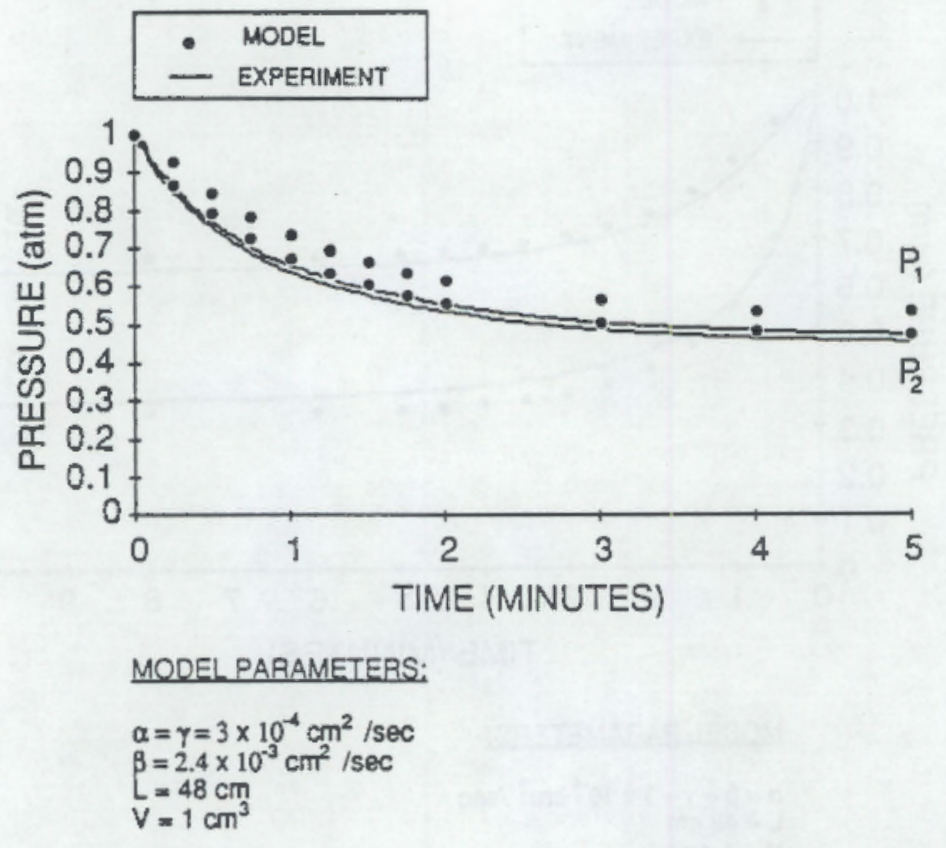

FIGURE 3.12. Experimental and Model Plots of the Intravolume Pressures where the Middle 0-Ring Leak Rate is about 8 Times that for the Other Two Seals 


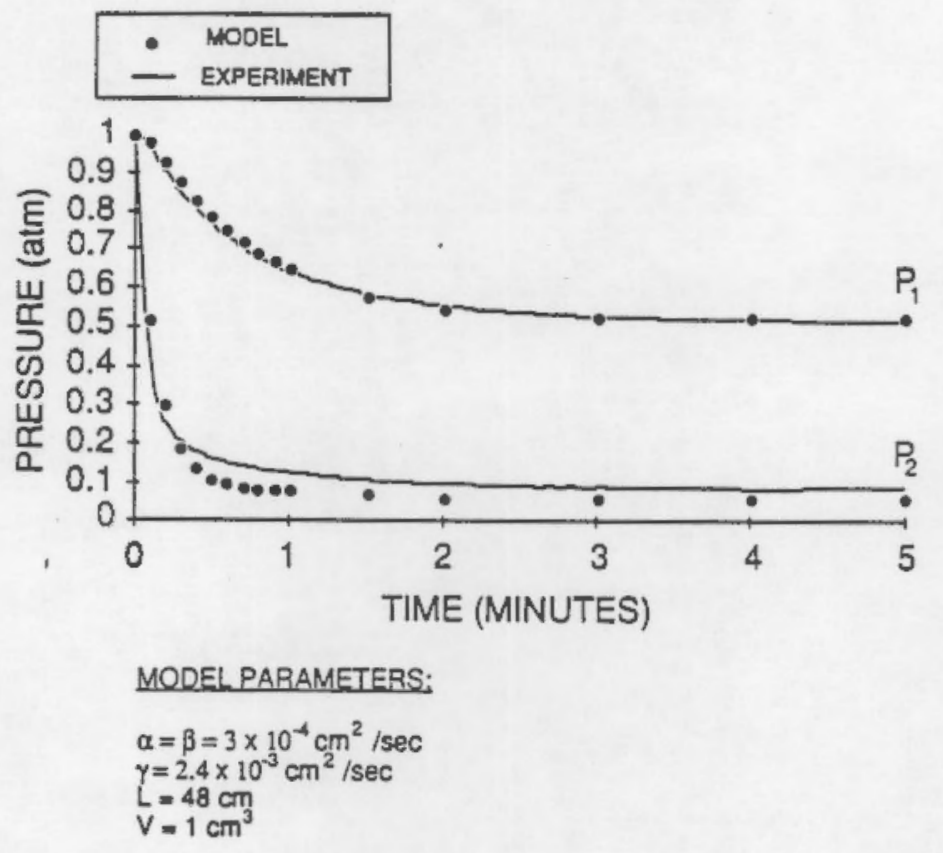

FIGURE 3.13. Experimental and Model Plots of the Intravolume Pressures where the Innermost 0-Ring Leak Rate is about 8 Times that for the Other Two Seals 



\subsection{IMPACT/LEAKAGE DETECTION -- ACOUSTIC EMISSION TECHNOLOGY}

\subsection{OVERVIEW OF IMPACT/LEAKAGE ASSESSMENT TASK}

The ability of acoustic emission (AE) methods to detect both transient signals simulating impacts and continuous signals was examined. Leaks through the shell were produced by drilling successively larger holes at a given location and allowing pressurized air ( 1 atmosphere $\Delta$ pressure) to escape, while monitoring with $\mathrm{AE}$. The effects of source/receiver distance and position on the transmitted signals were examined from these data. Finally, a fatigue test was performed on a sample of the shell material in order to obtain an estimate of the AE signal amplitude and event density during fatigue crack growth.

\subsection{MATERIALS, EQUIPMENT, AND SETUP}

One-half of a waffle grid shell section and some smooth $1 / 8$-inch thick plates of the same material were obtained from Boeing Aerospace of Huntsville, Alabama. The rib junctions on the shell section were left thicker than the ribs, so that at most rib nodes, there is an approximately a 1-inch square block of material, as illustrated in Figure 4.1. Parallel to the axial and circumferential directions, the ribs are displaced along one line and the nodes are about three inches by one inch. Two holes had been drilled in each of the large nodes in the axial direction on the smooth (inner) side of the shell section, and they serve very well to mount sensors.

The plates probably had different heat treatment than the shell, since they did not go through the milling or the final forming process. One of the plates contained a weld. This plate measured 46 by 48 inches, and was used to examine the effect of the weld on signal propagation. A fatigue specimen, with dimensions 4 inches by 12 inches, was cut from one of the plates, and a $1 / 2$-inch by $1 / 8$-inch starter notch sawed in from one edge. The specimen was fatigue precracked to a length of 0.8 inch after 18,800 cycles at $2 \mathrm{~Hz}$, with a maximum load of 4500 pounds, and an R-ratio of 0.1 . The remainder of the crack was grown at $2 \mathrm{~Hz}$, maximum load of 5000 pounds, and an R-ratio of 0.7 (R-ratio is the ratio of the minimum and maximum loads). 


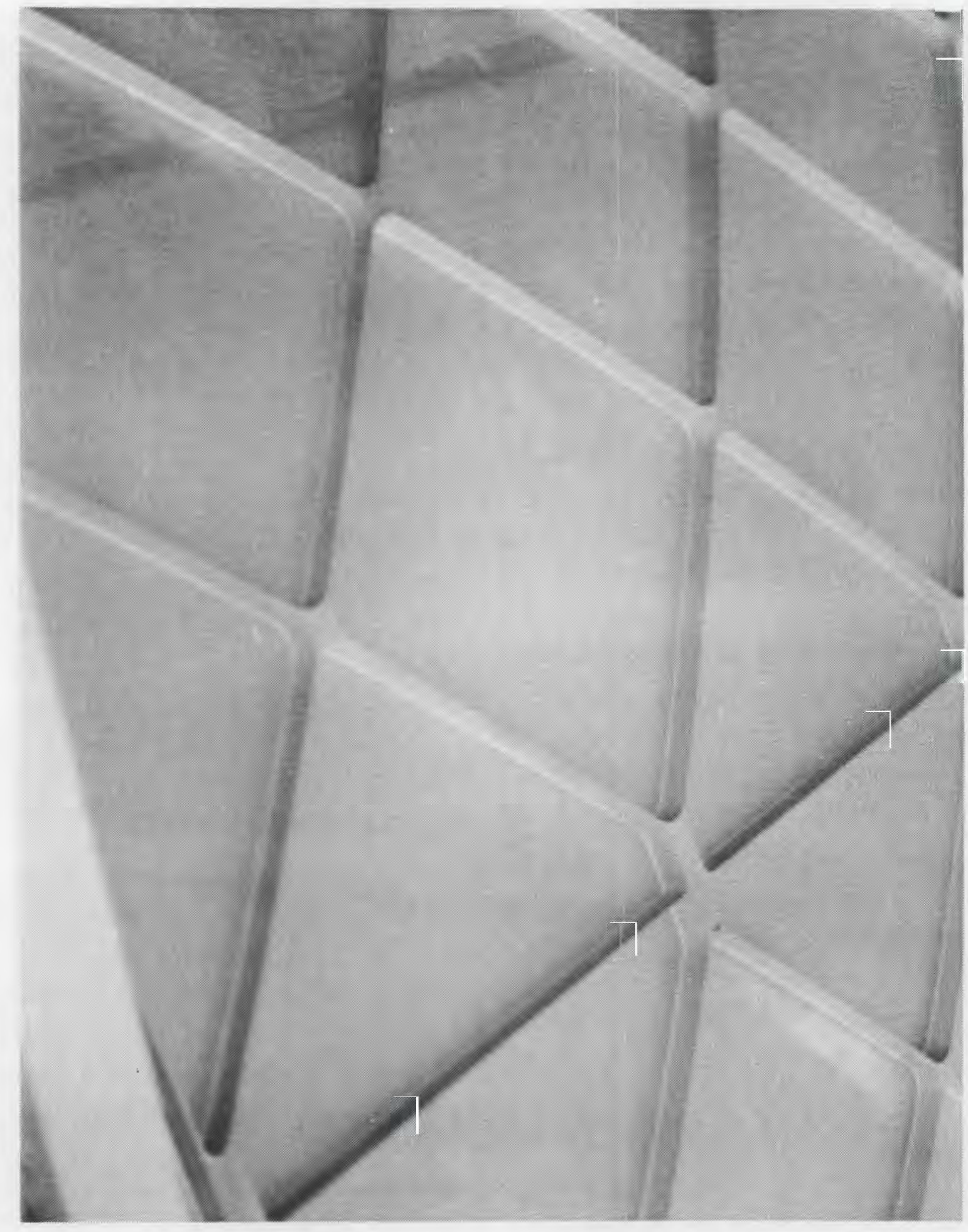

FIGURE 4.1. Detail of Ribbing on the Outer Side of the Space Station Shell 
The test equipment varied according to the test to be run and the information desired. The primary AE instrument used to detect, analyze, and record AE event parameters, was a Battelle-built device based on systems designed and built by Battelle for the Nuclear Regulatory Commission (NRC). One of the NRC instruments was used in the present tests to record signal waveforms. Amplifiers were also designed and built at Battelle and were of two types. The first was a nominally $20 \mathrm{~dB}$ microamplifier with a flat response (less than $5 \mathrm{~dB}$ deviation over $1 \mathrm{MHz}$ ), which was designed to be mounted near the sensor. The second was a 20 or $40 \mathrm{~dB}$ second stage amplifier with wideband flat or tuned $(0.1$ to $0.6 \mathrm{MHz})$ response. The $\mathrm{AE}$ instrument contained $30 \mathrm{~dB}$ of flat, wideband gain. Sensors used were Physical Acoustics Corporation's (PAC) R15 model, with a peak response between about $60 \mathrm{kHz}$ and $200 \mathrm{kHz}$, and a National Bureau of Standards (now National Institute for Standards and Technology or NIST) broadband conical sensor. For one set of experiments, a PAC $\mu 30 d$ sensor was epoxied to a short, threaded waveguide and mounted in a hot in a large junction on the plate with the waveguide bottomed in the hole. Fifty ohm coaxial cable was used throughout.

Pencil lead breaks were utilized to produce transient signals for calibration and signal attenuation measurements. A 3 -mm length of $0.2-\mathrm{mm}$ diameter, $H$ hardness pencil lead was measured for each lead break, and the mechanical pencil end rested across a small wood dowel, with the lead pointed toward the sensor to further reduce random variability in the signals. It is noteworthy in light of claims regarding the lead break calibration, that few lead break signals were similar enough to one another to be considered identical, regardless of the care taken in preparation. This may be due to lead inhomogeneity, or the condition of the end of the lead and splintering from the previous fracture.

A helium gas jet was used for AE sensor frequency response calibration. The excitation signal was produced by allowing pressurized gas to impinge on the specimen through a hollow needle connected to the gas bottle by a flexible hose. A fixture was made to hold the needle normal to the specimen surface at a distance of one centimeter, placed so as to avoid any obstruction in the source/sensor path. The needle was 0.03 inch ID, and gas pressure was held constant at 15 psi. Maintaining constant gas pressure despite repeatedly 
turning the jet on and off was facilitated by the use of two valves. The first allows gas to be turned on or off without changing the second valve setting, which controls the downstream pressure. After the gas was turned on at a new location, two signals were captured but not recorded in order to clear the instrument memory and to ensure that initial transients in the gas jet were not captured.

For both transients and continuous signals, events were captured when the signal crossed a preset threshold set just above the background noise level after the system was manually enabled. At least five signals were recorded at each location for each set of test conditions and source type. Analys is of recorded data was performed using a VAX 780, and a MacIntosh II computer was used to produce most of the final figures. Analysis routines were written and tested by one of the authors using FORTRAN 77. All signals were read from tape, scaled, and the dc level subtracted. The RMS voltage was calculated in the usual way, using $N=2000$ points sampled at a 0.2 microsecond sample interval, and the voltages averaged over the signals in each data group where appropriate in order to reduce random error. Power spectra were computed with a Cooley-Tukey algorithm and a 1/20 cosine window acting on $2^{11}$ data points collected at the above rate.

\subsection{EXPERIMENTAL RESULTS}

\subsubsection{Experiment 1: Pencil Lead Break Calibration}

The $\mu 30 \mathrm{~d}$ sensor on a short waveguide was mounted as described above at the position illustrated in Figure 4.2. Pencil leads were broken on the ribbed side of the section, at points along the lines labeled LI through L5 in the figure.

Because of the signal amplitudes, the second-stage amplifier was removed leaving $50 \mathrm{~dB}$ net system gain. Saturation of the instrument (amplified signal levels in excess of 0.03 volts at the sensor output) always occurred at source/sensor distances of three inches, and also at six inches for some orientations, despite a probable loss of sensitivity due to the waveguide mounting technique. In general, signal levels decreased with increasing source/sensor distance, as shown in Figure 4.3. At distances greater than about 40 inches, the signal levels are similar regardless of distance or line. 


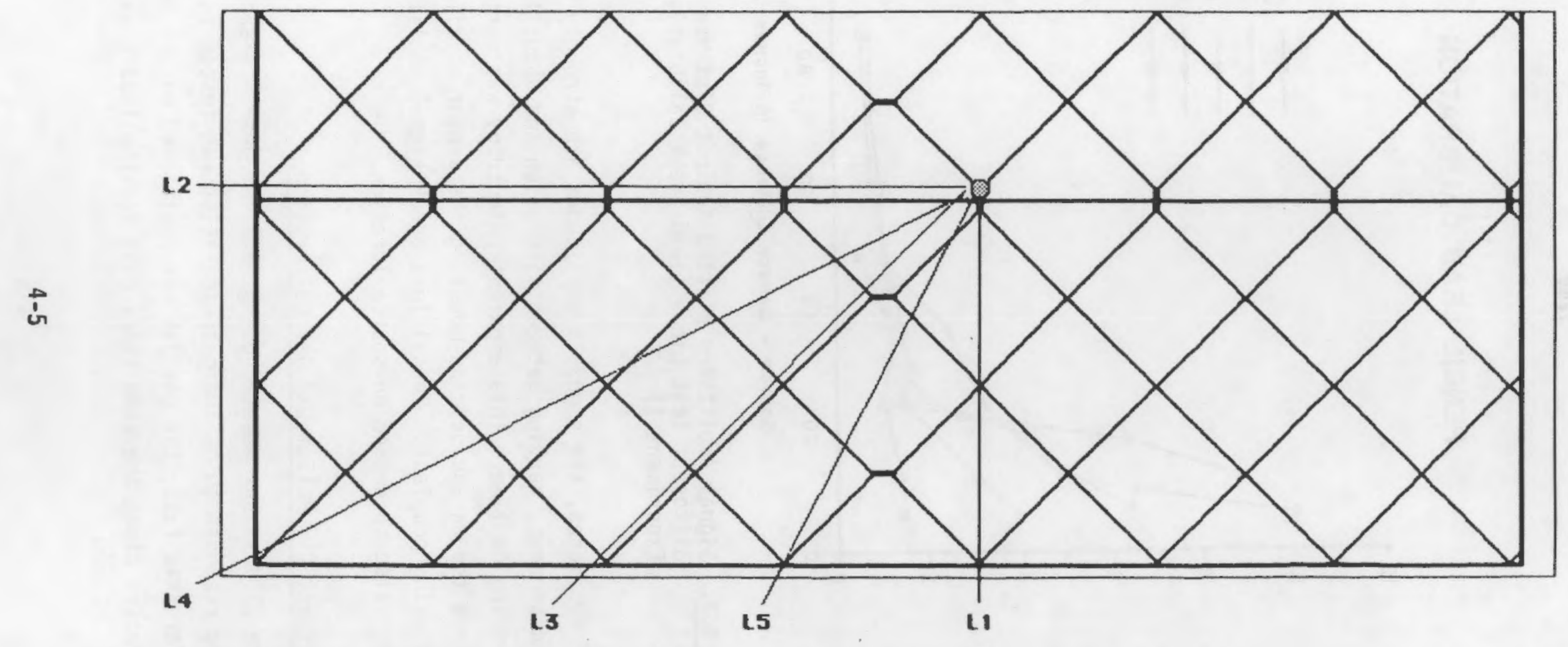

FIGURE 4.2. Layout for Pencil Lead Break and Gas Jet Experiments 


\section{PENCIL LEAD CALIBRATION}

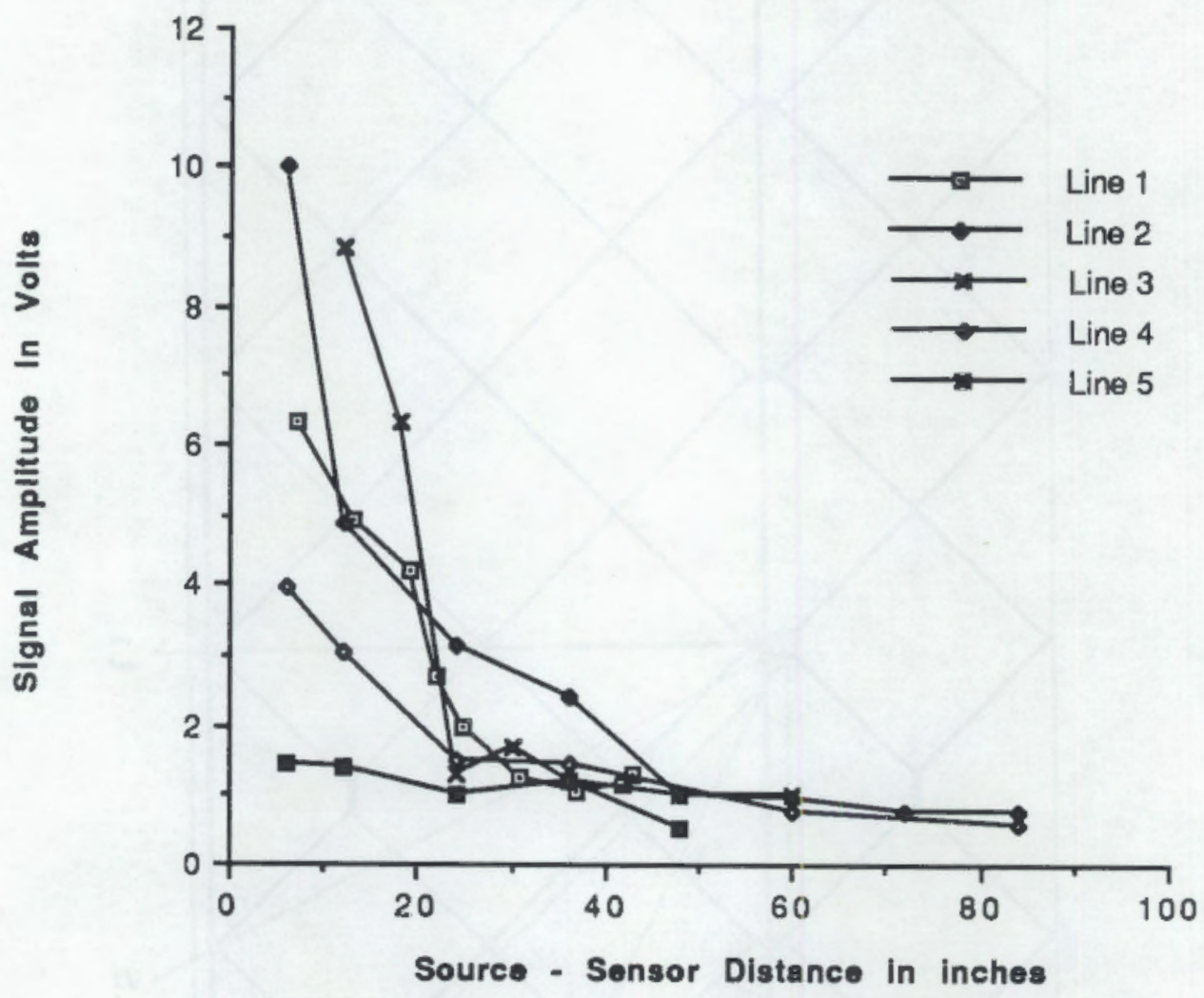

FIGURE 4.3. Signal Amplitudes Plotted Against Distance along Different Test Lines (lead break calibration, Experiment 1)

At less than 40 inches, the signal's amplitudes are strongly distance and orientation dependent, varying between saturation and about 1.5 volts at six inches, depending on line. This apparent anisotropy was verified by removing the sensor from the waveguide, and mounting the sensor at different locations on the plate using couplant. Pencil lead break signal amplitudes were seen in these cases also to depend on source location.

\subsubsection{Experiment 2: Helium Gas Jet Calibration}

With the $\mu 30 \mathrm{~d}$ sensor mounted using couplant near its experiment 1 location, the response to helium gas excitation was tested in the same manner as above. For this test, the gas jet was positioned on the inner surface of the shell section along the same lines used for the lead breaks. Examination 


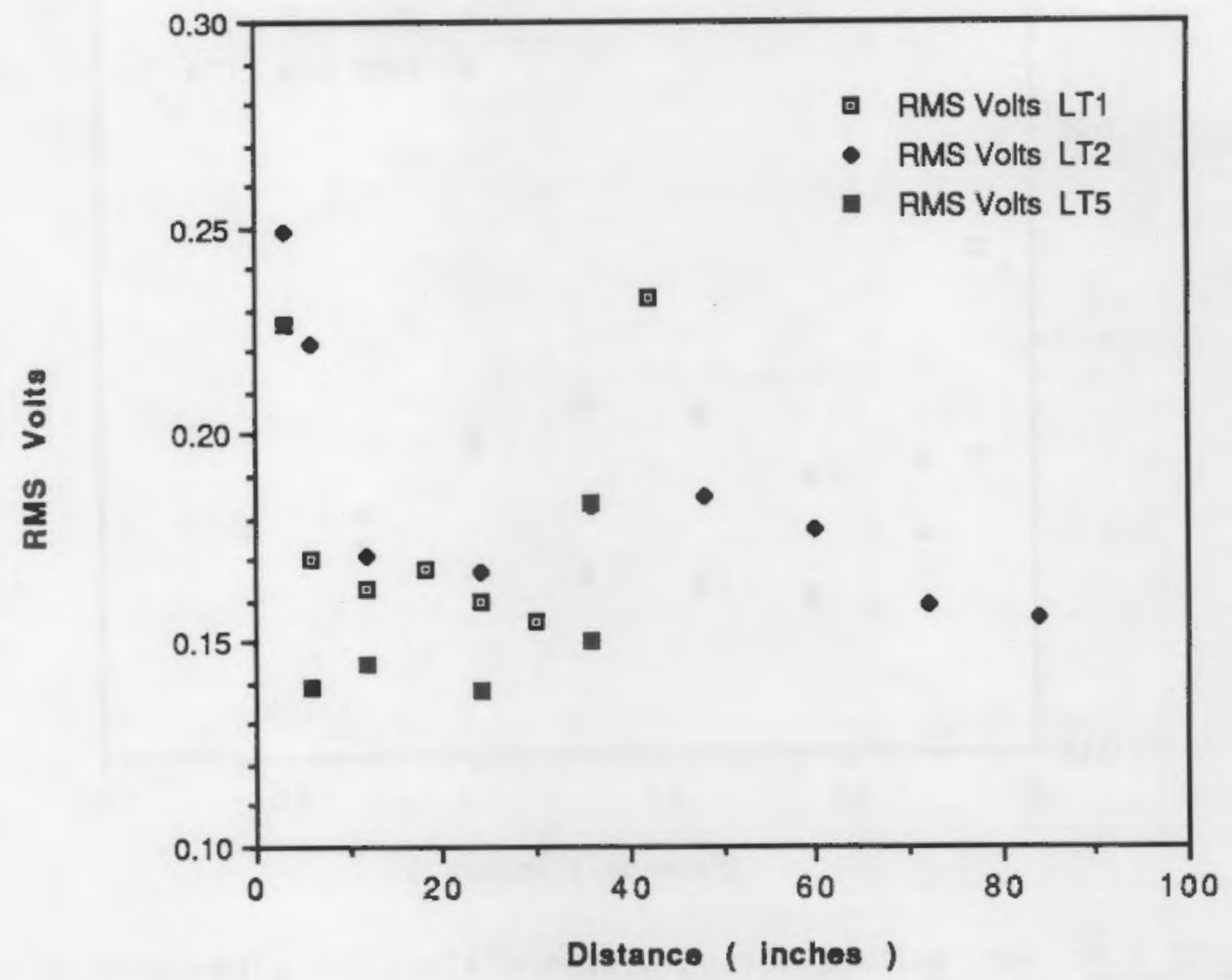

FIGURE 4.4. RMS Voltage Versus Distance along Two Lines with Similar Geometry (helium gas jet calibration, Experiment 2)

of the frequency bandwidth of the excitation signal indicated that there was little energy in these signals above $600 \mathrm{kHz}$. A second stage amplifier tuned to a band of 0.1 to $0.6 \mathrm{MHz}$ was added for this test to provide an additional $20 \mathrm{~dB}$ gain, yielding $70 \mathrm{~dB}$ overall. Figure 4.4 illustrates the effect of position on the RMS voltage level for lines 1, 2, and 5 . The initial drop in voltage level is similar to that seen in experiment 1 , but there are substantial differences in RMS levels at the same source/sensor distances among different lines, and a lack of strong distance-dependence along a given line. A tendency for RMS to increase at a distance of 35-55 inches was noted in some instances. To check whether the variations in voltage level are geometry-induced, data was taken along two additional lines which were geometrically symmetrical about the sensor position to lines 2 and 5 . The 


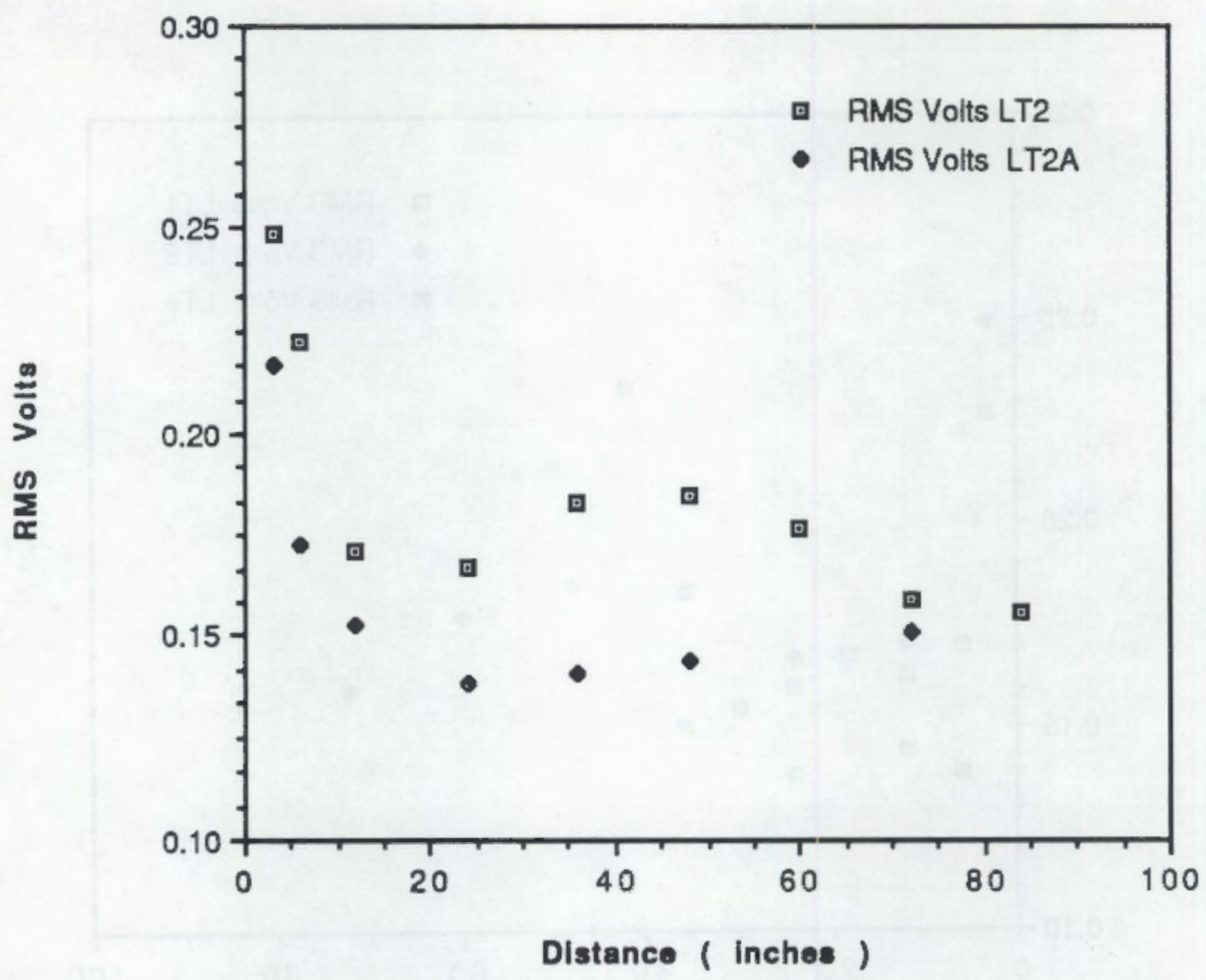

FIGURE 4.5. RMS Voltage Versus Distance along Two Lines with Similar Geometry (helium gas jet calibration, Experiment 2)

results from these lines are sufficiently similar to the results from lines 2 and 5 that the differences in RMS voltage can be ascribed with some confidence to the structure of the shell section. The least similar are line 2 and its counterpart, line $2 A$, shown in Figure 4.5. The difference in RMS level is probably due in part to a slight difference in gas pressure, since the two sets of data were obtained at different times. Standard deviations of these data were near $10 \%$ of the means.

The frequency of the sensor response signals was next derived and examined. Three bands were chosen which appeared to encompass the primary response peak and two lower frequency maxima observed in some of the data. Within each band, the mean power density was derived, averaged with values from other signals in each group, and plotted against distance along with the ratios of the mean densities in each band. As with RMS voltage, no consistent distance effects were observed. 


\subsubsection{Experiment 3: Detectability of Leakage and Effect of Source Position}

A hole was drilled through the plate at the location, shown in Figure 4.6, and a hose connecting to the hole was sealed to the inner surface of the shell using epoxy and silicon rubber. The other end of the hose was connected to a bottle of pressurized air via a pressure gauge (placed nearest the hole to ensure an accurate pressure reading across the leak) and a flow meter, so that air flow could be measured while maintaining constant pressure. The smallest hole which could be drilled through the shell section with reasonable facility was 0.0145 inch diameter (No. 79). The leak rate obtained from this hole while maintaining a pressure drop $\Delta p \approx 15 \mathrm{psi}$, was about 5.5 pounds per day or $3.2 \mathrm{SCFH}$. While maintaining this leak rate, detectability of the acoustic signal generated by the leak and position effects were examined. This test used the NIST sensor and $70 \mathrm{~dB}$ of wideband gain. Since it was desirable to find the available frequency range for monitoring leakage, the loss in sensitivity inherent in obtaining wideband response was not of concern. The sensor was placed at the locations shown in Figure 4.6, and signals measured in the same manner as for the gas jet.

Figure 4.7 shows the RMS voltage response for two separate sets of measurements. Although there appears to be some effect on signal level due to small discrepancies in sensor orientation or coupling, the response behavior of the two passes is fairly similar. Standard deviations of the measurements were again about $10 \%$ of the mean values. The response appears to show pronounced geometry-dependent effects, in agreement with earlier experiments, where the source was moved while the receiver remained stationary.

Frequency spectra were strongly peaked between $100 \mathrm{kHz}$ and $150 \mathrm{kHz}$. Figure 4.8 shows the effects of distance on mean power in $50 \mathrm{kHz}$ wide bands of the spectra. The low response in the $0-50 \mathrm{kHz}$ region was due to the low frequency filter built into the amplifier. The filter also affects the $50-$ $100 \mathrm{kHz}$ band, hence the best monitoring region appears to be between 50 and $300 \mathrm{kHz}$. Distance is seen to affect the spectra in all bands in about the same way as it affects the RMS voltage. 
TEST LINE FOR LEAK TESTS

VIEW FROM SMOOTH SIDE OF SHELL SECTION

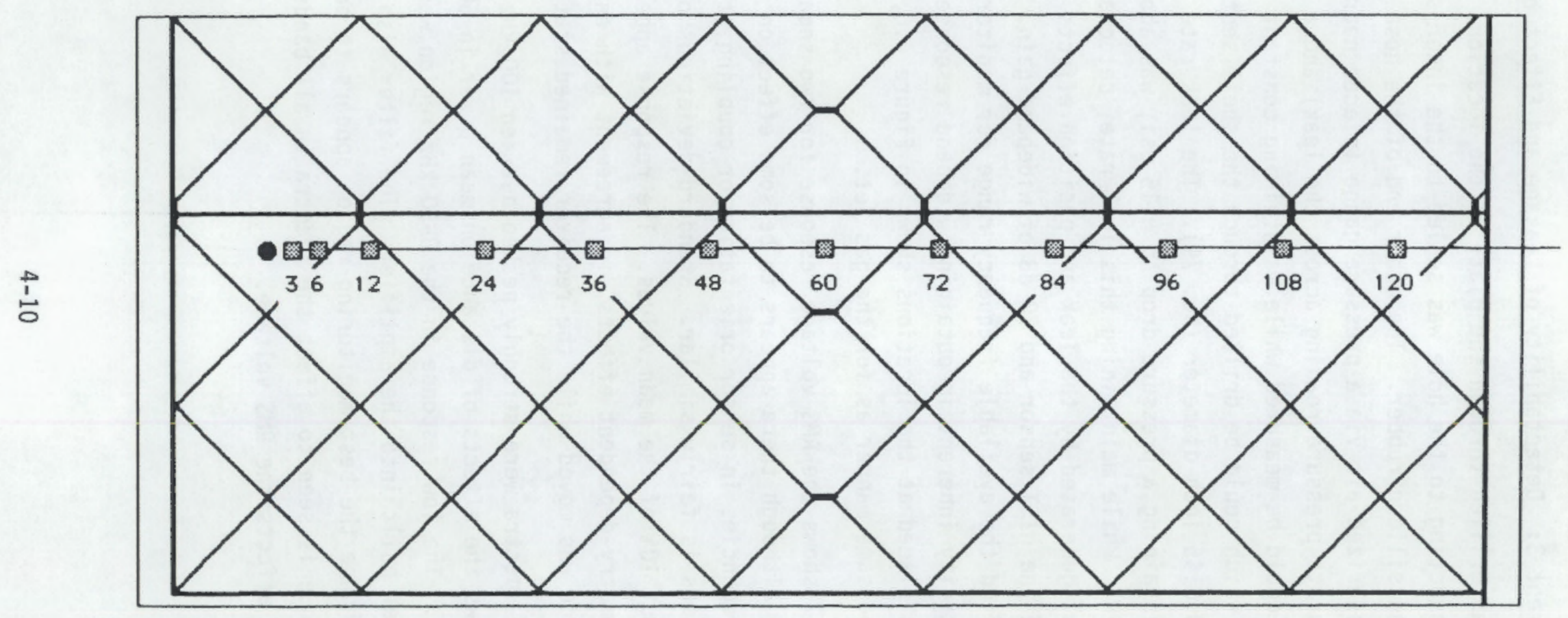

- leak location

a gensor locations (INCHES)

FIGURE 4.6. Layout for Leak Experiments 


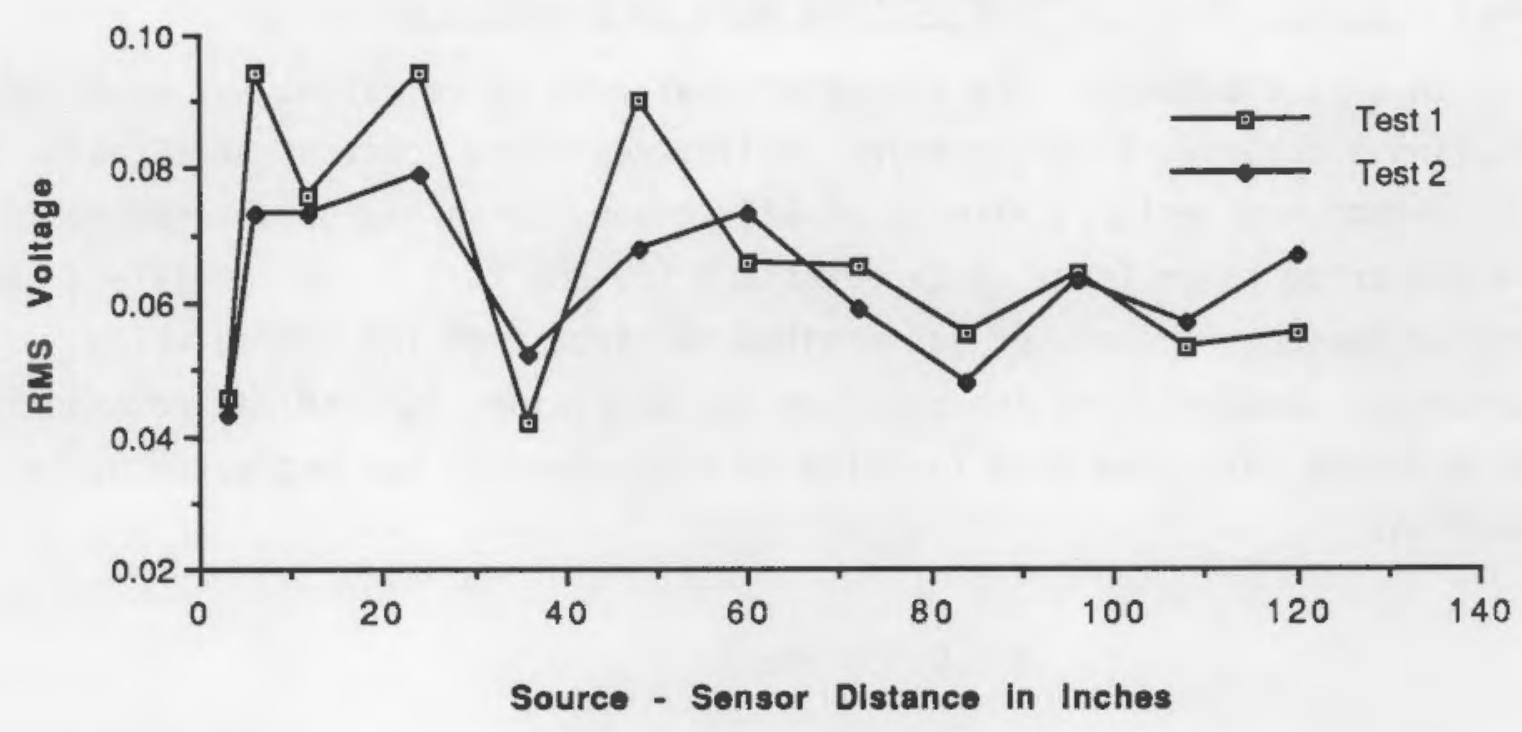

FIGURE 4.7. RMS Voltage Versus Distance for Leakage from a Round Hole (hole diameter is 0.014 inch, the leak rate is 5.7 pounds per day, and the pressure drop constant at 15 psi

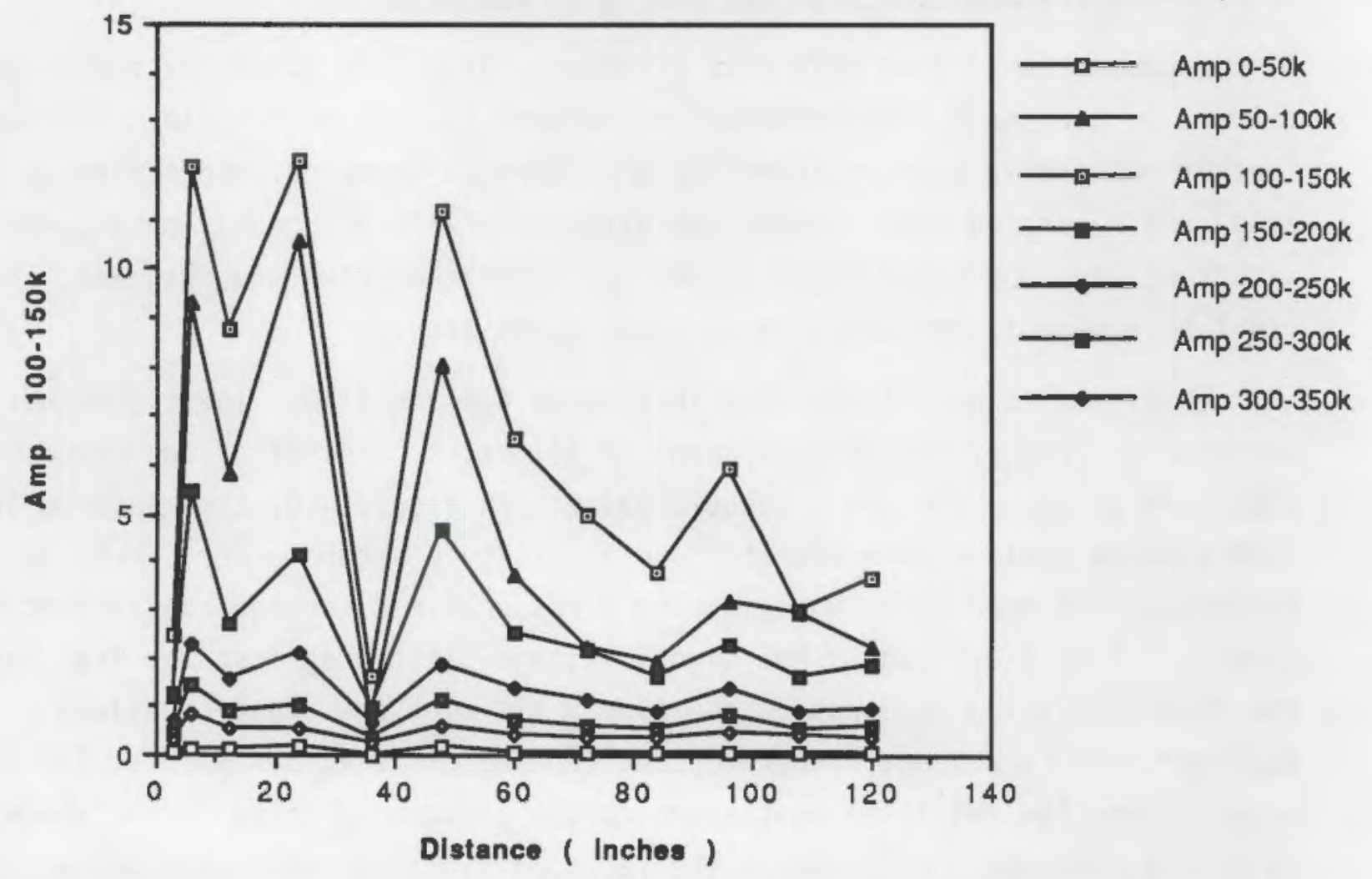

FIGURE 4.8. Power in $50 \mathrm{kHz}$ Bands Plotted against Distance for Leakage from a Round Hole (hole diameter is 0.0145 inch, the leak rate is 5.7 pounds per day, and the pressure drop constant at 15 psi) 


\subsubsection{Experiment 4: Effect of Leak Rate on Acoustic Emission}

In this experiment, the effect of leak rate on emissions was examined by drilling successively larger holes, while keeping $\Delta p$ constant at $15 p s i$. The NIST sensor was replaced with a PAC R15 sensor, which has good response in the preferred range found in Experiment $3(50-300 \mathrm{kHz})$. The amplifiers used were unchanged. The sensor was mounted two feet from the source using commercial couplant, and its position was maintained for the entire experiment. The expected leak rate as a function of hole diameter was estimated using the equation:

$$
m=0.53 \mathrm{CA}_{2} \mathrm{P}_{1} / \mathrm{T}_{1}
$$

derived in the Mark's Standard Handbook for Mechanical Engineers. In the equation, $C$ is a discharge coefficient, $A_{2}$ the hole cross-section, $P_{1}$ the pressure upstream of the orifice, and $T_{1}$ is the upstream temperature.

Because the initial hole size produced a leak rate about 10x the maximum allowed in the space station under the current specifications, the hole was further reduced in size by inserting a 0.005 -inch diameter copper wire in the hole, and injecting epoxy around the wire. The wire was gently moved, and withdrawn when the epoxy began to set up. From the leak rate obtained, the final hole size is estimated to be about 0.008 inch.

Test results are illustrated in Figures 4.9 and 4.10 . The signal was observed to trigger the $\mathrm{AE}$ instrument in all cases, indicating an increase in signal level above the set threshold value. In Figure 4.9, the measured leak rate plotted against hole diameter can be fit by a second order curve, in agreement with prediction and yielding a reasonable discharge coefficient of about 1. Figure 4.10 shows RMS signal voltage plotted against the leak rate. The data provides a reasonably good linear fit over the range of values examined. It is evident, however, that the signal level deviates at low leak rates, since the RMS level must approach the background noise level, which in this case, was small compared to the recorded signal levels. The signal level obtained from the smallest hole probably indicated this trend, although the signal level may be affected by the epoxy or the shape of the orifice. Although smaller hole sizes could not be produced without substantial 


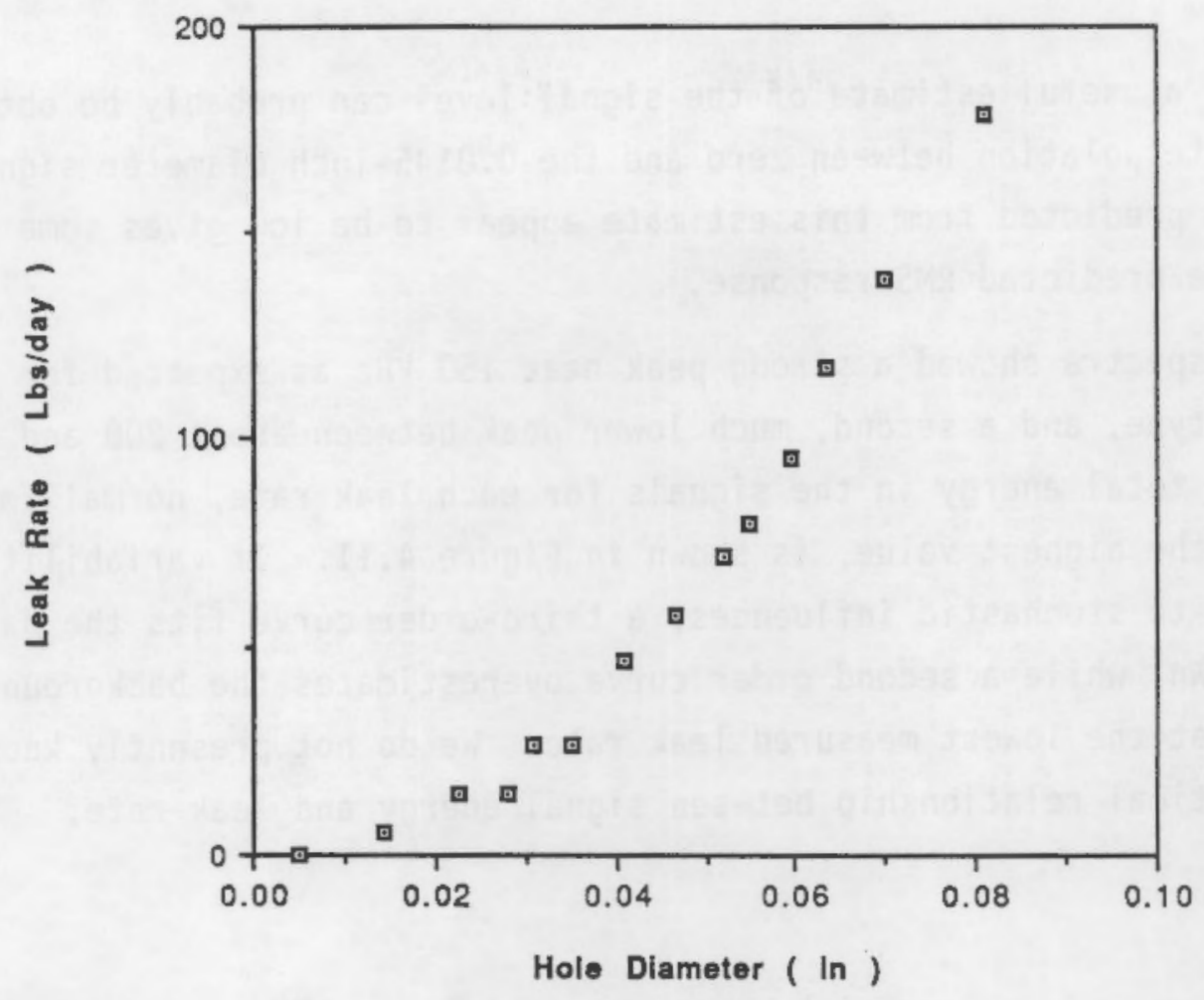

FIGURE 4.9. Leak Rate Versus Hole Diameter (pressure drop is a constant 15 psi; Experiment 4)

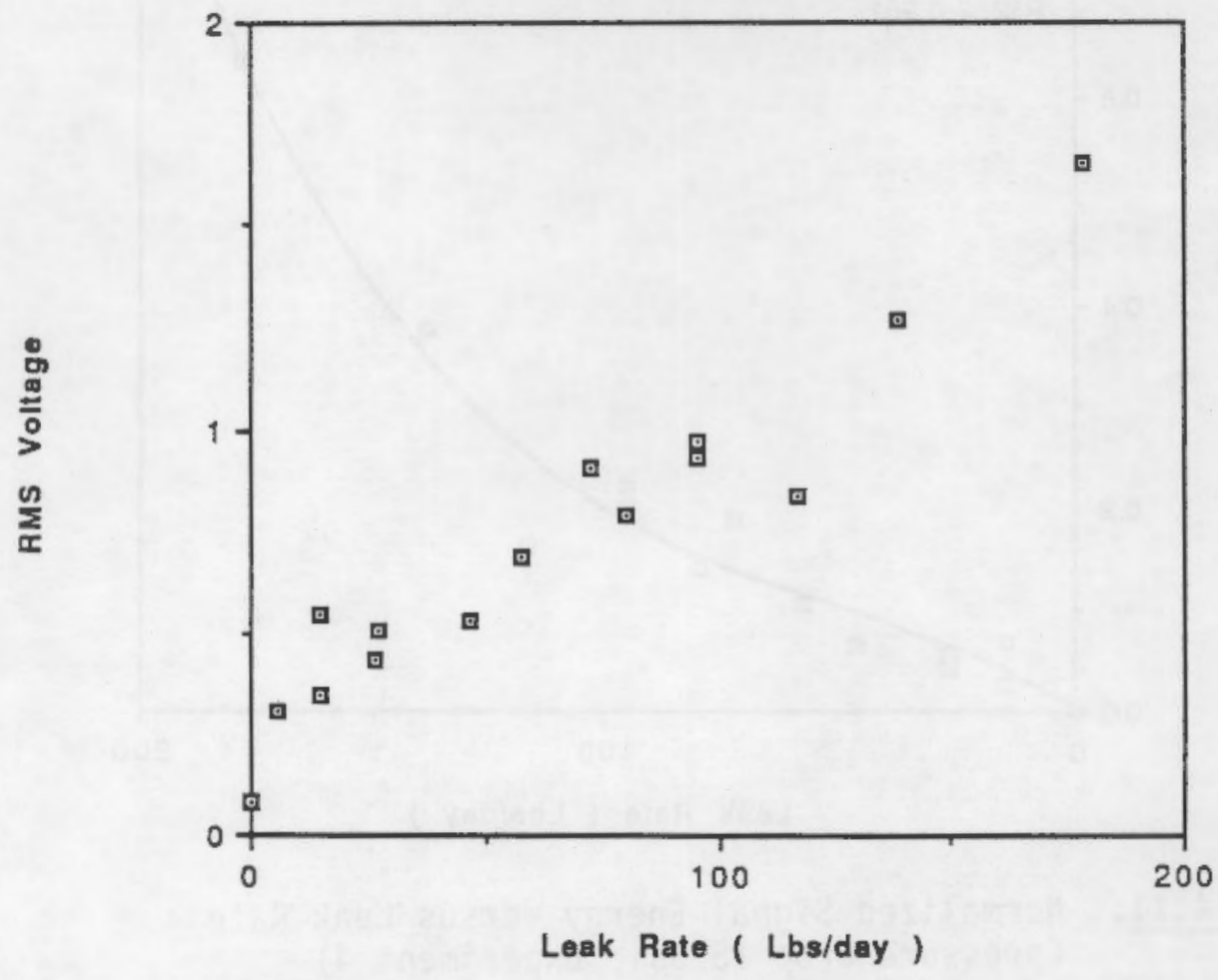

FIGURE 4.10. RMS Signal Voltage Plotted Against Leak Rate (pressure drop 15 psi; Experiment 4) 
difficulty, a useful estimate of the signal level can probably be obtained by a linear interpolation between zero and the 0.0145 -inch diameter signal levels. That values predicted from this estimate appear to be low gives some margin for error in the predicted RMS response.

Power spectra showed a strong peak near $150 \mathrm{kHz}$ as expected for the transducer type, and a second, much lower peak between about 200 and $250 \mathrm{kHz}$. The average total energy in the signals for each leak rate, normalized with respect to the highest value, is shown in Figure 4.11. If variability is assumed due to stochastic influences, a third-order curve fits the data fairly well as shown, while a second order curve overestimates the background level and energy at the lowest measured leak rate. We do not presently know of a good theoretical relationship between signal energy and leak rate.

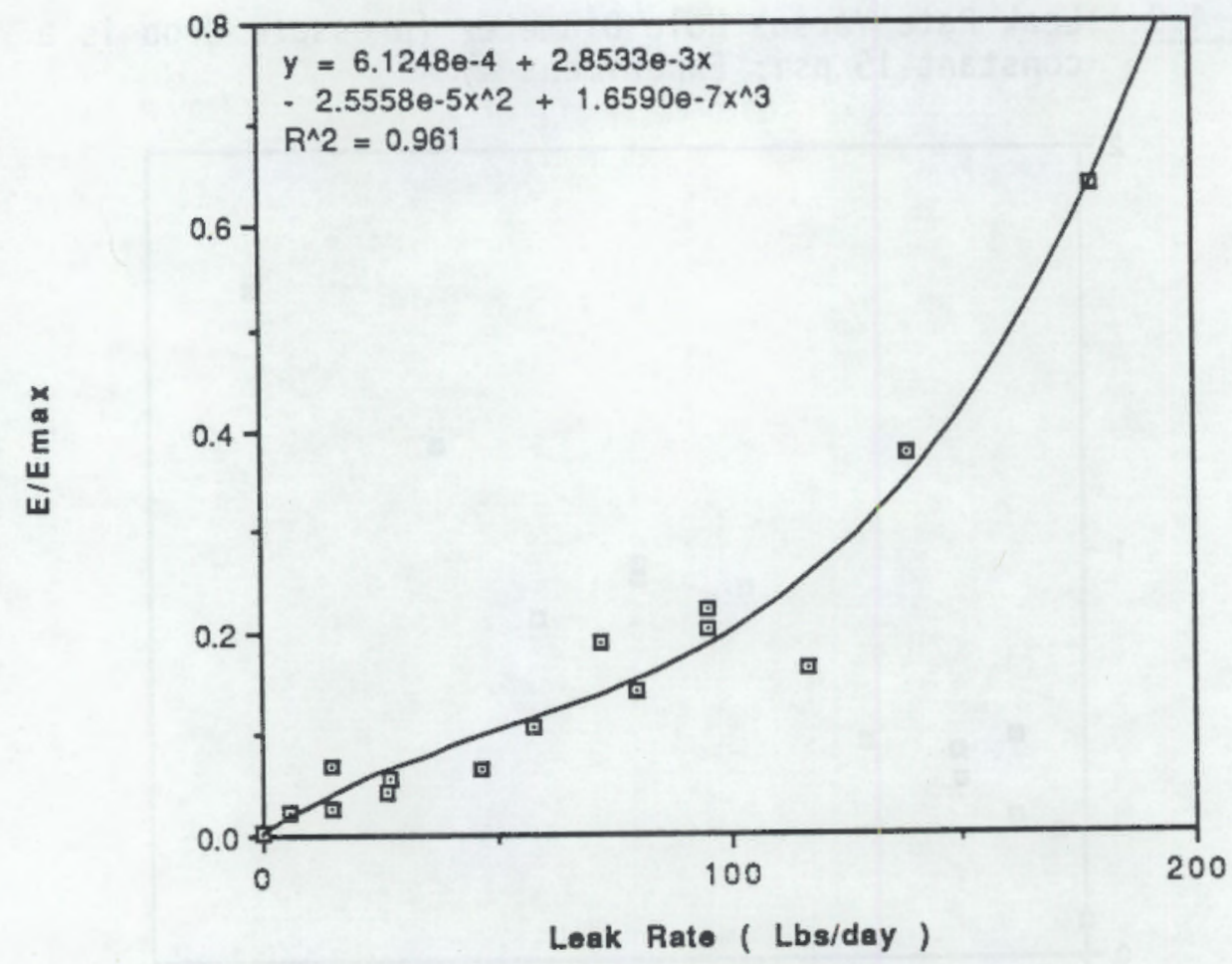

FIGURE 4.11. Normalized Signal Energy versus Leak Rate (pressure drop 15 psi; Experiment 4) 


\subsubsection{Experiment 5: Fatigue Test}

A fatigue test was carried out as described above. A pair of $\mu 30 \mathrm{~d} A E$ sensors were mounted on the same side of the plate and on either side of the crack line using a commercial epoxy. The distance of the sensors from the crack line was about 3 and 4 inches, respectively. Wide band amplifiers produced nominally $70 \mathrm{~dB}$ system gain. Oue to a high background noise level, the detection threshold was set somewhat above 3.5 volts (of note is that choosing appropriate tuning would enable the threshold level to be reduced). Noise not originating from the vicinity of the crack was eliminated by limiting the maximum difference in signal arrival times at the two sensors.

An average of more than 5000 valid AE events per inch of crack extension were detected. From the shape of the amplitude distribution curve (Figure 4.12) many more events were produced which did not exceed the detection threshold. The principal amplitude peak appears to be centered at or below

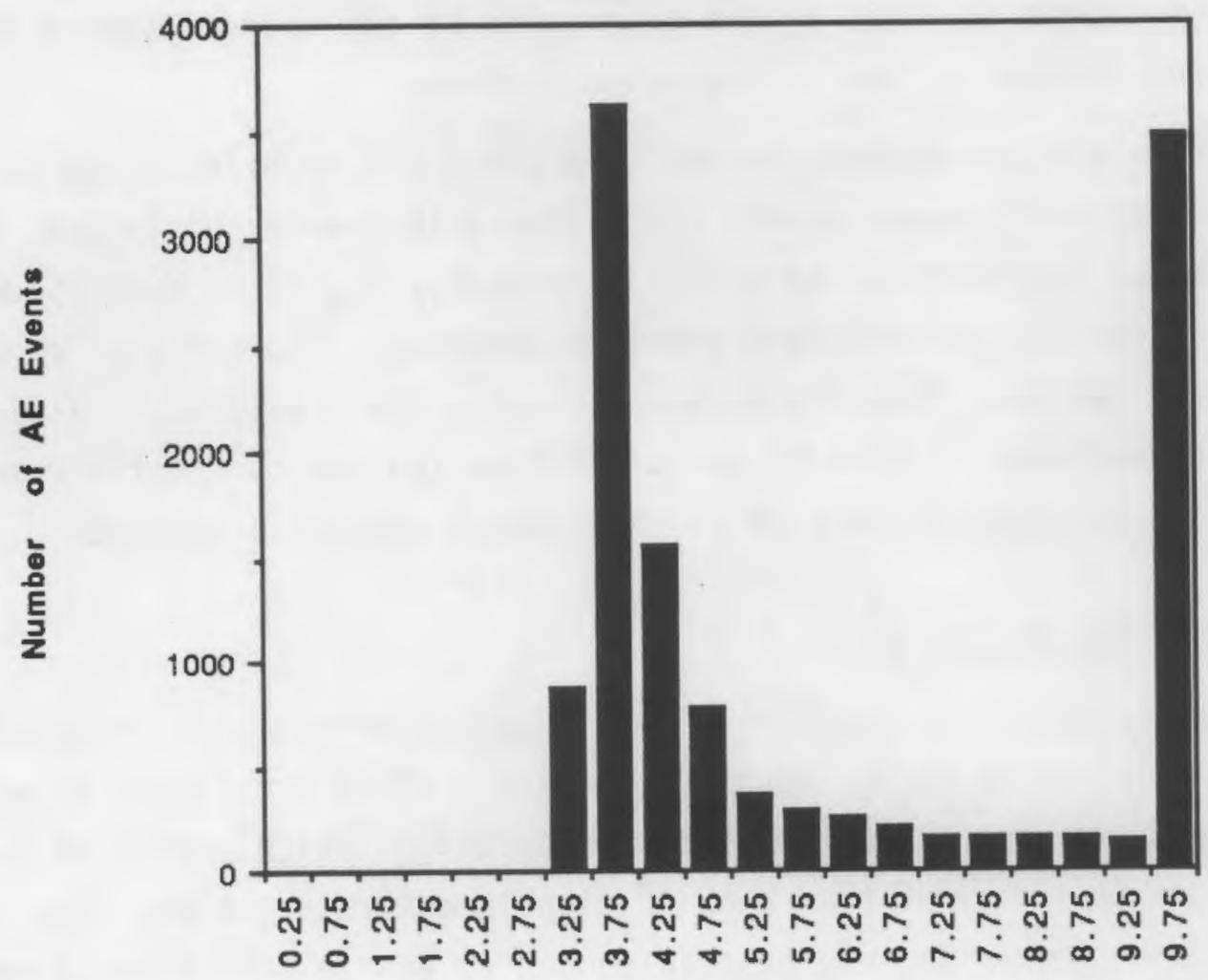

Amplltude

FIGURE 4.12. Amplitude Distribution for AE from Fatigue Crack Growth; Experiment 5 
the threshold level, although a substantial number of events saturated the system and are collected in the 10 volt amplitude bin. Saturated signals were fairly uniformly distributed in test time. After the test had been placed on hold and restarted, few AE events were detected for a number of cycles al though the crack was observed to grow. At present, it is assumed that events are produced in these regions which have amplitudes below the detection threshold.

\subsubsection{Experiment 6: Location of Transient Sources}

For this experiment, four sensors were mounted on the shell section in a $44 \times 81$-inch rectilinear array, and the difference in time of signal arrival at the various sensors was measured to facilitate triangulation of the signal source. Pencil lead calibration was performed at the location of each of the four sensors, and the effective wavespeed calculated for each measurement. Since the path length to the sensor nearest the source is very small, the effective wavespeed is given by the separation of the nearest sensor and a second sensor divided by the arrival time difference.

The calculated wavespeeds ranged from about $3.5 \mathrm{~mm} / \mathrm{microsecond} \mathrm{to} 5.5$ $\mathrm{mm} / \mathrm{microsecond}$, with slower speeds associated with greater distances. Because of the distance dependence, the effect is probably caused by dispersion, and indicates a tendency to mislocate transient sources. Sources will probably be placed too far away from the sensor measuring the greatest delta-time if the fastest wavespeed is used to calculate location, or too near the sensor measuring the shortest delta-time if the slowest wavespeed is used.

\subsection{ANALYSIS AND DISCUSSION}

The above results indicate the feasibility of monitoring the space station for impact and leakage using acoustic emission. Crack growth may be a more difficult problem, but there are some considerations which should be further examined. Because many of the crack AE signals saturated, their true amplitudes are unknown and may be high enough to enable detection at reasonable distances. Attenuation is probably dependent on the spectral content of the signal as well. Finally, the sensitivity of the detection system in Experiment 1 can be improved, for example, by improving the waveguide or changing the 
monitoring technique. The detected signal amplitudes, RMS voltage levels, and signal power obtained from standard sources apparently varies with source and receiver location. This variability appears to be caused by the geometric asymmetry of the ribs.

Pencil lead break tests indicate that most of the energy loss for transient signals occurs in the near field. At large distances, little attenuation occurs, and using an appropriate signal threshold, such signals should be detectable even from very remote sources. Using a simple linear fit to the last four points of Line 2 data from Experiment 1, a pencil lead break would be detectable to about 10 feet using $50 \mathrm{~dB}$ system gain and a 0.5 volt detection threshold. The threshold level is entirely reasonable for the given amplification for many applications, although the ambient background noise is a critical factor. Impacts capable of causing damage should greatly exceed the strength of a lead break and should be detectable, therefore, at much greater distances.

Helium gas and leak tests verify the geometry-dependent attenuation observed in the pencil lead break experiment. These results indicated that the strength of signals propagating in the plate could not be used to accurately locate leak sources; however, an approximation may be possible. Experiment 2 showed that the ratio of power in high and low frequency bands will be of little value in source location, although such a technique may prove useful in isotropic materials.

Continuous signals caused by leakage through circular holes were easily detected at all distances for all achievable leak rates, but again, the eventual $S / N$ ratio will be a determining factor in application. Deviation of the experimental RMS voltage from a linear dependence on leak rate for small hole sizes raises a question on useful extrapolation into the small leak rate domain of RMS versus leak rate from data obtained for larger rates.

In practice, RMS levels can be obtained by sampling and do not require a threshold crossing. Such sampling may be performed at preset intervals, or following a transient event. By comparing VRMS to the background level, a decision can be made as to whether a leak is present. 
The ability to locate leak source is essential. It should be possible to use secondary events, which cause leaks such as impacts, to locate leak sources. If a leak arises without an associated transient to provide location, a technique developed at Argonne National Laboratory (Kupperman, Prine, and Mathiesen 1988) to locate leaks in piping may be of use. For this approach, signals would be sampled at each sensor in an array, and the envelopes crosscorrelated. The lags producing the highest correlation coefficient should be proportional to the delta-times, permitting source location in the usual manner.

Only a partial estimate of the range of fatigue crack detection can be made, since the amplitudes of saturate events and the distribution of events below the detection threshold as illustrated in Figure 4.11, are both unknown. An estimate of the maximum detection distance can be made based on the limited data obtained by accommodating the $20 \mathrm{~dB}$ gain difference between the fatigue test and the pencil lead break test, and by assuming that the ribless fatigue specimen produced the highest possible response. A four volt value at $70 \mathrm{~dB}$ reduces to 0.4 volts at $50 \mathrm{~dB}$, and the saturated signals to 1.0 volt or greater. The 0.4 volt signals would be undetectable at any distance using a 0.5 volt threshold, if additive background noise was disregarded. The higher amplitude signals would only be detectable at short distances along Line 2 if the far-field amplitude depends on the near field response. From Figure 4.3, however, far-field signal amplitudes may depend primarily on the strength of the source, and there is, therefore, some chance of crack event detection at greater distances. In the context of extensive work done under other programs on detection of fatigue cracking in both steel and structural aluminums, we feel that there is good potential for effective detection of fatigue cracking using AE methods. 


\subsection{INSTRUMENTATION CONCEPT}

\subsection{OVERVIEW}

Two different monitoring techniques -- acoustic emission and pressure differential -- were selected as the basic technologies for a leak monitoring system. These will be illustrated with functional block diagrams, interface drawings, and specification sheets. Both concepts involve mounting sensors at specified locations (windows, hatches, inner walls, etc.) and cabling them back to chassis boxes located in the instrumentation racks. Due to each monitoring technique having different signal characteristics and analysis requirements, different chassis types are required. The pressure sensors have essentially a $D C$ characteristic output which can be periodically sampled by an analog-to-digital ( $A / D)$ converter and the data archived for post-processing. This type of interface can be accomplished with one of NASA's standard instrumentation chassis, namely a multiplexer-demultiplexer (MDM) box. The acoustic emission (AE) sensor output has a high frequency signal ( $₫ 400 \mathrm{kHz}$ ) which requires continuous monitoring, specialized hardware processing and custom software analysis. This type of interface would best be met using a customized electronics chassis which will be discussed in later detail. Based upon the aforementioned requirements and discussions with Boeing engineers, the interface for both $A E$ and pressure is shown in Figure 5.1. Both the $A E$ analyzer and the MDM box are linked to a space station standard data processor (SDP) over a local buss type 1553.

The AE system, which is intended to both detect and locate impacts and leaks, conceptually consists of 144 sensors and 5 electronic chassis. This configuration is shown in Figure 5.2 where the $H A B, L A B$, and resource nodes each require 32 sensors with the remaining 16 used for the logistics mode. Each module (node) has its own AE electronic processing chassis to which the sensors are cabled. Each AE chassis is linked to a space station SDP computer over a local buss for reporting acoustic activity and spatial location. Such a 144-channel system is estimated to weigh $160 \mathrm{lbs}$ and consume 54 watts. These calculations are based on using standard off-the-shelf electronic components and packaging hardware. If customized components and hardware are developed for miniaturization, then power and weight numbers 


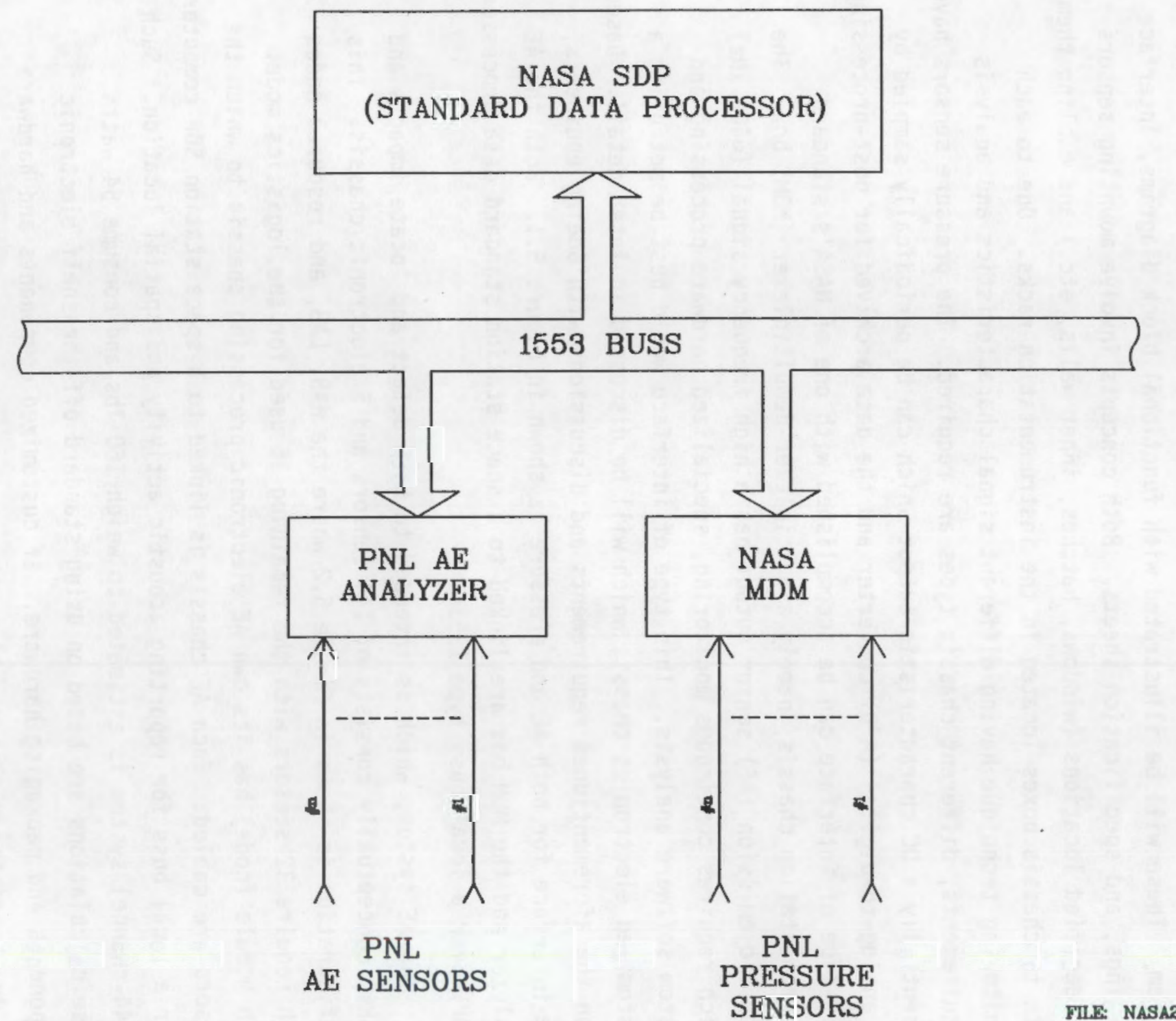

FIGURE 5.1. Conceptual Electronic Interface for PNL Sensors 


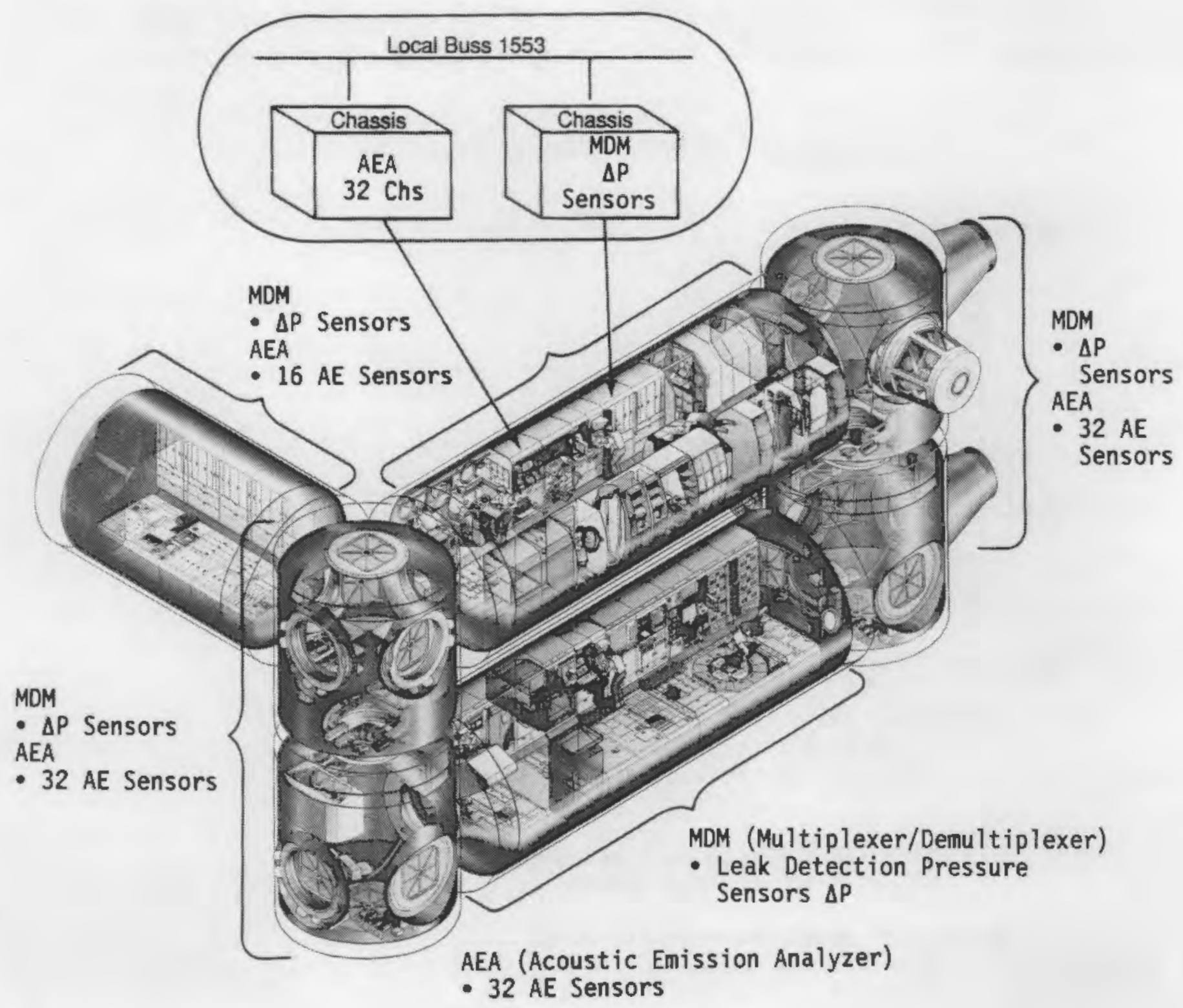

FIGURE 5.2. Configuration of AE and Pressure Monitor System

would be lowered. An estimate would be $100 \mathrm{lbs}$ at 27 watts. Normal AE systems employ coax cable for sensor runs; however, for the space station, fiber-optic cables may be more advantageous. They are lighter and are totally immune to crosstalk from other unrelated cables and systems. PNL has recently developed such an integral sensor/fiber-optic interface. For the 144-sensor 
layout, the fiber-optic interface adds an additional power requirement of 7 watts. Refer to Table 5.1 for a summary of the AE system performance.

\section{TABLE 5.1. AE System Concept Design Specifications}

\section{Sensor Location}

$32 \mathrm{HAB}$

$32 \mathrm{LAB}$

32 research node

32 research node

16 logistics node

144 total

Physical Package

5 electronic chassis 6 slots max each

VME or Multibus I backplane

Power Requirements

Individual chassis

12 watts $\max$ (standard of $f$-the-shelf components)

6 watts (customized components)

Total

54 watts $\max$ (standard off-the-shelf components)

27 watts (customized components)

Total with sensor fiber-optic link

68 watts $\max$ (standard off-the-shelf components)

34 watts (customized components)

\section{Weight}

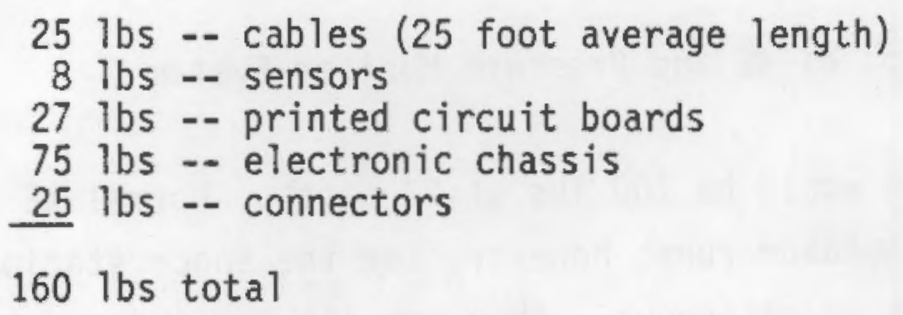

160 lbs total 
The AE system uses two primary techniques (triangulation and RMS correlation) to detect and locate impacts and leaks. A11 processing is performed by the AE system's own processors with only results reported to the space station computers. Since the AE system will yield a leak location zone and not a precise point, an acoustic airborne detector is proposed to serve as the final locator. This concept is shown in Figure 5.3 where a technician is scanning the designated zone with the hand-held detector. This unit is commercially available.

The instrumentation for the leak detection using differential pressure sensors is very straightforward. The configuration is shown in Figure 5.2.

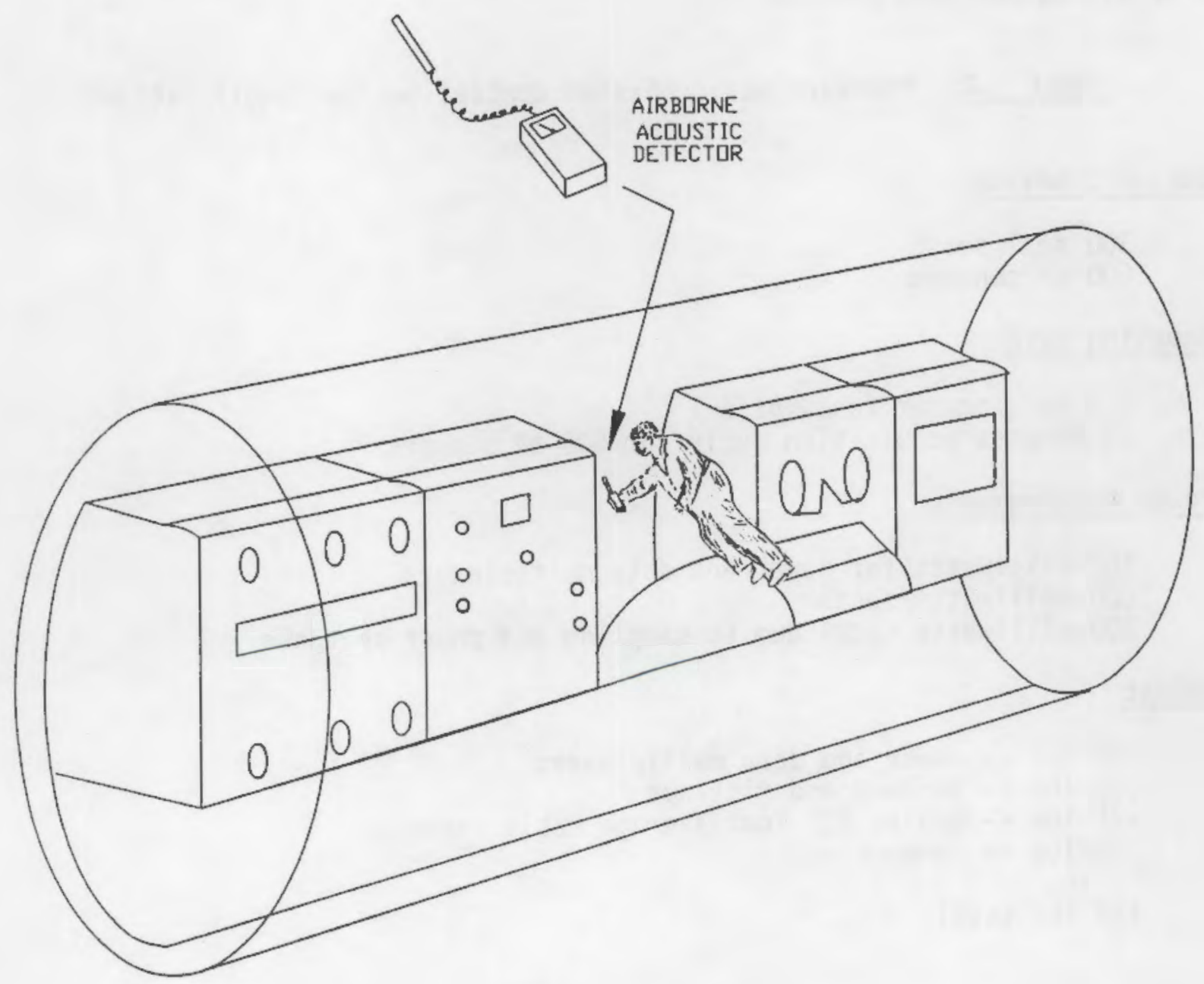

FIGURE 5.3. Use of Hand-Held Acoustic Detector to Pinpoint Leak Location 
For the 300 seal sets in the station, 600 sensors would be required. An integral preamplifier mates the sensor over twisted pair cable to a station MDM processor chassis. Here the signal is digitized on a sampled basis and the results bussed to a station SDP computer. Each sensor utilizes 200 millivolts of power which, times 600 sensors, is a significant power drain. Our proposal is to switch the bias power "on" to the individual sensor just prior to its reading. Assuming 1.5 seconds for a power-on and read cycle, all 600 sensors could be read over a 15 -minute period. Since only one sensor is ever powered at a given time, the power drain is only 200 milliwatts. An estimate for weight of a 600 -sensor system including cables, sensors, fitting, and connectors, is about 110 lbs. Table 5.2 summarizes the differential pressure system performance.

\section{TABLE 5.2. Pressure Sensor System Concept Design Specifications}

Sensor Quantity

300 seal sets

$600 \Delta \mathrm{P}$ sensors

Sampling Rate

$1.5 \mathrm{secs} /$ sensor (assumption)

15 minutes acquisition cycle for $600 \Delta \mathrm{P}$ sensors

\section{Power Requirements}

100 milliwatts for power and data multiplexers

$200 \mathrm{milliwatts} /$ sensor

300 milliwatts total due to sampling and power shutdown Weight

20 lbs -- power and data multiplexers

15 lbs -- sensors and fittings

75 lbs -- cables (25 foot average cable length)

20 lbs -- connectors

130 lbs total 


\subsection{AE INSTRUMENTATION CONCEPT}

The AE system has two functions: 1) impact detection and location and 2) leak detection and location as related to the module shell. Both of these features would be performed in the PNL AE analyzer shown in Figure 5.4. The analyzer resides in a chassis box with an industry standard buss such as Multibuss-II or VME. Two different types of AE cards would reside on the buss: ILC (impact location card) and LLC (leak location card). Each card would have its own on-board processor for controlling data acquisition and performing source location. Location data would be passed to the analyzer host card ( 80186 or 80386 based) for transmission over the 1553 local buss to a SDP unit.

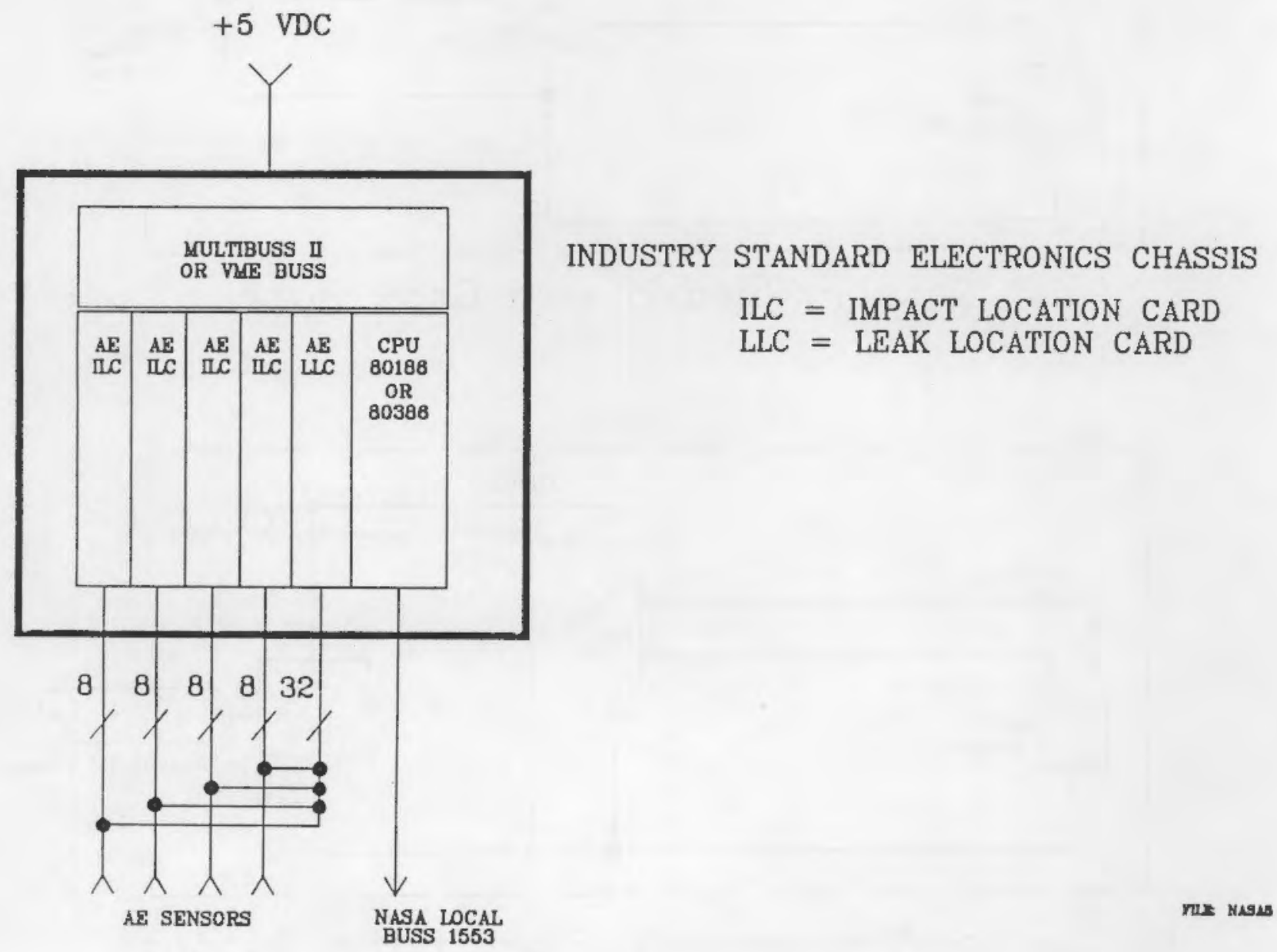

FIGURE 5.4. Conceptual Acoustic Emission Shell Impact and Leak Detector Interface 
Both location methods utilize the same AE sensors. The sensors would be packaged with an integral preamp as functionally shown in Figure 5.5. The $A E$ sensor is a piezoelectric device which produces a voltage output proportional to an arriving acoustic pressure wave. The sensor would be designed and fabricated for rejection of lower frequencies $(<100 \mathrm{kHz})$. To provide additional low frequency rejection plus increased sensitivity, a tuning network is inserted between the sensor and the preamp. The preamp has two functions:

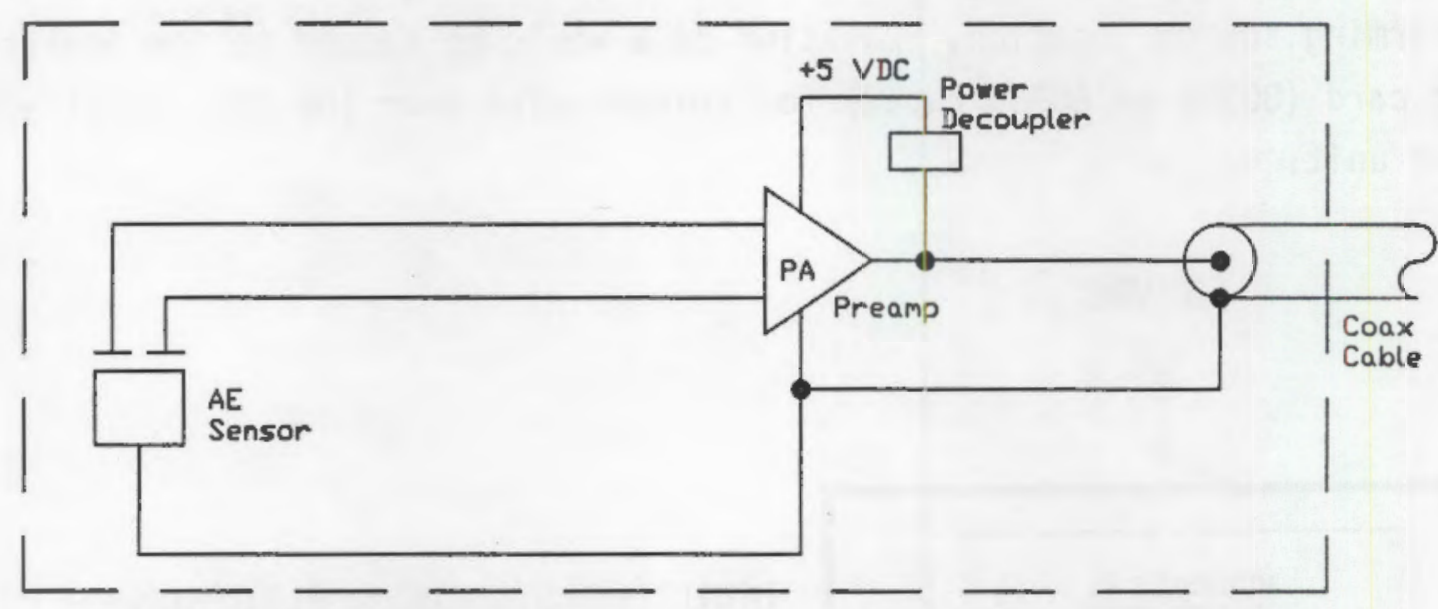

(a) Sensor/Preamp with Coax Dutput

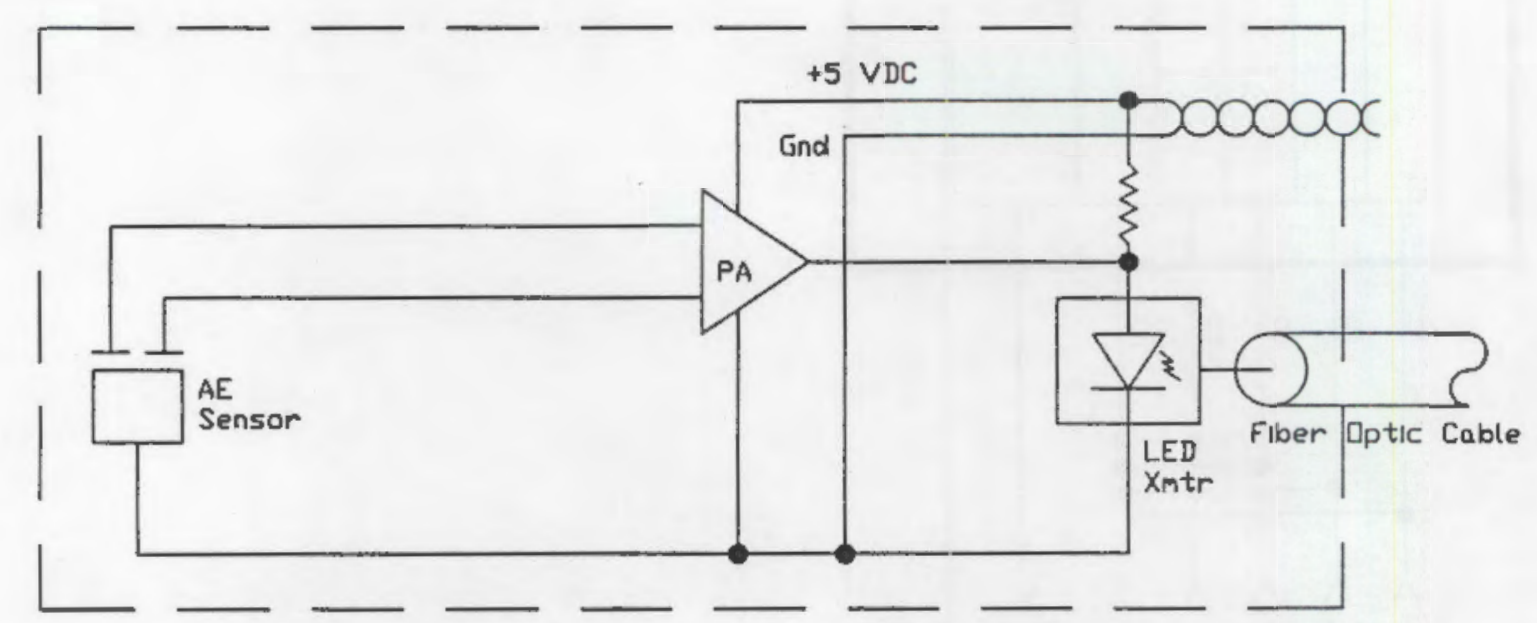

(b) Sensor/Preamp with Fiber Dptic Dutput

FIGURE 5.5. Acoustic Emission Sensor Packages 
1) establish signal-to-noise ratio and 2) match sensor output to coax cable. The sensor output level is small (microvolts) dictating a preamp to maintain the AE signal above any cable pickup noise. The preamp would also have a coax cable driving output stage. Power to the preamp would reside on the same wire with the signal. The sensor/preamp with a coax cable output is functionally shown in Figure 5.5a. An option to coax is fiber optics shown in Figure 5.5b. Fiber-optic cable is smaller and lighter than coax and eliminates any chance of being susceptible to signal or noise crosstalk. Power, though, to the preamp would have to be provided by a separate wire.

For both types, the sensor/preamp would be an integral device. PNL has already established a preamp design and has breadboarded it integral to a piezoelectric element. Preliminary discussions with IC hybrid houses have verified that standard IC practices could be used to comnercially fabricate such a unit. Small size and low weight is definitely advantageous for the space station applications.

\subsubsection{Impact Location with AE Methods}

The concept for performing impact location is shown in Figure 5.6 and would be implemented on the ILC. The initial requirement is to obtain time difference (delta time) measurements from a set of sensors known as an array. The space station concept will use a three-sensor array (triplet). The acquired delta-time values will be software processed using a PNL algorithm to establish source location data. Sensor data is first processed by signal conditioners (SC) to provide additional filtering and gain. The processed output is then amplitude detected referenced against a $D C$ detection threshold. The front edge of the detected signals are used to trigger timing circuits which measure a set of delta-time values. There is also monitoring circuits to prevent multiple measurements on the same AE pulse. Impact location is based on there being resulting pressure waves due to an impact force creating discrete $A E$ pulse bursts which rise above the detection threshold. If the excitation source is continuous, for example, a leak, then there would be no discrete burst that could be used for coordinated delta-time measurements. The sensor output would be continuously above the detection threshold, locking the system up and preventing any further measurements. To respond to a leak 
state, an RMS (root-mean-square) measurement check is periodically made. When a continuous level above background is detected then a leak state is assumed and a prompt sent to the LLC (leak location card) to perform analysis for leak location. The LLC will be discussed in more depth later.

The ILC processor would be 16-bit single chip, high performance, stateof-the-art, microcontroller. It contains embedded RAM, I/O, SIO, A/D, EPROM. The EPROM would contain program code. Coding would be done in either assembly or "C" language to implement the source location and RMS detection algorithms. With the use of gate arrays and hybrid circuits, it is anticipated that each impact location card (ILC) would accommodate six sensors.

\subsubsection{AE Leak Location}

The leak location concept is implemented on the LLC and is shown in Figure 5.7. It consists of a three-channel digitizer with associated buffer memory to store a data sample. When a leak is detected by the RMS analyzers or the ILC a prompt is issued to the LLC to initiate an analysis search. Along with the prompt would come sensor identifications to focus the search. The ILC would be in an idle mode (power-down state) until this prompt is received. The LLC processor would then activate itself and the acquisition electronics and start the search analysis.

Leak location is based on the assumption, verified in isotropic homogeneous media at Argonne National Laboratory, that the leak signals at each sensor location contain similar features arising from the source. In data samples obtained simultaneously at each sensor in the array, specific features appear after a delay which depends upon the location of the source. Because the delays are proportional to the signal arrival time differences, or delta-times, used to locate transient events, finding these delay values permits standard source location. Identifying the delays requires that the envelope of each rectified signal be calculated. The signal of an arbitrarily designated sensor is then cross-correlated with each remaining signal over the range of lags (time shifts) representing the range of delta-times possible for the given array configuration. The $\Delta$-point lag, defined as the lag where the correlation coefficient is a maximum, is the lag of interest and its value must be saved. The lowest lag obtained in this manner determines the sensor 
closest to the source, and the remaining lags correspond to the delta-times associated with each sensor. As an example, assign Channel 1 as the designed sensor. If all lags are positive, Channel 1 is first hit. The lag between the Channel 1 and Channel 2 signals is the delta-time associated with Channel 2 , etc. The LLC processor would be of the same type as on the ILC and was described in that section.

\subsubsection{AE System Specification}

The AE preliminary system specifications are itemized in Table 5.3. Power and size are key features of the concept that need to be minimized but at this point in time cannot be quantified exactly. Accurate limits would result from follow-on design phases. It would be accurate to tabulate power requirements by totaling the number of channels. An approximation, without a detailed analysis, would be around $1 / 2$ watt per channel.

\subsubsection{Sensor Layout Design}

The fundamental approach in acoustic emission source location is to have a series of overlapping triangles formed by sensors at each triangle corner. To reduce the number of sensors needed, it is advantageous to have each sensor serve as a member of more than one triangular sensor array. Obviously, there must be a trade-off made between gaining increased sensitivity to leaks by having more and more sensors, and the weight and cost penalties that more sensors bring. Based on these concepts and constraints a preliminary sensor layout design was developed and is shown in Figures $5.8 \mathrm{a}, \mathrm{b}$, and $\mathrm{c}$.

The design consists of two sensors located in two corners of each of the shell wall sections. The acoustic attenuation studies showed that the axial welds (connecting adjacent sections going around the circumference of the module) cause only about a $10 \%$ loss of acoustic signal. Therefore, it was deemed unnecessary to have three sensors located on each segment. For every set of four sensors in adjacent wall segments, there are four sensor arrays possible. These are shown as arrays A1 through A4 in Figure 5.8a. Depending on where the leak or impact is located, the optimum set of sensors can be used to estimate location. 
Table 5.3. PNL Acoustic Emission Analyzer Specifications

\section{Acoustic Emission Sensor}

Type: Piezoelectric device either commercially procured or PNL-fabricated Frequency: $\approx 400 \mathrm{kHz}$

Power: None, passive device

Output: Differential

\section{Preamp}

Type: PNL design with differential input Gain: $46(33 \mathrm{~dB})$

Noise: < 10 uVms at input

Power Supply: +5 VDC shared with signal out

Power Drain: Continuous at $15 \mathrm{~mA}$ (75 milliwatts) $35 \mathrm{~mA}$ with fiber-optic link

Output: Single ended into 50 ohm coax

\section{Impact Location Card (ILC)}

Inputs: 8 channels

Delta-Time Measurement Circuits: 3 each with 1 us resolution

Signal Conditioners: 8 each, with software programmable gain

Amplitude Detectors: 8 each with software programmable thresholds

Microcontroller: Intel $87 C 196$ with embedded EPROM, RAM, I/O, SIO, and A/D Power Supply: +5 VDC

Power Drain: Continuous at 3 watts

Interface: Multibuss II or VME

Card Size: Double size $8.66^{\prime \prime} \times 9.18^{\prime \prime}$

\section{Leak Location Card (LLC)}

Inputs: 16 channels

$\mathrm{A} / \mathrm{D}: \quad 8$-bits at $5 \mathrm{MHz}$

RAM: 3 banks of $2 \mathrm{~K}$ bytes each

Microcontroller: Intel 87C196 with embedded EPROM, RAM, I/O and SIO

Power Supply: +5 VDC

Power Drain: Command activated -- $O N \approx 1$ watt

Interface: Multibuss II or VME

OFF $=25$ microwatts

Card Size: Double Size, $8.66^{\prime \prime} \times 9.18^{\prime \prime}$ 


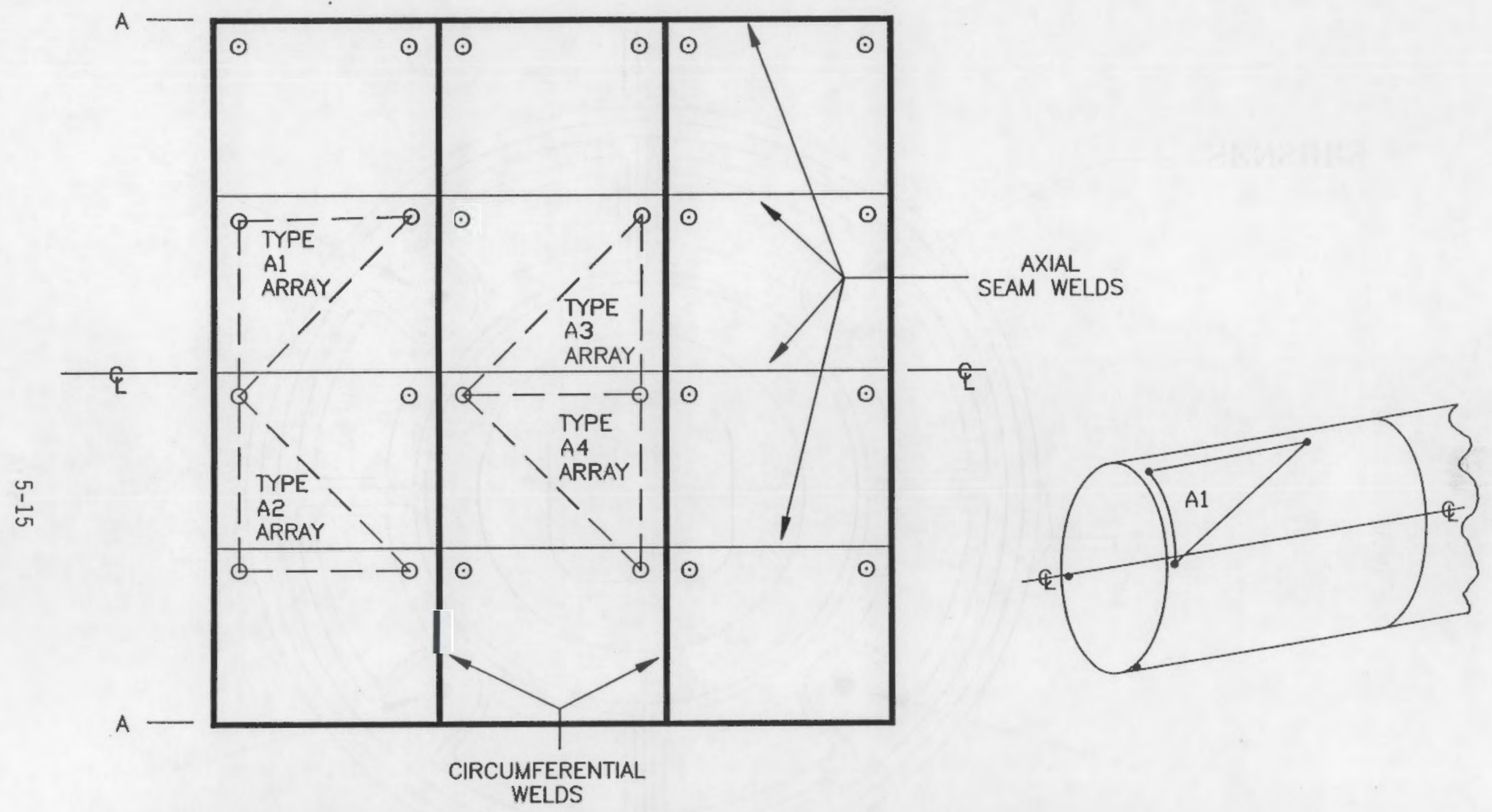

FIGURE 5.8a. Sensor Layout Plan -- Space Station Module Roll-Out View 
䆝

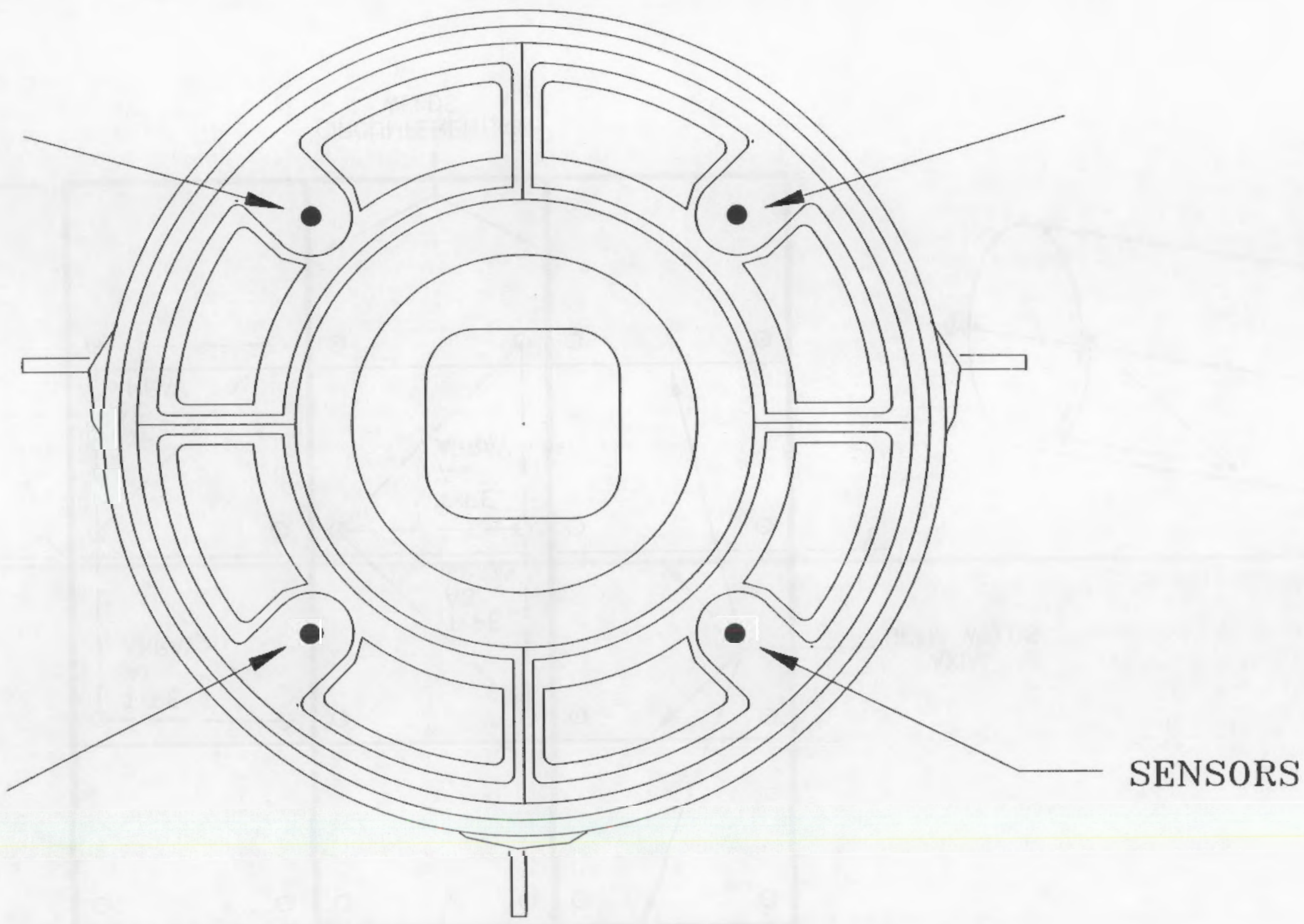

FIGURE 5.8b. Sensor Layout Plan -- Module/Node End Section View 


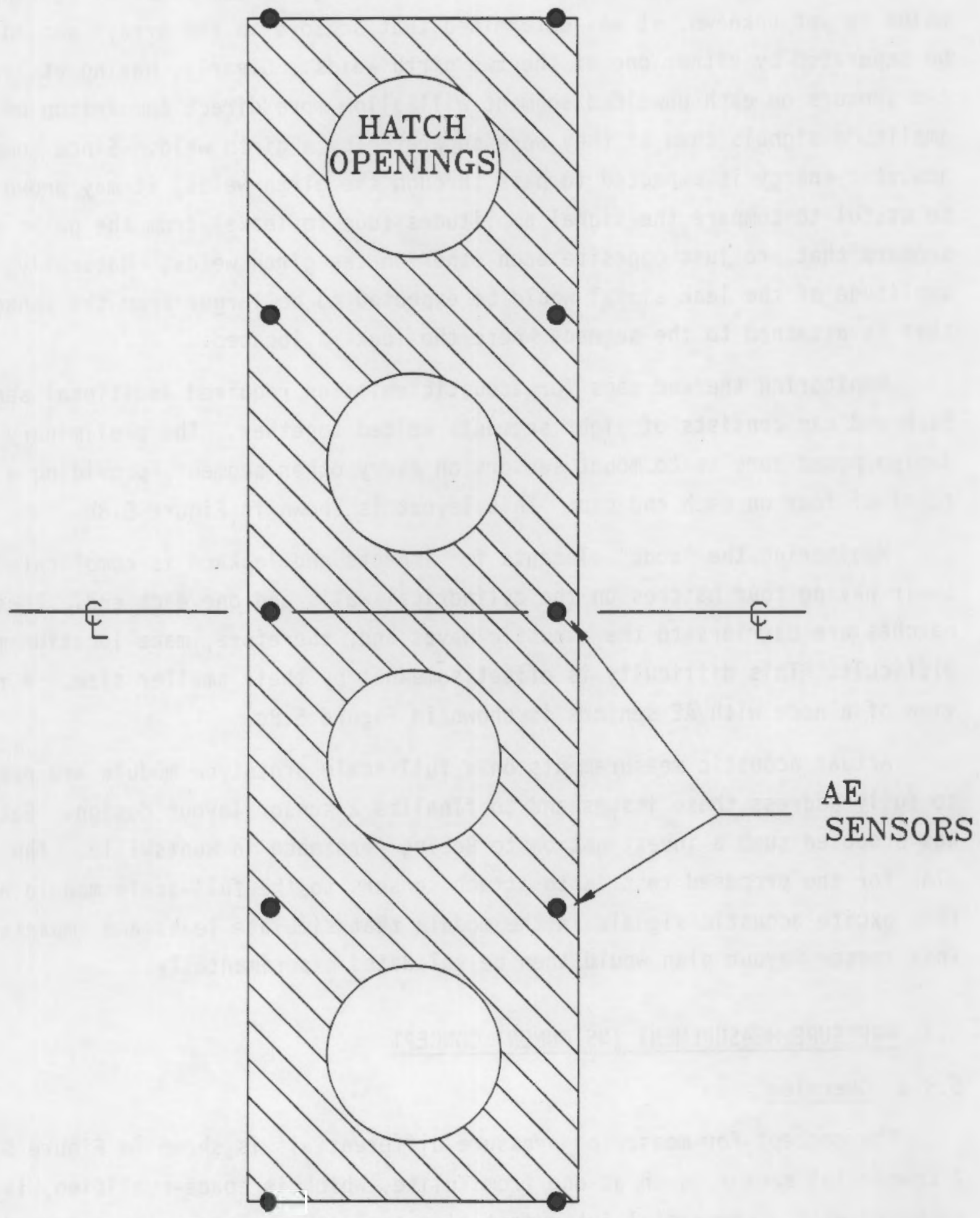

FIGURE 5.8C. AE Sensor Layout Plan -- Node Element - Roll-out View 
Since the attenuation effect of the two large circumferential (girth) welds is yet unknown, it was determined that sensors in the arrays should not be separated by either one of the two girth welds. Clearly, having at least two sensors on each unwelded segment will allow more direct comparison of leak amplitude signals than if they were separated by a girth weld. Since some acoustic energy is expected to pass through the girth welds, it may prove to be useful to compare the signal amplitudes (due to leaks) from the pairs of sensors that are just opposite each other on the girth welds. Naturally, the amplitude of the leak signal would be expected to be larger from the sensor that is attached to the segment where the leak is located.

Monitoring the end caps for acoustic emission required additional sensors. Each end cap consists of eight segments welded together. The preliminary design posed here is to mount sensors on every other segment, providing a total of four on each end cap. This layout is shown in Figure $5.8 \mathrm{~b}$.

Monitoring the "node" elements for impacts and leakage is complicated by their having four hatches on the cylindrical walls and one each end. These hatches are barriers to the acoustic waves and, therefore, make location more difficult. This difficulty is offset somewhat by their smaller size. A rolled view of a node with $A E$ sensors is shown in Figure $5.8 \mathrm{c}$.

Actual acoustic measurements on a full-scale prototype module are needed to fully address these issues and to finalize a sensor layout design. Battelle has proposed such a investigation to Boeing Aerospace in Huntsville. The plan for the proposed test is to attach sensors to the full-scale module and then excite acoustic signals in the module that simulate leaks and impacts. This sensor layout plan would then be validated experimentally.

\subsection{PRESSURE MEASUREMENT INSTRUMENT CONCEPT}

\subsubsection{Overview}

The concept for measuring pressure differentials is shown in Figure 5.9. A commercial sensor, such as one from Kulite, which is space-qualified, is packaged with a commercial instrumentation amplifier. The pressure transducer internally has a four-arm whetstone bridge upon which the sensing principle is based. The output is in the hundreds of millivolts, which is amplified by 


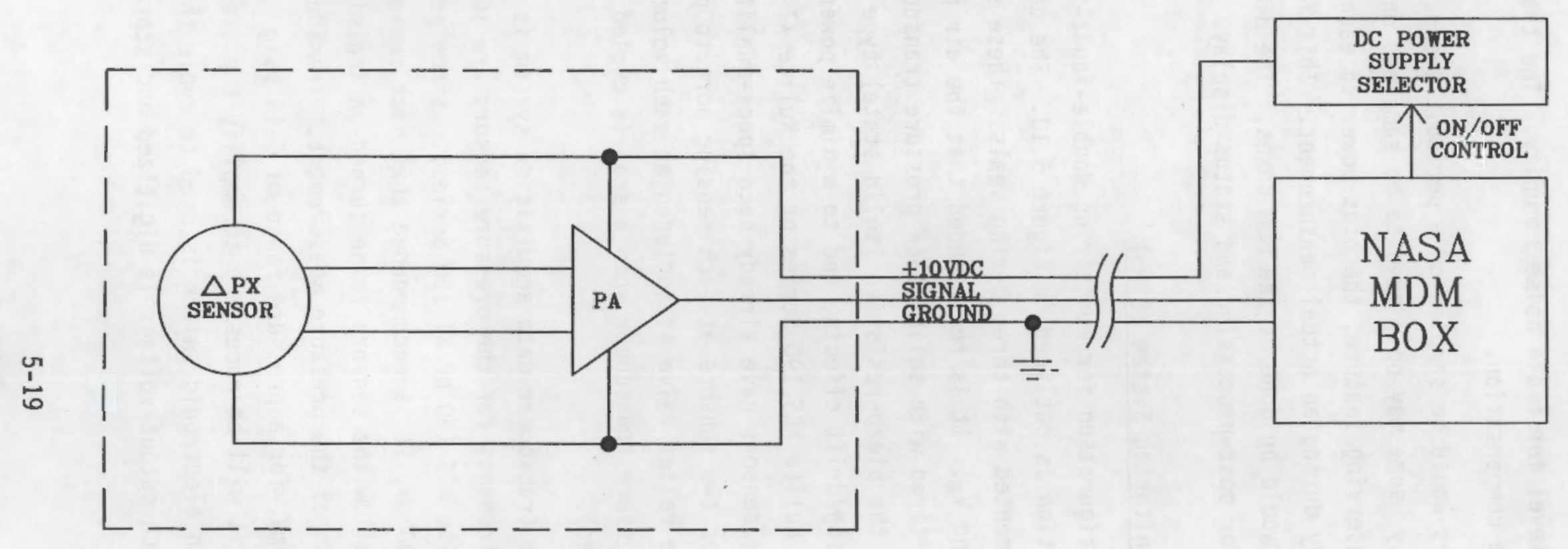

PRESSURE SENSOR PACKAGE

FIIX XLSA4 
the preamp to a higher level for cable noise immunity. The transducer also has internal temperature compensation.

The pressure sensors would be sampled on a periodic basis. Depending upon location criticality, some may only need to be sampled once or twice per day. As a power conserving feature, the bias power to each sensor package could be turned "on" only during an actual measurement. This feature, along with the $A / D$ conversion would be done by the MDM boxes. The digitized pressure data would be archived for post-processing and status display.

\subsubsection{Seal Integrity Monitoring System (SIMS)}

The recommended configuration for monitoring double-fault-tolerant seal systems in the space station is outlined in Figure 5.10. The double-faulttolerant design is implemented with three 0 -ring seals. These seals enclose two volumes denoted $V_{1}$ and $V_{2}$. It is recommended that the air pressure in these two volumes be monitored with solid state pressure transducers. The transducers should be of the piezo-resistive (solid state) type to maximize lifetime, to minimize aging/drift effects, and to minimize power consumption. Suggested senors are the Kulite XCS 190 Series or the Kulite XT 190 Series. It is believed that these sensors have already been space-qualified. Note that Figure 5.10 indicates two sensors at each sensing port to provide for a backup. An over-pressure relief valve is included at each volume tap to prevent damage to the pressure transducer when a seal is cycled (e.g., when a hatch is opened and closed).

A suggested pressure transducer data acquisition system is depicted in Figure 5.11. Power requirements for the pressure sensors are 10-15 volts $D C$ at 10-30 mA (for the Kulite XCS 190 or XT 190 Series). Since power consumption for each transducer is $200 \mathrm{~mW}$, it is recommended that each sensor be powered separately. This would allow the sensors to be turned-on individually and turned-off upon completion of the pressure measurement. Transducer output is either $0-100 \mathrm{mV}$ or $0-200 \mathrm{mV}$, for a pressure range of $0-15 \mathrm{psig.} \mathrm{If} \mathrm{this} \mathrm{signal}$ level is deemed too low, it will be necessary to amplify the transducer outputs prior to digitization. An electronic switch is used to cycle through the sensor array outputs. Each output voltage is digitized and stored for 


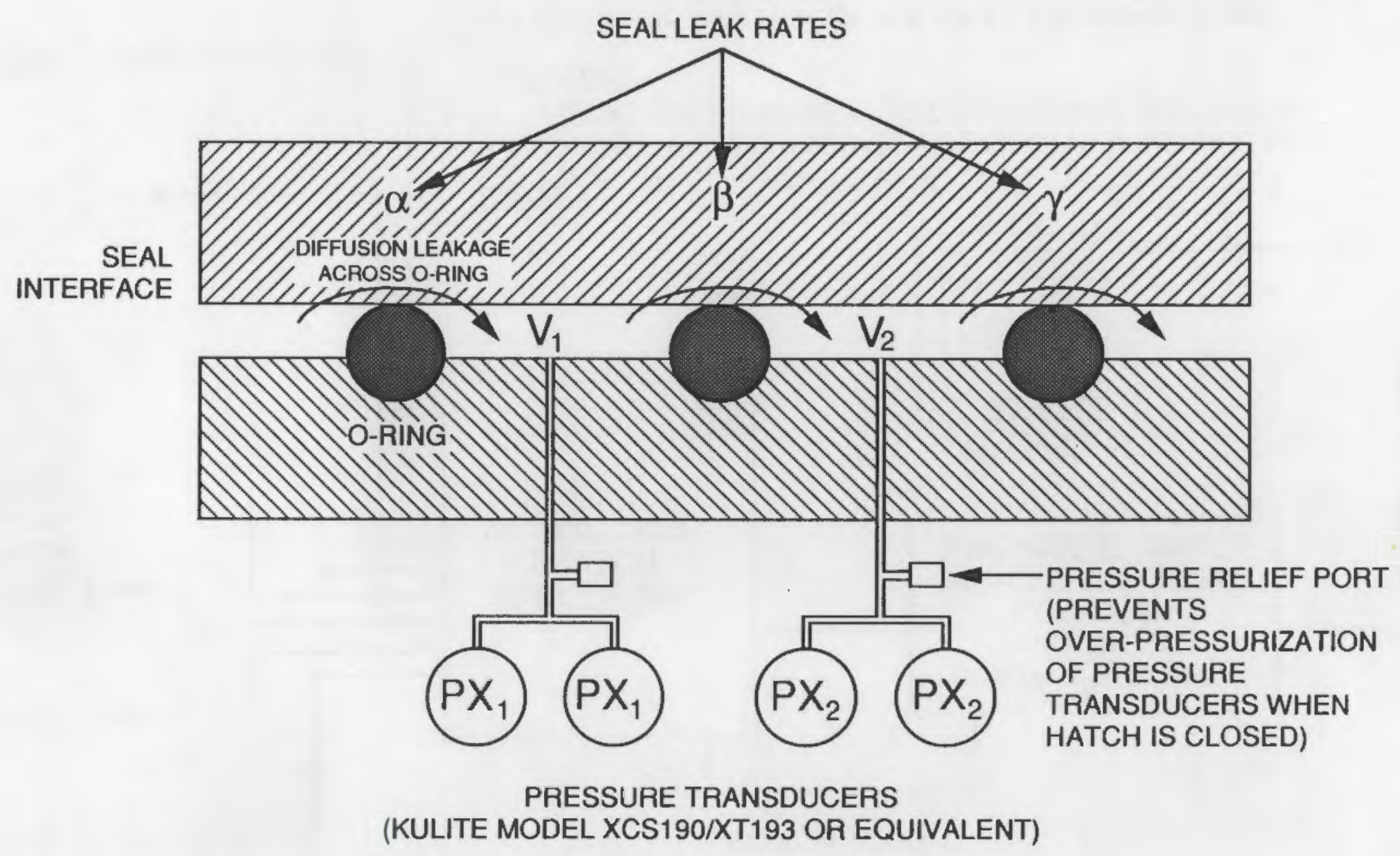

FIGURE 5.10. Conceptual Design for Seal Leak Monitor 


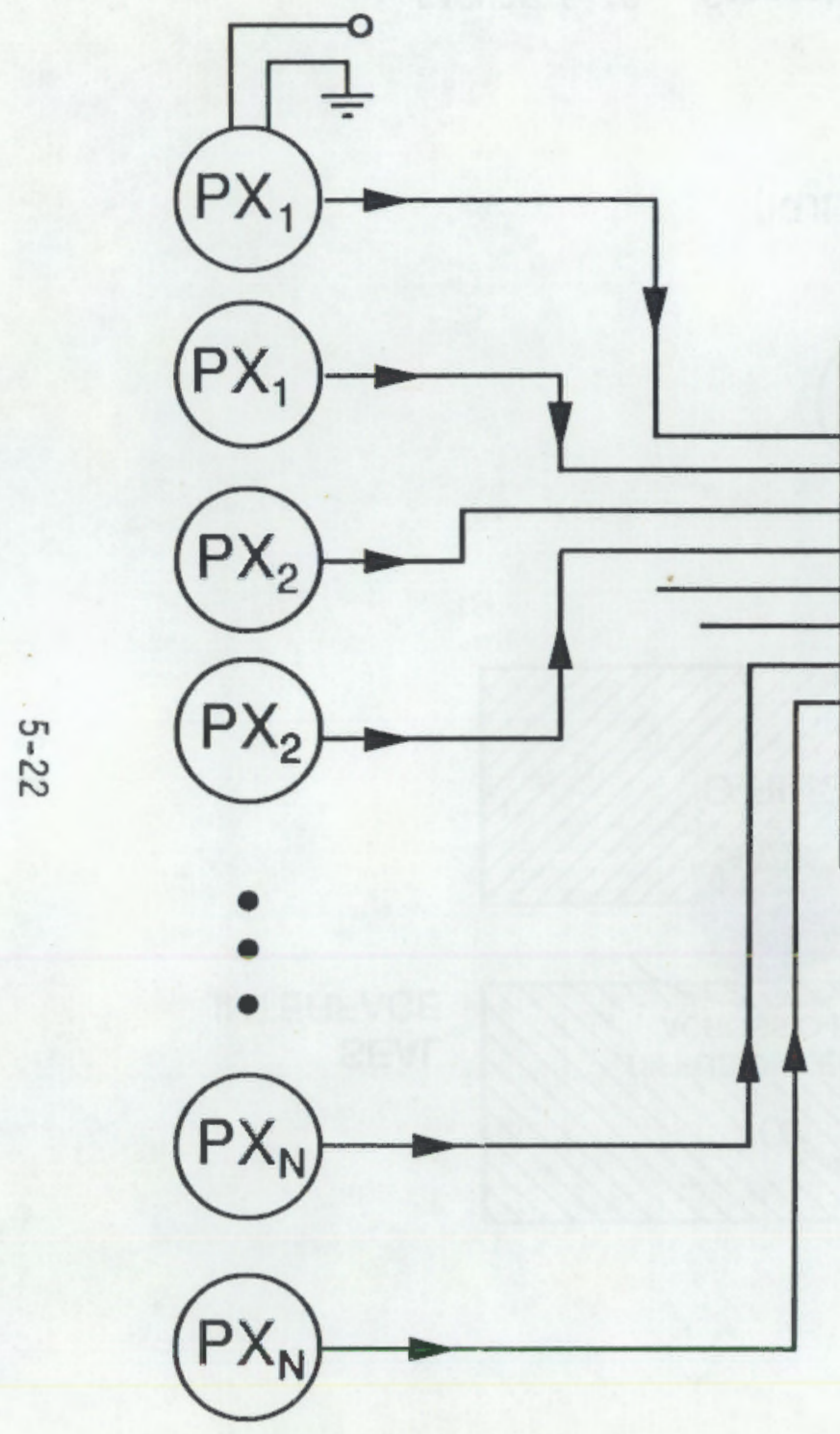

SWITCH TOGGLE

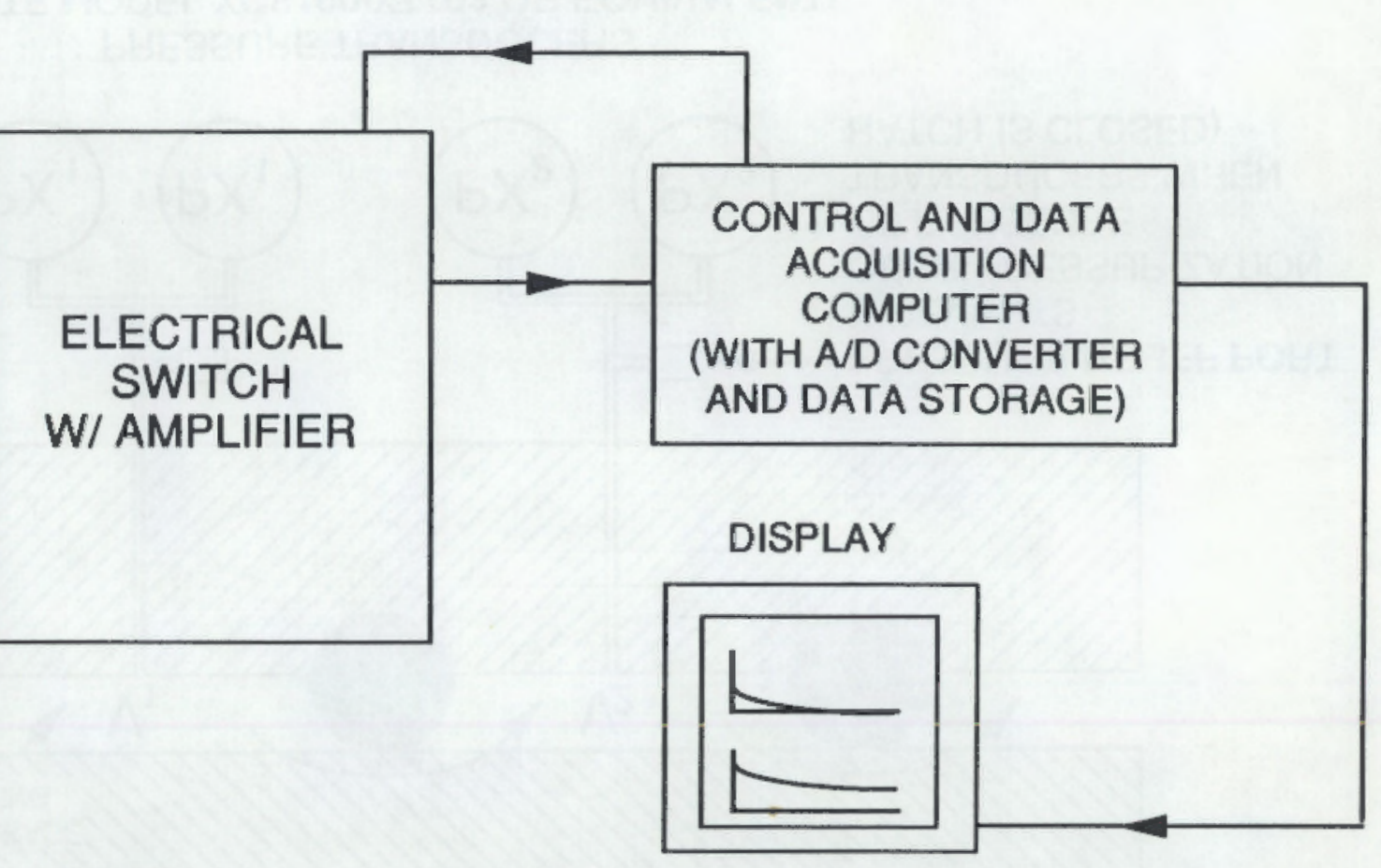

NOTES:

1.) SENSORS WOULD PROBABLY BE POWERED INDIVIDUALLY ONLY FOR LIMITED PERIODS TO CONSERVE ELECTRICAL POWER.

2.) POWER DISSIPATION OF KULITE XT-190 AND XCS- 190 SERIES SENSORS IS $200 \mathrm{~mW}$.

FIGURE 5.11. Pressure Transducer Data Acquisition System 
subsequent analysis via an on-board computer. Anomalous or alarm conditions are indicated via a visual display.

The data analysis protocol for a single seal set (i.e., for a window) is depicted in Figure 5.12. The transducer output voltages are digitized and stored over a period of time. Subsequently, the data is recovered and inverted to obtain the seal leak rates. Alternatively, the equilibrium pressures are monitored for indications of anomalous pressure conditions indicative of a leak.

Technical specifications for the Kulite pressure transducers appear in Figures 5.13 and 5.14 .

\subsubsection{Pressure System Specification}

Preliminary specifications are shown in Table 5.4. Power drain per channel will be very low if the command power supply activation is employed. The instrumentation amplifier is a CMOS device, drawing very little power, which leaves the sensor itself as the primary drain. PNL has not yet performed a detailed search to find the lowest power pressure transducer.

Table 5.4. PNL Pressure Sensor Package Specifications

\section{Pressure Sensor}

Type: Commercial device such as Kulite XT-190

Output Range: $0-40 \mathrm{mVolts}$

Power Supply: +10 VDC

Power Drain: Command activated -- ON: 200 milliwatts

OFF: 0 watts

Preamp

Type: Commercial instrumentation operational amp such as LT 1101 AMJ8 Gain: $100(40 \mathrm{~dB})$

Output Range: $0-4$ volts

Power Supply: +10 VDC

Power Drain: Command activated -- ON: 1 milliwatt

OFF: 0 watts 
(EXAMPLE FOR A WINDOW SEAL SET)
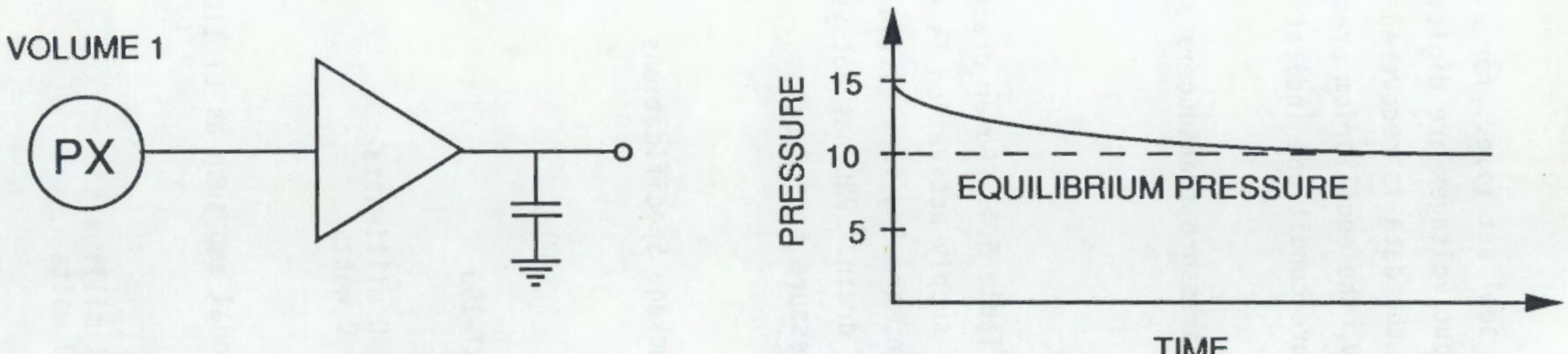

VOLUME 2
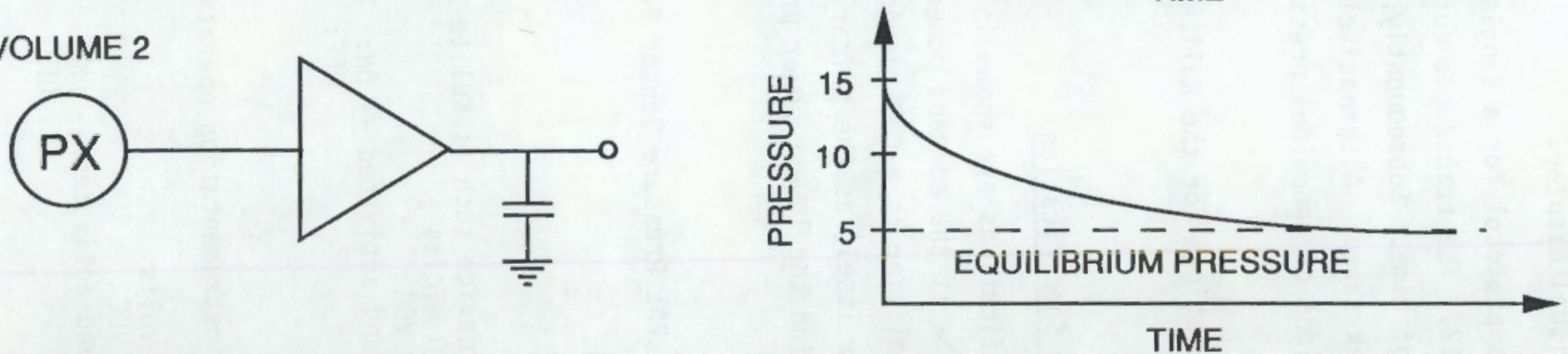

DATA ANALYSIS PROTOCOL

1) PRESSURE VS. TIME DATA IS ACQUIRED FOR ALL PRESSURE TRANSDUCERS (PX).

2) DATA IS INVERTED (WITH KNOWLEDGE OF $T_{1}, V_{1}$ AND $T_{2}, V_{2}$ ) TO DETERMINE LEAK RATES $\alpha, \beta$, AND $\gamma$.

3) ALTERNATIVELY, EQUILIBRIUM PRESSURES ARE MONITORED FOR ANOMALIES INDICATIVE OF LEAKS.

4) EXCESSIVE LEAKS AND/OR ANOMALOUS PRESSURE INDICATIONS RESULT IN ALARM CONDITION ON SYSTEM DISPLAY.

FIGURE 5.12. Data Analysis Protocol for Seal Leak Monitor 
T. 1 SO SEAIES

7 Integrated Sensor (IS) ${ }^{\circ}$

$\exists$ Easy Installation

3 High Natural Frequencies

10.32 UNF Thread
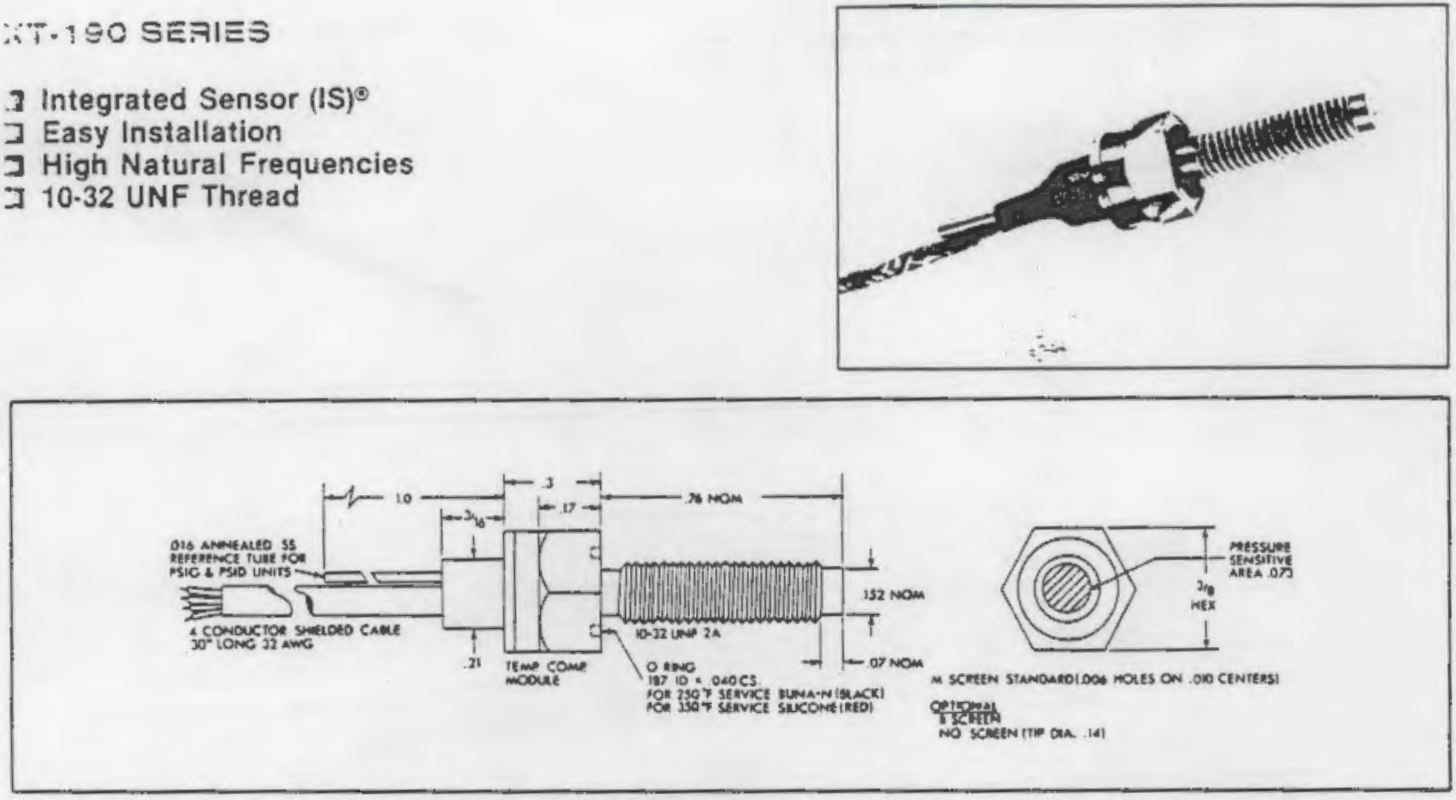

\begin{tabular}{|c|c|c|c|c|c|c|c|c|c|c|}
\hline $\begin{array}{l}\text { INPUT } \\
\text { Pressure Range }\end{array}$ & 5 & 10 & 25 & so & 100 & 200 & 300 & 500 & 1000 & $2000 \mathrm{PSI}$ \\
\hline Operational Mode & \multicolumn{10}{|c|}{ Absolute, Gage, Sealed Gage, Differential } \\
\hline Over Pressure & 20 & 20 & 100 & 100 & 200 & 400 & 600 & 1000 & 2000 & 3000 PSI \\
\hline Burst Pressure & \multicolumn{10}{|c|}{3 Times Rated Pressure } \\
\hline Pressure Media & \multicolumn{10}{|c|}{ All Noneonductive, Noncorrosive Liquids or Gases } \\
\hline Rated Electrical Excitation & \multicolumn{10}{|c|}{10 VDCIAC } \\
\hline $\begin{array}{l}\text { OUTPUT } \\
\text { Output Impedance }\end{array}$ & \multicolumn{10}{|c|}{500 Ohms (Nom.) } \\
\hline Full Scale Output (FSO) & \multicolumn{10}{|c|}{$100 \mathrm{mV}$ (Nom.) } \\
\hline Residual Unbaiance & \multicolumn{10}{|c|}{ $\pm 5 \%$ FSO } \\
\hline $\begin{array}{l}\text { Combined Non-Linearity } \\
\text { ant Hysleresis }\end{array}$ & \multicolumn{10}{|c|}{$=0.3 \%$ FS BFSL 'See Note 1} \\
\hline Natural Frequency (KHz) & 70 & 70 & 100 & 130 & 160 & 200 & 270 & 350 & 500 & 650 \\
\hline $\begin{array}{l}\text { Acceleration Sensitivity \% FS/g } \\
\text { Porpendicular } \\
\text { Transverse }\end{array}$ & $\begin{array}{l}.002 \\
.0004\end{array}$ & $\begin{array}{l}.01 \\
.0002\end{array}$ & $\begin{array}{l}.0005 \\
.0001\end{array}$ & $\begin{array}{l}.0004 \\
.00008\end{array}$ & $\begin{array}{l}.0002 \\
.00004\end{array}$ & $\begin{array}{l}.00013 \\
.000026\end{array}$ & $\begin{array}{l}.00012 \\
.00024\end{array}$ & $\begin{array}{l}.00009 \\
.000018\end{array}$ & $\begin{array}{l}.000006 \\
.000012\end{array}$ & $\begin{array}{l}.00005 \\
.00001\end{array}$ \\
\hline Insulation Aesistance & \multicolumn{10}{|c|}{50 Megohm Min. at 100 voC } \\
\hline $\begin{array}{l}\text { ENVIRONMENTAL } \\
\text { Operating Temperature Range }\end{array}$ & \multicolumn{10}{|c|}{$-65^{\circ} \mathrm{F}$ to $250^{\circ} \mathrm{F}\left(-55^{\circ} \mathrm{C}\right.$ to $\left.120^{\circ} \mathrm{C}\right)$ Temperatures $10350^{\circ} \mathrm{F}\left(175^{\circ} \mathrm{C}\right)$ Avaitable on Soecial Order } \\
\hline Compensated Temperature fange & \multicolumn{10}{|c|}{$80^{\circ} \mathrm{F}$ to $180^{\circ} \mathrm{F}\left(25^{\circ} \mathrm{C}\right.$ io $\left.30^{\circ} \mathrm{C}\right)$ Any $100^{\circ} \mathrm{F}$ Range Within The Operating fange on Request } \\
\hline Thermal 2aro Shift & \multicolumn{10}{|c|}{$=1 \%$ FSi $100^{\circ} \mathrm{F}$ (Max.) } \\
\hline Thermal Sensitivity Shift & \multicolumn{10}{|c|}{$=1 \% / 100^{\circ} \mathrm{F}(\mathrm{Max})}$. \\
\hline $\begin{array}{l}\text { Steady Acceleration and } \\
\text { Linest Vibration }\end{array}$ & \multicolumn{10}{|c|}{ 1000g, Sine } \\
\hline
\end{tabular}

Mote 1:. $15 \%$ aweitrote on special arder.

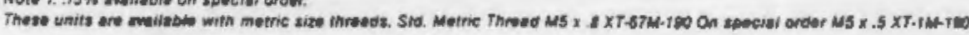

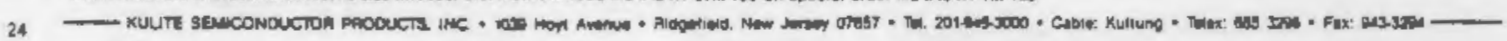

\section{FIGURE 5.13. Miniature Ruddegized IS Pressure Transducer}


XCS-19O SERIES HIGH IMPEDANCE XCW-190 SERIES LOW IMPEDANCE

] High Output $(45 \mathrm{mV} / \mathrm{psi})$

High Natural Frequency
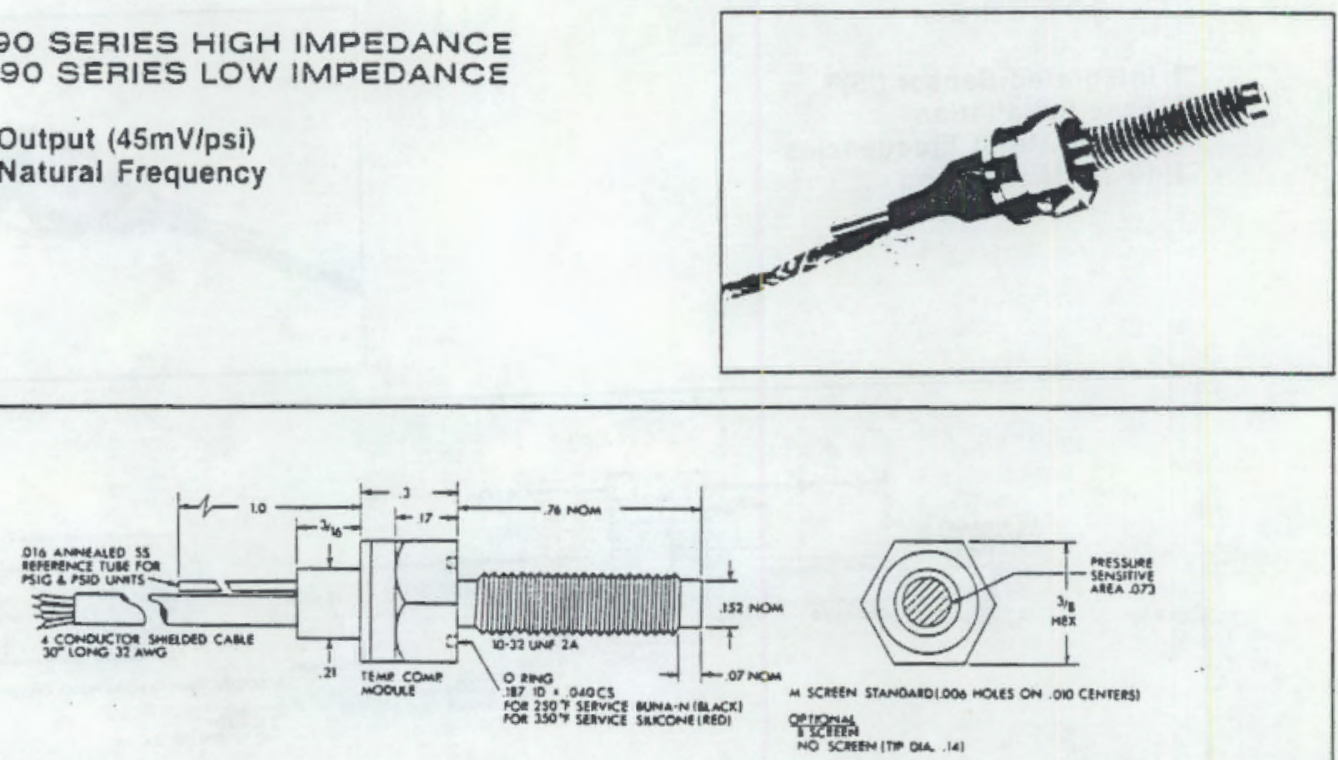

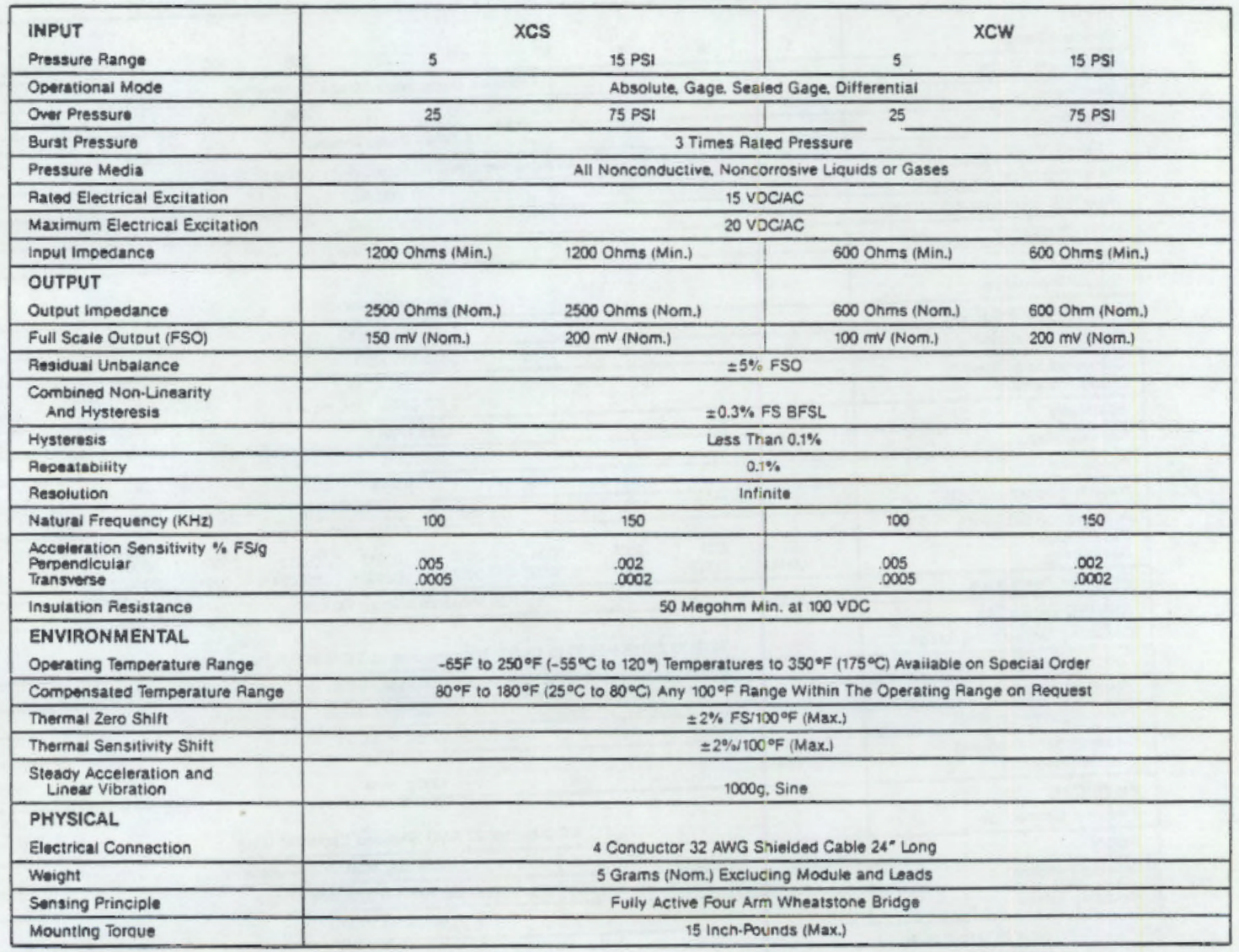

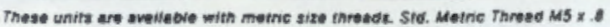

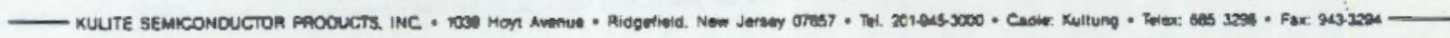

FIGURE 5.14. High Sensitivity IS Pressure Transducers 


\subsection{CONCLUSIONS AND RECOMMENDATIONS}

Our conclusions derived from the results of the feasibility evaluation performed under this program are:

a. Of the various technologies assessed, measurement of pressure differential was selected for detection of atmosphere leaks across seals and acoustic emission techniques were selected for detection of particle impacts on the module wall, cracking in the module wall, and atmosphere leaks through the module wall.

b. Assessment of thermal imaging methods for detecting leaks by viewing the outside of the module units indicates that this could be a feasible approach. However, based on guidance received from NASA and Boeing Aerospace staff at the time of the review of results from Phase I of this program, thermal imaging is not included in the recommendations for further attention.

c. Pressure differential methods for detecting atmosphere leaks around seals were evaluated using analytical models and limited experimental validation with the conclusion that the necessary leak sensitivity was attainable and that proven, conventional electronic pressure sensors are well suited to the problem.

d. Evaluation of acoustic emission monitoring methods for detection and location of particle impacts on the module wall, cracking in the module wall, and leaks through unplanned module penetrations was performed primarily by experimental methods using one half of a module wall plate section provided by NASA. Acoustic signal attenuation in the plate, detection of air leaks through holes drilled in the plate, and detection of fatigue cracking in a sample of similar material were all assessed with the conclusion that $\mathrm{AE}$ methods can effectively perform the required functions described. There is existing technology for location of impacts, cracking, and leaks based on transient acoustic signals (impacts and cracking) and continuous acoustic signals (leaks) which is generally applicable. 
e. An instrumentation concept has been developed which supports the conclusion that the pressure differential measurement and AE monitoring methods are realistically implementable.

Based on the conclusions presented above, we recommend follow-on research and development efforts to include:

a. Seal Integrity Monitoring System

- Refine the seal sensor engineering design by developing a complete seal integrity monitoring subsystem. Included in the design would be specifications for the pressure transducers, transducer preamplifiers, power supplies, data acquisition and storage system, and data display system.

- Develop alternative seal leak detection algorithms for analysis of pressure transducer outputs to determine the presence of a leak. At least two algorithms would be developed -- one based on the analysis of asymptotic pressure values and one based on data inversion for determination of leak rates. The latter algorithm would enable early detection of seal leaks. Also, in this task, a sensor polling and data reduction protocol would be developed for the entire pressure sensor array. Finally, a software-driven seal integrity display protocol would be developed for use by the Space Station crew.

- Build a model verification test bed. Constraints (time and funding) of the current program allowed for only minimal experimental verification of the seal leak model. The planned test bed would be a complete experimental model verification system. This system would operate at pressures and with seal leak rates anticipated in the actual Space Station scenario. Purpose of the test bed would be to provide further verification of the seal leak model. 
b. Acoustic System to Detect and Locate Particle Impacts, Model She11 Cracking, and Leaks Through the Module Wall

- Perform more in-depth laboratory investigation to confirm the reason for some of the anomalies which appear in the acoustic signal attenuation data, and to achieve a more thorough understanding of the significance of frequency range in monitoring to detect leaks.

- Experimentally and analytically verify the applicability and implementability of cross correlation techniques for performing source location on a continuous acoustic signal generated by a leak.

c. Develop Design for a Prototypic Instrumentation System

- Evaluate miniaturization of system components to save weight and/or power consumption.

- Develop and demonstrate a broadband sensor that will reproduce the waveform of the acoustic emission energy pulse traveling through the material.

- Develop an algorithm(s) to perform leak source location using a continuous acoustic signal, and to perform impact and cracking source location using transient acoustic signals.

- Develop interface between prototypic system and the space station electronic system including hardware and cabling layout.

- Integrate the pressure monitor development results from "a" above with acoustic monitoring requirements into a single system prototype design.

- Refine design and upgrade technical and performance specifications.

- Prepare a design document for a prototypic monitor system and obtain NASA/Boeing Aerospace approval of the document.

d. Fabricate a Prototypic Monitor System (probably 16 data channels) and Demonstrate Functional Capability on a Full-Size Module

Time and cost estimates for the proposed follow-on effort will be provided on request. 



\subsection{REFERENCES}

Aerospace America, June 1988 and April 1989 issues.

Butkov, E. 1968. Mathematical Physics. Addison-Wesley, Reading, MA, Ch. 5 .

Cour-Palais, B. G. 1987. "Hypervelocity Impact in Metals, Glass, and Composites," Int. J. Impact Engng, Vol. 5, pp. 221-237.

Herrmann, W. and J. W. Wilbeck. 1987. "Review of Hypervelocity Penetration Theories," Int. J. Impact Engng, Vol. 5, pp. 307-322.

Hutton, P. H., 1984. Acoustic Emission Monitoring of Hot Functional Testing, Watts Bar Unit 1 Nuclear Reactor, NUREG/CR-3693, PNL-5022, prepared by Pacific Northwest Laboratory for the U.S. Nuclear Regulatory Commission, Washington, D.C.

Hutton, P. H., et al. 1985a. Acoustic Emission Results Obtained from Testing the ZB-1 Intermediate Scale Pressure Vessel - An Interim Report. NUREG/CR3915, PNL-5184, prepared by Pacific Northwest Laboratory for the U.S. Nuclear Regulatory Commission, Washington, D.C.

Hutton, P. H., et al. 1985b. "Aircraft Structural Surveillance In-Flight Using Acoustic Emission," Journal of Acoustic Emission, Vol. 4, No. 2/3, pp. $\$ 138$.

Hutton, P. H. 1988. "Acoustic Emission for Continuous Monitoring of LightWater Reactor Systems: A Status Review, "Materials Evaluation, Vol. 46, No. 2, pp. 241.

Kupperman, D. S., D. Prine, and T. Mathieson. 1988. Application of Acoustic Leak Detection Technology for the Detection and Location of Leaks in Light Water Reactors, prepared by Argonne National Laboratory for the U.S. Nuclear Regulatory Commission, Washington, D.C.

Martin, H. 1983. "Impinging Jets," Chapter 2.5.6 in Vol. 2 of the Heat Exchanger Design Handbook. Hemisphere Publishing, Washington D.C.

Merrigan, M. A. and R. S. Reid. 1988. Multimegawatt Space Power Systems: Thermal Management. Los Alamos National Laboratory Report LA-11254-MS, LoS Alamos, NM.

Scott, E. J. 1955. Transform Calculus. Harper and Brothers, New York, Ch. 2 and 3.

Scott, I. G. and G. G. Martin. 1985. "In-Flight AE Monitoring," Journal of Acoustic Emission, Vol. 4, No. 2/3, pp. S142. 
Shapiro, A. H. 1953. The Dynamics and Thermodynamics of Compressible Fluid Flow. The Ronald Press, New York, NY.

Sparrow, E. M. and B. J. Love11. 1980. "Heat Transfer characteristics of an Obliquely Impinging Circular Jet," J. Heat Transfer, Vol. 102, pp. 203-209.

Taylor, T. T., et al. 1982. Acoustic Emission Monitoring of ASME Section III Hydrostatic Test, Watts Bar Unit 1 Nuclear Reactor, NUREG/CR-2880, PNL-4307, prepared by Pacific Northwest Laboratory for the U.S. Nuclear Regulatory Commission, Washington, D.C.

Tilton, D. E. and L. C. Chow. 1988. "Fluid Loss from a Puncture of a Space Radiator," J. Thermophysics, Vol. 2, No. 1, pp. 84-86.

Tilton, D. E. and L. C. Chow. 1986. "Flow Through a Pierced Membrane in a Vacuum." AIAA-86-1324. 


\section{APPENDIX A}

DESCRIPTION AND USE OF THE PRESSURE COMPUTATION CODE 


\section{DESCRIPTION AND USE OF THE PRESSURE COMPUTATION CODE}

The computer code (provided to Boeing via computer disk) calculates the pressures $P_{1}$ and $P_{2}$ according to Equations (3.5) and (3.6). The program is written in BASIC and will run on any IBM/PC-compatible machine.

To execute the program type PVIEW $\langle C R>$.

Upon execution the program prompts the user for the necessary input parameters; the initial pressures $P_{1}(0)$ and $P_{2}(0)$, the leak rates $\alpha^{\prime}, \beta^{\prime}$, and $\gamma^{\prime}$, the seal lengths $\ell_{1}, \ell_{2}$, and $\ell_{3}$, and the entrapped volume $V\left(V_{1}\right.$ is assumed equal to $V_{2}$ ). Upon receipt of these parameters the program calculates and displays the pressures at a special time where the value of $(\Gamma+\theta) 1 / 2 t=10$ (see Eqs. 3.5 and 3.6). At this time the values of the time dependent terms of Eqs. 3.5 and 3.6 are near zero and the equilibrium pressures have been obtained. There is little reason for continuing the calculations beyond this time. This calculation is performed and then the user has some options shown on the screen.

If a new calculation at a different time is desired simply type the time value followed by $\angle C R>$ and the results will be displayed. Repeat as often as desired for virtually any time values.

If a change of input parameters is desired type $C<C P>$ and reply to the prompts to change the parameter. The calculation is performed after the change is entered. Changes must be done one parameter at a time, unless $R<C R>$ is typed, in which case all of the parameters will need to be specified.

If it is desired to end computing, type $Q<C P>$ to exit the program.

To obtain a table of the pressures as a function of time type $T<C R>$ and the pressures will be calculated for approximately 550 times between zero and the maximum time given by $t=10 /(\Gamma+\theta)^{1 / 2}$. The tabled results are presented on the screen. 
To plot the pressures as a function of time type $P<C R>$ and the plot will be displayed from zero time to the same maximum time. The plot can be modified through use of cursor control keys (to view an expanded portion of the plot) and by setting Y-axis limits. The plot data can be saved to an ASCII file. The plot can be sent to a printer by typing $P<C R>$. Exit the plot and return to the main program by typing $R<C R>$. 
PNL-7269

\section{DISTRIBUTION}

No. of

Copies

2 DOE/Office of Scientific and Technical Information

J. Heyman

NASA Langley Research Center

Mail Stop 499

Hampton, VA 23665

10 T. Hollingsworth

Marshall Space Flight Center, KA-40

Alabama 35812

10 J. E. O'Neil

The Boeing Company

P. 0. Box 1470

Huntsville, AL 35807-3701

C. Salkowski

Johnson Space Center

Mail Code ES52

Houston, TX 77058

\section{ONSITE}

DOE Richland Operations Office

D. R. Segna, A5-90

19 Pacific Northwest Laboratory

Z. I. Antoniak, K5-21

C. L. Shepard, K5-25

M. A. Friesel, K2-31

J. W. Griffin, K2-25

P. H. Hutton, K2-31

R. J. Kurtz, K2-31

D. K. Lemon, K2-28 (5)

J. R. Skorpik, K2-31

C. L. Shepard, K5-25

Publishing Coordination

Technical Report Files (5) 
